NASA/CR-1999-209561

NA SA

\title{
Characterizing Secondary Debris Impact Ejecta
}

W.P. Schonberg

University of Alabama in Huntsville, Huntsville, Alabama

Prepared for Marshall Space Flight Center under Contract NAS8-97095

and sponsored by

The Space Environments and Effects Program managed at the Marshall Space Flight Center

National Aeronautics and

Space Administration

Marshall Space Flight Center • MSFC, Alabama 35812 


\section{Acknowledgments}

The author is grateful for the support providad by the NASA Marshall Space Flight Center that made this study possible. The author would also like to acknowledge Gregory Olsen for his guidance during the course of this effort.

Available from:

NASA Center for AcraSpace Information 800 Elloidge Landing Road

Linthicum Heights, MD 21090-2934 (301) 621-0390
National Technical Information Service 5285 Port Royal Road Springfield, VA 22161 (703) $487-4650$ 


\section{PREFACE}

The effort described in this report was supported by the Structural Development Branch (ED52) of the NASAMarshall Space Flight Center in Huntsville, Alabama. The Contracting Officer's Technical Representatives for this program was Mr. Gregory Olsen (ED52). 



\section{TABLE OF CONTENTS}

4.1 INTRODUCTORY COMMENTS

4.2 OBLIQUE LMPACT MODEL DEVELOPMENT

4.3 TRAJECTORY ANGLES

4.4 Debris Cloud MasSes

4.5 Debris Cloud aXial Velocities

4.6 DEBRIS CLOUd EXPANSION VELOCITIES

4.7 OBLIQUE IMPACT MODEL VERIFICATION 
6.1 SUMMARY

44

6.2 RECOMMENDATIONS

7.0RTARTNCRS 46

APPENDXA-FMPTICALTEST PARAMTYTSAND RESULTS

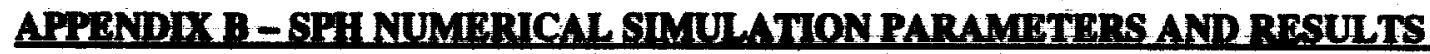

APPRNDX C-MEASURED CRATRR DFPTHS ANDDHARTERS

APPENDER D-FMPIRICAL DTVTANDDMMTTER BOUATIONS

APPENDX E-CALCULATED RICOCHET PABTICLE VELOCITIES AND DIAMETERS

APPENDX E-CALCULATED BCOCHIT PARTCLE MAX-MIN COMBINATIONS 


\section{LIST OF FIGURES}

Figure 2.1 Hypervelocity Impact of a Generic Multi-Wall System .................................................3

Figure 3.1 Typical Oblique Hypervelocity Impact Test Set-up with Ricochet Debris Cloud..........7

Figure 3.2 Comparison of $\theta_{\mathrm{r}}$ Regression Equation Predictions Against Empirical and Numerical

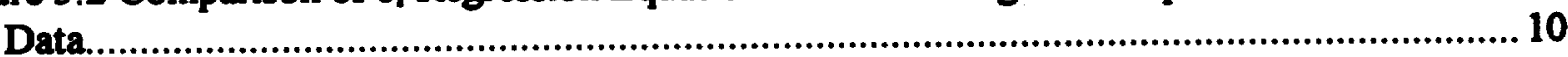

Figure 3.3 Comparison of $\theta_{99}$ Regression Equation Predictions Against Empirical and Numerical

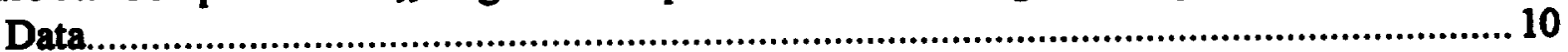

Figure 4.1 Oblique Hypervelocity Impact of a Flat Plate ............................................................. 13

Figure 5.1 Penetration Depth Equations (D.1-D.10) ................................................................37

Figure 5.2 Crater Diameter Equations (D.13-D.18) ….............................................................. 37

Figure $5.3 \mathrm{~V}_{\min }, \mathrm{V}_{\max }$ and $\mathrm{D}_{\min ,} \mathrm{D}_{\max }$ for a $30^{\circ}$ Impact ........................................................ 41

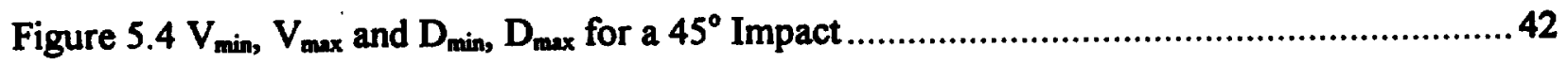

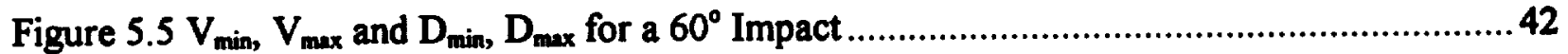

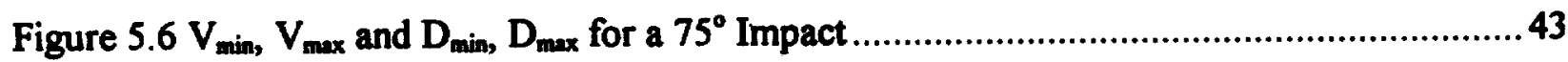




\section{LIST OF TABLES}

Table 3.1 Parameter Values And Correlation Coefficients For Equations (3.1)...........................9

Table 4.1 Impact Conditions Considered in Model Validation...................................................25

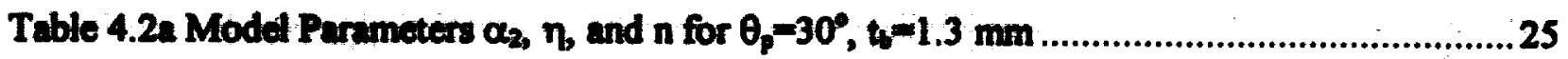

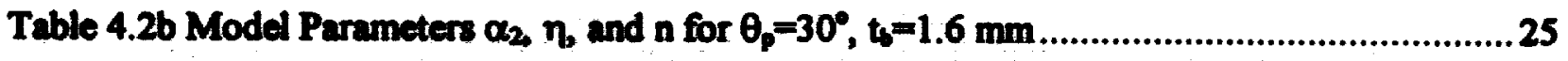

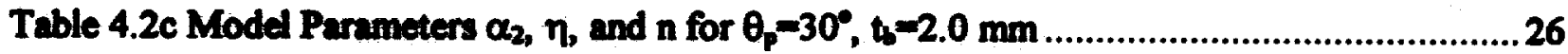

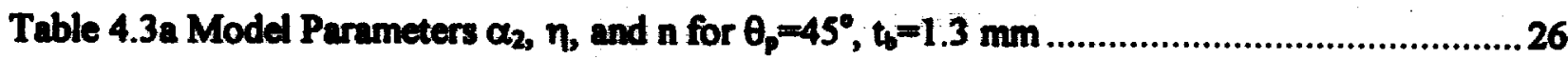

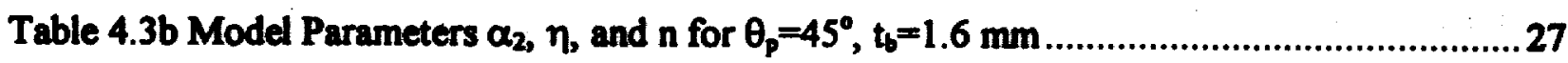

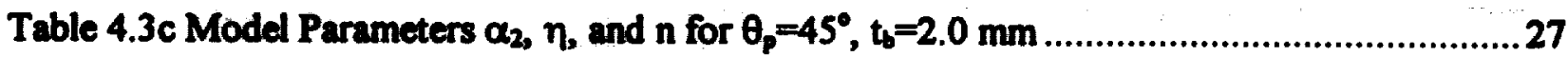

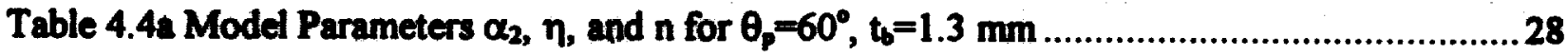

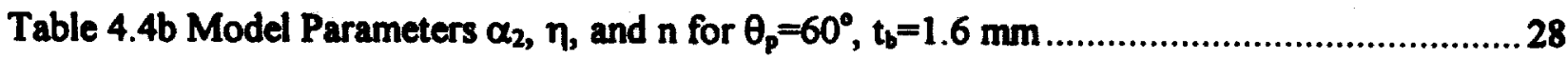

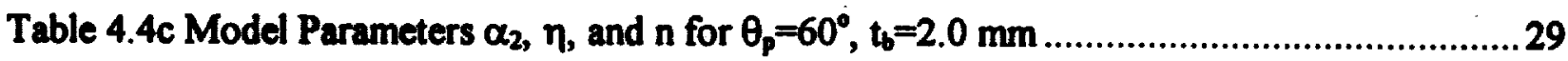

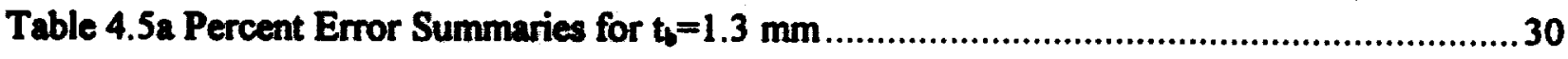

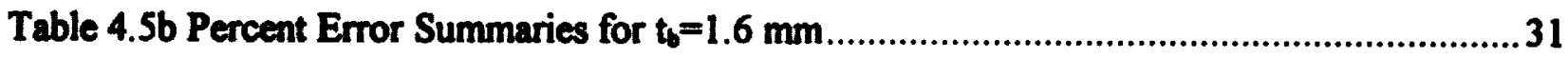

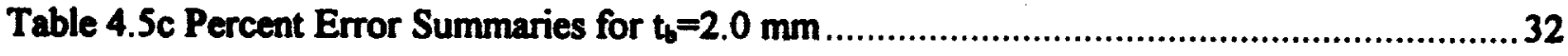

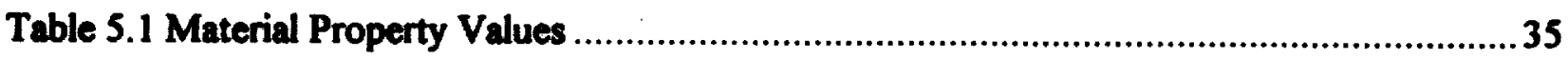

Table 5.2 Penetration Depth-Crater Diameter Equation Pairs...................................................38

Table 5.3 Parameter Values and Correlation Coefficients for Equations (5.1) and (5.2)..............39

Table 5.4 Comparison of Average Ricochet Particle Diameters and Velocities ..........................41 


\subsection{INTRODUCTION}

All spacecraft in low earth orbit are subject to high speed impacts by meteoroids and orbital debris particles. These impacts can damage flight-critical systems, which can in turn lead to catastrophic failure of the spacecraft. Therefore, the design of a spacecraft for an earth orbiting mission must take into account the possibility of such impacts and their effects on the spacecraft structure and on all of its exposed subsystem components.

In addition to threatening the operation of the spacecraft itself, on-orbit impacts also generate a significant amount of damaging ricochet ejecta particles. These high speed particles can destroy critical external spacecraft subsystems, which in turn also poses a threat to the spacecraft and its inhabitants. Ricochet debris particles also increase the contamination of the orbital environment and, as a result, constitute a threat to other missions into that environment. Since the majority of on-orbit debris impacts are expected to occur at oblique angles, the characterization of ricochet debris created in an orbital debris particle impact is an issue that must be addressed.

This report presents a summary of the work performed towards the development of an empirical model that that characterizes the secondary ejecta created by a high speed impact on a typical aerospace structural surface. The empirical model developed provides the following information as a function of impact parameters (speed, angle, projectile diameter) and target plate geometry (e.g. thickness, etc):

- angles defining the spread of ricochet debris and the trajectory of the ricochet debris cloud center-of-mass;

- average velocity of the ricochet debris cloud material; and,

- velocity and mass of the largest particle(s) in the ricochet debris cloud. 
In this report, Chapter 2 presents an overview of the phenomenology associated with oblique hypervelocity impacts on thin plates, and compares them with the processes typically involved in normal (i.e. non-oblique) impacts. Chapter 3 presents a summary of the analysis performod to obtain the spatial diatributions of ricochet debris particle impacts. This analysis is used to determine ricochet debris cloud spray and trajectory angles in terms of impact parameters and target plate geometry.

The technique for cellaulating the avenge velocity of the ricochet debris cloud is presented in Chapter 4. This method is a baced on a model doveloped previoualy that chanacterizes the mases, trajoctories, and velocities of the debris clouds created in an oblique high-speed impact [1]. This model employs the three convervation principles, dementary shock physics theory, and fundamental thermodynamic principles to obtain a syatem of algebraic equations for the various debris cloud masses, trajectories, and velocities. This existing model is modified by incorporating the information presented in Chapter 3 and by reducing its dependence on empirical parameters.

In Chapter 5, relationships for crater diameter and depth are applied to the deepest craters in each ricochet witness plate to "back out" the diameters, masses, and velocities of the ricochet debris cloud particles that created these craters. These calculations are performed using a method similar to that developed in a previous study of ricochet debris particles created in oblique hypervelocity impact [2]. The information obtained is then used to develop empirical relationships that predict the velocity and mass of the largeat ricochet debris cloud particle in terms of impact parameters and bumper plate thickness. Results obtained using these relationships are compared with those obtained previously and presented in Reference [2]. Conclusions derived from the work presented herein, as well as recommendations for future activities in this area, are presented and discussed in Chapter 6. 


\subsection{OVERVIEW OF HYPERVELOCITY IMPACT PHENOMENOLOGY}

Consider the normal hypervelocity impact of a projectile on the outer bumper of a multiwall system as shown in Figure 2.1. Upon impact, shock waves are set up in the projectile and outer bumper materials. The pressures associated with these shocks typically exceed the strengths of the materials by several orders of magnitude. For example, in an $8 \mathrm{~km} / \mathrm{sec}$ aluminum-onaluminum impact, the ratio of the impact pressure $(116.5 \mathrm{GPa}=1.15 \mathrm{MBar})$ to the strength of the material (310 MPa for aluminum 6061-T6) is approx. 375, or roughly 2.5 orders of magnitude.

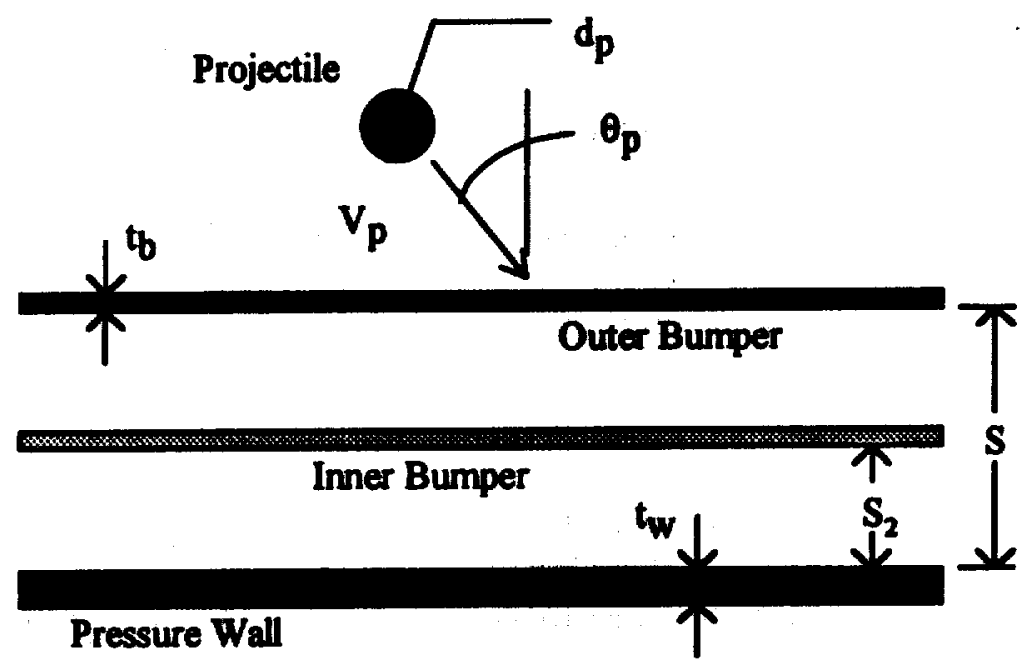

Figure 2.1. Hypervelocity Impact of a Generic Multi-Wall System

As the shock waves propagate, the projectile and outer bumper materials are heated adiabatically and non-isentropically. The release of the shock pressures occurs isentropically through the action of rarefaction waves that are generated as the shock waves interact with the free surfaces of the projectile and the outer bumper. This process leaves the materials in high energy states and can cause either or both to fragment, melt or vaporize, depending on the 
material properties, geometric parameters, and the velocity of impact.

The outer bumper of the multi-wall structure protects the pressure wall against perforation by disintegrating the impacting particle and by creating one or more diffuse debris clouds. In a normal impect, only one debris cloud containing both projectile and bumper plate fragments is evident. It first strikes the inner bumper and then travels towards and eventually impacts the pressure wall. However, in an oblique impect, three dobris clouds are typically formed. Two of them, travel inward towards and eventually atike the presoure wall.

These two debris clouds typiestly form two diatinct ares of damage on the pressure wall. In one damage zone, craters and holes (if any) are nearty circular, which is characteristic of nearnormal impact. In the other, the craters (and holes, if any) are oblong, indicating that they are formed by oblique impacts. As a result, these two debris clouds are often referred to as the "norma" and "in-line" debris clouds, respectively. It has hypothesized that the "normal" debris cloud contains mainly bumper plate framents while the "in-line" debris cloud contains mainly projectile fragments [3].

The third debris cloud, often referred to as the "ricochet" debris cloud, travels backwards, away from the multi-wall system. When the projectile obliquity is $45^{\circ}$ or less, only a small quantity of very fine ricochet debris particles are formed. There can be, however, extensive damage to the pressure wall, typically in the form of one or more jagged or petalled holes. As the trajectory obliquity is increased beyond $45^{\circ}$, the amount of ricochet debris produced by the impact increases significantly. Impacts at obliquities beyond $60^{\circ}$ or $65^{\circ}$ produce a tremendous amount of ricochet debris and only a small quantity of "penetration" debris. The change in behavior that occurs near $60^{\circ}$ has led Schonberg [4] to postulate the existence of a "critical angle of impact obliquity". For aluminum projectiles impacting aluminum bumpers, Schonberg estimatod the value of this critical 
angle to be near $60^{\circ}-65^{\circ}$. Impacts of projectiles with obliquities less than this critical value would result in more damage to the pressure wall than to any exterior spacecraft component, while impacts at obliquities greater than this critical value would result in more damage to external components than to the spacecraft pressure wall. 


\subsection{RICOCHET DEDRT CLOUD SPRTAD AND TRAJCTORY}

In this Chapter, we present a summary of the analyses performed to develop empirical equations that define the in-plane spread and trajectory of the ricochet debris cloud in terms of impact parameters, material properties and bumper thickness. This analysis is based on empirical data from two sources: 1) 225 high speed impact teets performed at the NASAMarahall Space Flight Center, and, 2) 39 numerical simulation runs performed using SPH, also provided by the NASAMarshall Space Flight Center.

Figure 3.1 below shows a typical test set-up. This figure is similar to Figure 2.1, except that a "ricochet witness plate" has been added to the diagram. These witness plates were typically $0.3 \mathrm{~cm}$ to $1.3 \mathrm{~cm}$ thick, depending on the impact conditions, and were provided in each test to capture the ricochet debris particles created by oblique impacts. In Figure $3.1, \theta_{\mathrm{r}}$ and $\theta_{99}$ denote the trajectory of the center-of-mass of the fragments in the ricochet debris cloud and the angle below which lies $99 \%$ of the damage to the ricochet witness plate, respectively. Based on its definition, $\theta_{29}$ is presumed to model the spread of the ricochet debris cloud particles. Post-test examination of damaged ricochet witness plates revealed several interesting characteristics about oblique hypervelocity impact. 


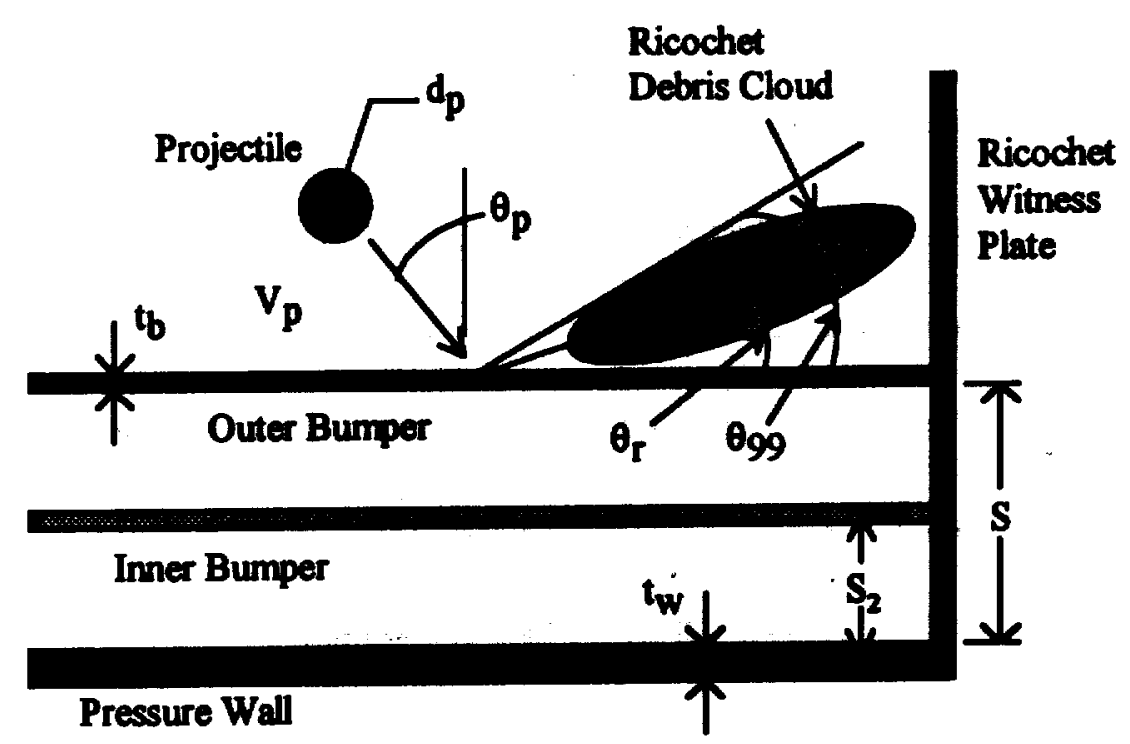

Figure 3.1. Typical Oblique Hypervelocity Impact Test Set-up with Ricochet Debris Cloud

For impact tests in which the obliquity angle was $30^{\circ}$ or less, there was virtually no damage to the ricochet witness plate. Under such conditions, only a splash deposition was evident on that plate. As obliquity increased to $45^{\circ}$, the damage to the ricochet witness plate became more pronounced. Small, shallow craters were now evident on the witness plate, typically less than 2 $\mathrm{mm}$ in diameter and less than $2 \mathrm{~mm}$ deep, and fairly evenly distributed along the height of the witness plate. With further increases in obliquity, an increasing amount of deep cratering became evident on the ricochet witness plates. In fact, if a thin ricochet witness plate (i.e. on the order of $0.3 \mathrm{~cm}$ ) were used in a test with an obliquity exceeding $65^{\circ}$, it was not unusual to find that the witness plate was perforated along the entire length of the border between it and the outer bumper.

From these observations, it became evident that as impact angle increased, the angle defining the trajectory of the ricochet debris cloud center-of-mass decreased dramatically, that is, as $\theta_{\mathrm{p}}$ increased, $\theta_{\mathrm{r}}$ decreased. However, even in the high obliquity tests, there were still a fair 
number of craters near the top of the ricochet witness plates, indicating that as $\theta_{p}$ increased, $\theta_{9}$ did not experience any significant changes. Appendix $A$ presents a compilation of the $\theta_{9 s}$ and $\theta_{r}$ data for the oblique impact teats oomidered in this study. The value of $\theta_{\mathrm{r}}$ for each test was obtained by calculating the vertical losation of the center of the riocchet witneas plate craters using a weighted average technique bued on the vertical diatribution of the witness plate craters. The angle $\theta_{29}$ was determined based on the height below which lay $99 \%$ of the ricochet crater damage, and was found simply by counting craters and noting their vertical locations along the witness plate.

To eupplement the empirical dets, 39 mimerical runs were performed using SPH, a smooth particle hydrodynamica code developed for modelling hypervelocity impact phenomena. The impact parameters governing the numerical simulations were chosen to exceed, in terms of projectile diameter and impact velocity, those normally attainable with a light gas gun. In this manner, the "tests" performed using SPH extended the data provided by light gas gun testing. Appendix B presents a compilation of the $\theta_{99}$ and $\theta_{\mathrm{r}}$ data for the oblique impact tests considered in this study. For the SPH runs, the value of $\theta_{r}$ for each run was obtained by estimating the angle defining the trajectory of the center-of-mass of the ricochet debris cloud based on several SPH output plots. The angle $\theta_{99}$ was obtained by eatimating the angle below which lay $99 \%$ of the ricochet debris cloud particles as shown on the SPH output plots.

Three sets of equations for $\theta_{8}$ and $\theta_{99}$ were obtained: 1) an equations for each based solely on empirical data; 2) an equation for each based solely on SPH data; and, 3) an equation for each based on a combined database including both empirical and SPH data. These equations are all in the following form: 


$$
\tan \theta_{r, 99}=A\left(\frac{t_{b}}{d_{p}}\right)^{B}\left(\frac{V_{p}}{C_{b}}\right)^{c} \cos ^{D} \theta_{p}
$$

where $C_{b}$ is the bumper material speed of sound.

Table 3.1 below presents the values of the regression coefficients A-D and the correlation coefficients for equations (3.1a-f). Figures 3.2 and 3.3 present a plot of these equations for a $0.795 \mathrm{~cm}$ diameter projectile impacting at $0.127 \mathrm{~cm}$ thick bumper at a velocity of $6.5 \mathrm{~km} / \mathrm{s}$ at trajectory obliquities ranging from $45^{\circ}$ to $75^{\circ}$. Also shown in these figures are test data and numerical simulation data for $\theta_{\mathrm{r}}$ and $\theta_{99}$.

Table 3.1 Parameter Values and Correlation Coefficients for Equations (3.1)

\begin{tabular}{|c|c|c|c|c|c|c|c|}
\hline Equation & Quantity & Database & $\mathbf{A}$ & $\mathbf{B}$ & $\mathbf{C}$ & $\mathbf{D}$ & $\begin{array}{c}\text { Correlation } \\
\text { Coefricient }\left(\mathbf{R}^{2}\right)\end{array}$ \\
\hline 3.1a & $\theta_{\mathrm{s}}$ & Empirical & 0.4725 & 0.4085 & 0.2299 & 0.6458 & 0.629 \\
\hline 3.1b & $\theta_{9 g}$ & Empirical & 0.7052 & 0.2272 & 0.06828 & 0.1404 & 0.343 \\
\hline 3.1c & $\theta_{\mathrm{r}}$ & SPH & 0.1377 & -0.5421 & 0.1028 & 1.2255 & 0.837 \\
\hline 3.1d & $\theta_{9 g}$ & SPH & 1.6519 & 0.2201 & 0.1689 & 1.4587 & 0.964 \\
\hline 3.1e & $\theta_{r}$ & Combined & 0.4206 & 0.2651 & 0.4345 & 0.7988 & 0.662 \\
\hline 3.1f & $\theta_{99}$ & Combined & 0.7608 & 0.1989 & 0.1146 & 0.3191 & 0.429 \\
\hline
\end{tabular}

As can be seen from Table 3.1, the SPH-only equations have the highest correlation coefficients, indicating that the SPH data is very consistent from run to run. In addition, the empirical-only and combined equations for $\theta_{r}$ have reasonable $R^{2}$ values, which indicates that although there is a fair degree of scatter in the empirical $\theta_{8}$ data, the trends in the data are consistent over the range of empirical parameters considered. However, as is apparent from the very low $\mathbf{R}^{2}$ values for the empirical and combined $\theta_{99}$ equations, there are some features in the $\theta_{9 g}$ data that are not accounted for in the regression model selected. Additional discussion of thes: features follow Figures 3.2 and 3.3 below. 


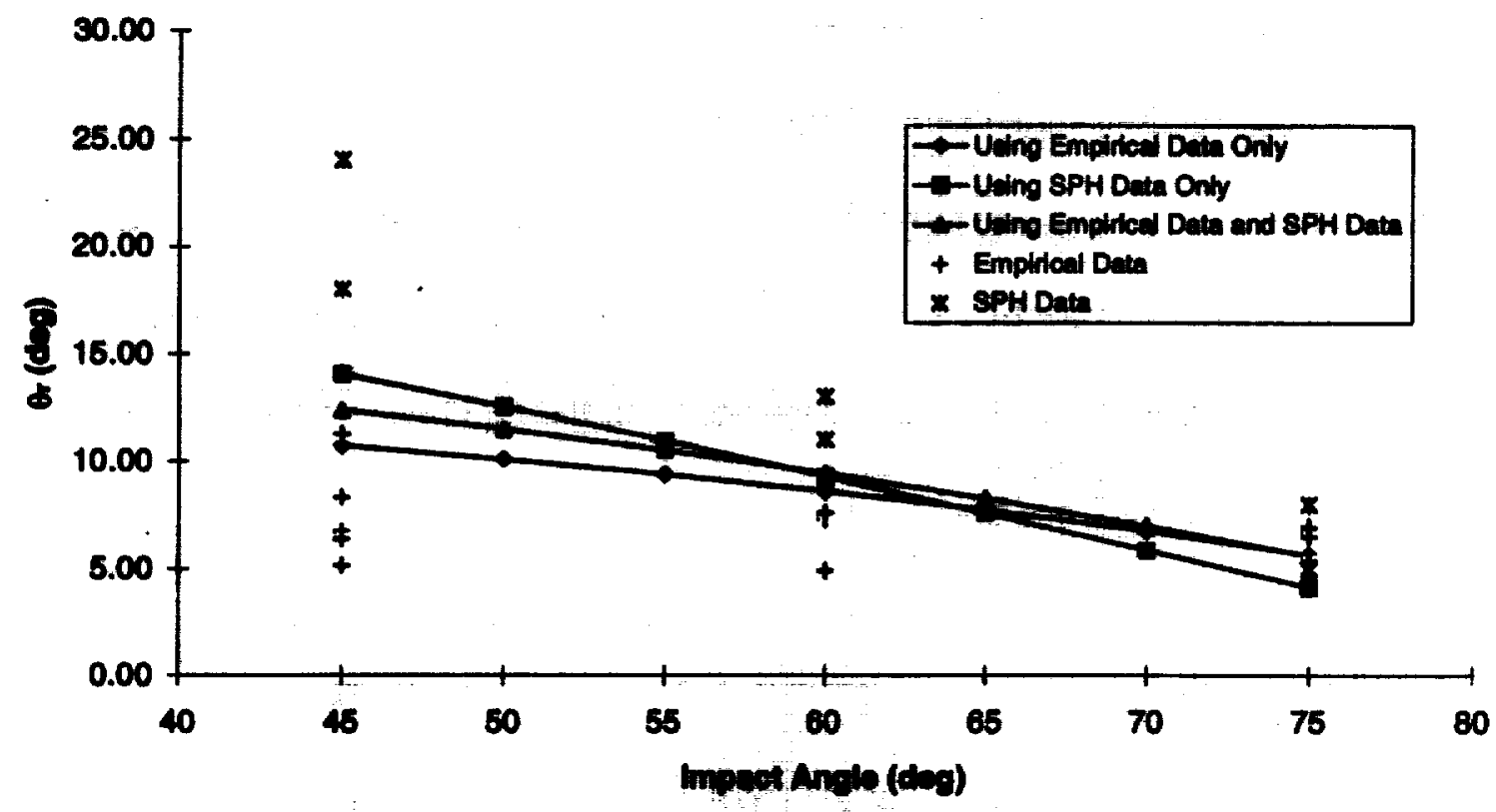

Figure 3.2 Comparison of $\theta_{\mathrm{r}}$ Regression Equation Predictions Against Empirical and Numerieal Data

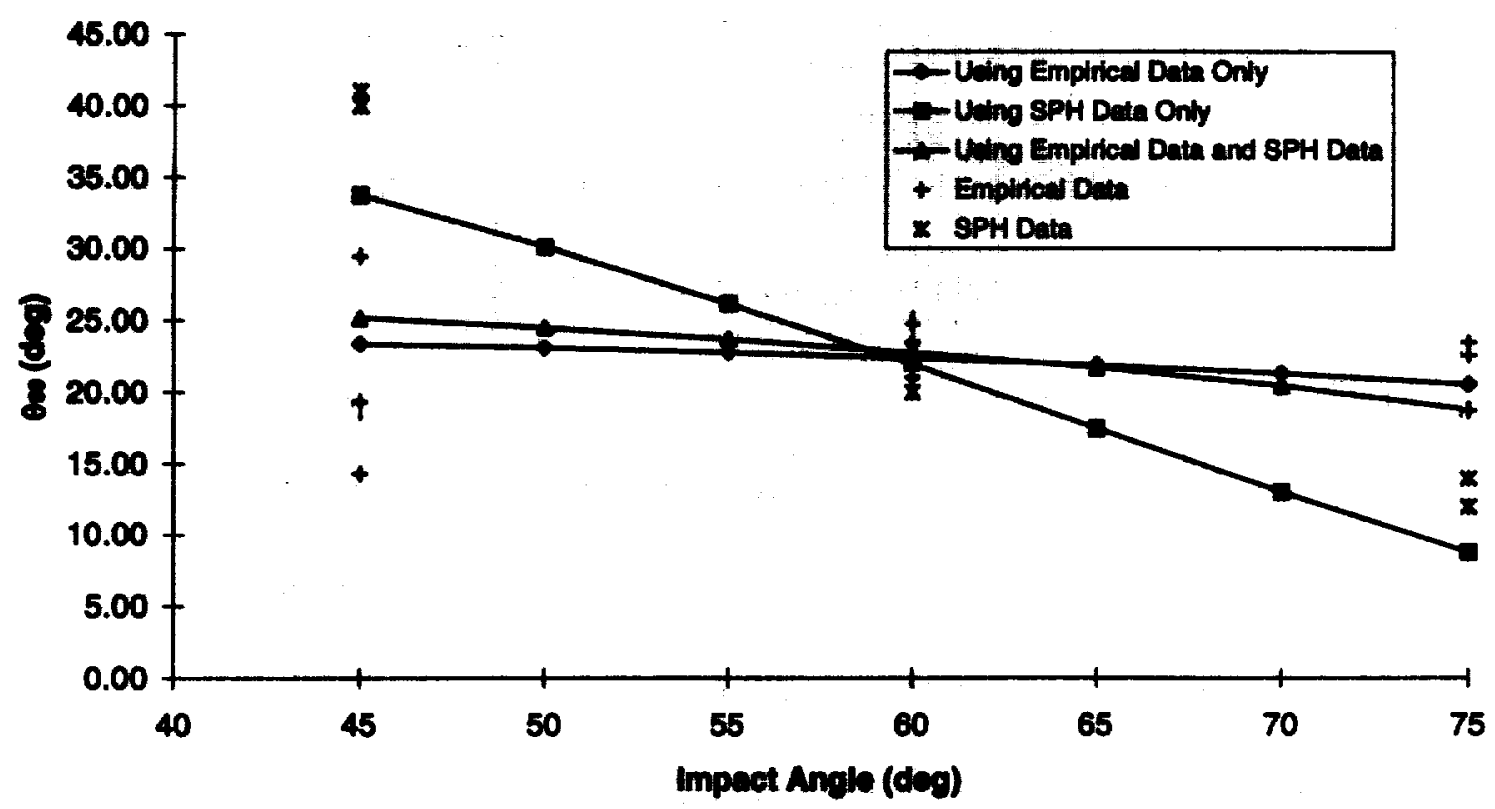

Figure 3.3 Comparison of $\theta_{9 g}$ Regression Equation Predictions Against Empirical and Numerical Data 
It is clear from the plots of all three regression equations in Figure 3.2 (empirical-only, SPH-only, and combined) that $\theta_{\mathrm{r}}$ decreases monotonically as $\theta_{\mathrm{p}}$ increases. This is a statistical demonstration of the empirical observation made previously regarding the nature of the damage to the ricochet witness plates and its relationship to the trajectory obliquity of the impacting projectile.

However, Figure 3.3 shows a divergence in the trend predicted by the SPH-only regression and those predicted by the empirical-only and combined egressions. The SPH data and the associated curve clearly show a dependence of $\theta_{99}$ on $\theta_{p}$, one that is similar to that observed for $\theta_{\mathrm{r}}$ : as $\theta_{\mathrm{p}}$ increases, $\theta_{99}$ decreases. However, the empirical data and the associated curves show $\theta_{99}$ to be relatively insensitive to any variation in $\theta_{\mathrm{p}}$. The implication is that the empirical evidence dictates that the majority of the ricochet debris cloud particles will always be contained within the same spread angle ( $25^{\circ}$ in this case), regardless of the impact parameters.

The apparent lack of dependence of $\theta_{99}$ on any impact parameter would also explain the low correlation coefficients obtained when regressing the $\theta_{99}$ data. A multi-variable regression process seeks to find trends in the data. When there are none, such as in the case of a constant dependent function value, the process returns a correlation coefficient near zero. The discrepancy between the empirically-observed independence and the numerically-observed dependence of $\theta_{99}$ is an issue that needs to be explored in more detail in a subsequent investigation. Perhaps more consistent calculation (in the case of the test data) and measurement (in the case of the numerical data) processes are needed to ensure a more valid joining of the two data sets. 


\subsection{RICOCHIT DEBRIS CLOUD VILOCITY}

\subsection{Introductory Comments}

A model is developed that can be used to calculate the masses, velocitities, and trajectories of the three debris clouds created in an oblique hypervelocity impact in terms of impact parameters, material properties, and bumper thickness. This model is based on applying the principles of mass, momentum, and energy conservation before and after the oblique impact event. Elementary shock physics and thermodynamic principles are used in the model to determine the fraction of the initial projectile impact energy that is lost to shock heating of the projectile and bumper materials. The model developed is verified by comparing its predictions with available experimental information.

The model is an improvement of the original model developed by Schonberg and Yang [1] for two reasons. First, it contains a more widely-applicable empirical equation for $\theta_{\mathrm{r}}$ than the previous model. Second, it has a decreased dependence on empirical, or user-controlled, parameters by explicitly calculating the fraction of the initial projectile kinetic energy that is expended in the shock heating and release of the projectile and bumper materials.

Figure 4.1 below shows a schematic of the parameters that characterize the motion of the three debris clouds created in an oblique hypervelocity impact. In this figure, $M_{1}, M_{2}$, and $M_{r}$ are the masses of the 'normal", 'in-line', and 'ricochet' debris clouds. Analogously, the quantities $V_{1}$, $V_{2}$ and $V_{n}$, and $\theta_{1}, \theta_{2}$, and $\theta_{1}$ are the axial velocities and trajectories, respectively, of these debris clouds. We also later introduce the parameter $V_{.}$(not shown in Figure 4.1) which is used to characterize the (assumed equal) radial expansion velocity of each of these three debris clouds. 


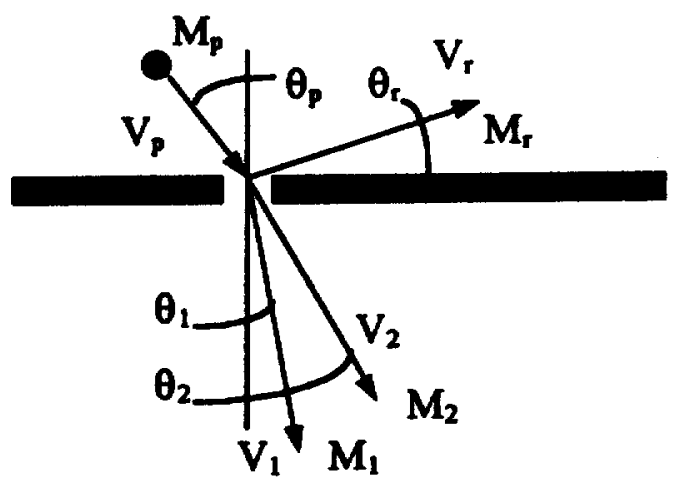

Figure 4.1. Oblique Hypervelocity Impact of a Flat Plate

\subsection{Oblique Impact Model Development}

Applying conservation of momentum before and after the initial impact of the projectile on the bumper plate in the vertical and horizontal directions, we arrive at the following equations:

$$
\begin{aligned}
& M_{p} V_{p} \cos \theta_{p}=M_{1} V_{1} \cos \theta_{1}+M_{2} V_{2} \cos \theta_{2}-M_{r} V_{r} \sin \theta_{r} \\
& M_{p} V_{p} \sin \theta_{p}=M_{1} V_{1} \sin \theta_{1}+M_{2} V_{2} \sin \theta_{2}+M_{r} V_{r} \cos \theta_{r}
\end{aligned}
$$

Assuming that no mass is lost in the initial impact, the mass conservation principle yields

$$
M_{p}+M_{f}=M_{1}+M_{2}+M_{r}
$$

where $M_{f}$ is the mass of the material that is punched out in the creation of the eliptical hole in the bumper plate. This quantity is calculated by noting that for the trajectory obliquities considered, the bumper plate hole is elliptical [5]:

$$
M_{f}=\frac{1}{4} \pi \rho_{b} D_{\min } D_{\max } t_{b}
$$

where $\rho_{b}$ and $t_{b}$ are the bumper mass density and thickness, respectively.

The quantities $D_{\min }$ and $D_{\max }$ are the lengths of the minor and major axes of the bumper plate hole and were calculated using the following empirical equations [4]: 


$$
\begin{aligned}
& \frac{D_{\min }}{d_{p}}=2.698\left(\frac{V_{p}}{C_{b}}\right)^{0.600}\left(\frac{t_{p}}{d_{p}}\right)^{0.700} \cos ^{0.021} \theta_{p}+0.93 \\
& \frac{D_{\max }}{d_{p}}=2.252\left(\frac{V_{p}}{C_{b}}\right)^{0.622}\left(\frac{t_{b}}{d_{p}}\right)^{0.667} \exp \left(0.815 \theta_{p}\right)+1.00
\end{aligned}
$$

where $C_{b}$ is the bumper material speed of sound, $d_{p}$ is the projectile diameter, and $\theta_{p}$ is in radians. We note that these equations were derived from hypervelocity impact tests in which spherical aluminum projectiles impacted thin aluminum plates. Hence, while the general methodology described herein may be valid for other materials besides aluminum, the use of empirical equations based on tests employing aluminum plates renders this specific analysis valid only for spherical aluminum projectiles impecting aluminum bumper plates.

Equations (4.1-4.3) constitute a system of 3 equations in 9 unknowns which must be solved for: 3 debris cloud masses, 3 axial velocities, 3 center-of-mass trajectories. An additional unknown exists in the form of the average radial expansion velocity of the debris clouds $V_{o}$, which must also be solved for. The solution process is facilitated by utilizing experimental observations from high-speed impact tests of aluminum dual-wall structures to determine several of the unknowns in equations (4.1-4.3). The remaining unknowns can then be determined in closed form. Once this is accomplished, an additional equation can be introduced to solve for $V_{a}$. The process by which this is done is described in the following sections.

\subsection{Trajectory Angles}

The angles $\theta_{1}$ and $\theta_{2}$ initially increase as $\theta_{1}$ is increased [4]. This continues until a critical value of $\theta_{p}$ is reached beyond which $\theta_{1}$ and $\theta_{2}$ decrease with continued increases in $\theta_{p}$. This kind of behavior is very difficult to predict analytically without resorting to an advanced shock physics analysis. As a result, the analytical prediction of this behavior is beyond the scope of the present 
work. The empirical equations used to calculate values of $\theta_{1}$ and $\theta_{2}$ as functions of the initial impact parameters are given below [5]:

$$
\begin{aligned}
& \frac{\theta_{1}}{\theta_{p}}=0.471\left(\frac{V_{p}}{C_{b}}\right)^{-0.049}\left(\frac{t_{b}}{d_{p}}\right)^{-0.054} \cos ^{1.134} \theta_{p} \\
& \frac{\theta_{2}}{\theta_{p}}=0.532\left(\frac{V_{p}}{C_{b}}\right)^{-0.086}\left(\frac{t_{b}}{d_{p}}\right)^{-0.478} \cos ^{0.586} \theta_{p}
\end{aligned}
$$

The angle $\theta_{\mathrm{r}}$ is given by the following empirical equation, which was derived in the preceding chapter:

$$
\theta_{\mathrm{r}}=\tan ^{-1}\left[0.4206\left(\frac{\mathrm{t}_{\mathrm{b}}}{\mathrm{d}_{\mathrm{p}}}\right)^{0.2651}\left(\frac{\mathrm{V}_{\mathrm{p}}}{\mathrm{C}_{\mathrm{b}}}\right)^{0.4345} \cos ^{0.7988} \theta_{\mathrm{p}}\right]
$$

By using equations (4.7-4.9), $\theta_{1}, \theta_{2}$, and $\theta_{\mathrm{r}}$ can be treated as known quantities which reduces the number of unknowns in equations (4.1-4.3) to six.

\subsection{Debris Cloud Masses}

The three unknown debris cloud masses are calculated by systematically distributing the mass of the projectile and the mass of the bumper plate material that is punched out by the initial impact among the three debris clouds and then invoking the conservation of mass equation, equation (4.3). This distribution process is accomplished as follows.

First, it is noted that as $\theta_{\mathrm{p}}$ increases, the amount of material in the normal and in-line debris clouds monotonically decreases while that in the ricochet debris cloud steadily increases [5]. Furthermore, it has been hypothesized that the material in the normal debris cloud is primarily bumper plate material, while the material in the in-line debris cloud is primarily projectile material [3]. The obliquity of the initial impact on the bumper plate also mandates that the in-line and 
ricochet debris clouds contain a portion of the bumper plate material. Based on these observations, we postulate the following functional forms of $\mathbf{M}_{1}$ and $\mathbf{M}_{2}$ :

$$
\begin{aligned}
& M_{1}=\bar{M}_{f} \cos ^{2} \theta_{p} \\
& M_{2}=\alpha_{2}\left(M_{f}-\overline{M_{f}}\right) \cos ^{n} \theta_{p}+M_{p} \cos ^{n} \theta_{q}
\end{aligned}
$$

where $\mathrm{M}_{\mathrm{f}}$ is the mass of bumper plate material that would be ejected in a normal impact at a reduced velocity $V<V_{p}$ i.e. $M_{f}=M_{r}\left(\theta_{p}=0^{\circ}, V_{p}=V\right)$, and $\alpha_{2}$ is that fraction of the ejected bumper plate material in the in-line debris cloud. These forms satisfy the requirement that the debris cloud masses decrease as $\theta_{p}$ increases and do not violate the hypotheses regarding the origins of the material in the respective debris clouds. The values of the exponent $n$ and the coefficient $\alpha_{2}$ are adjusted so that the final predictions for the debris cloud spread angles based on this analysis procedure compare well with those obtained using empirical predictor equations for debris cloud spread angles.

The reduced velocity $\mathrm{V}$ ' used to calculate the mass of bumper plate material in the 'normal' debris cloud is taken to be the normal component of the original impact velocity. Any material in excess of that which such a normal impact would produce is allocated to the 'in-line' and ricochet debris clouds. Therefore, the reduced velocity $\mathrm{V}$ is given by

$$
V^{\prime}=\eta V_{p} \cos \theta_{p}
$$

where $\eta$ is a correction factor that is also adjusted so that the final predictions for debris cloud spread angles based on the analysis procedure presented herein compare well with those obtained using empirical predictor equations. Substitution of equations (4.10-4.11) into equation (4.3) results in the following expression for the mass of the ricochet debris cloud:

$$
M_{f}=\left(1-\alpha_{2}\right)\left(M_{f}-\overline{M_{f}}\right) \cos ^{n} \theta_{p}+\left(M_{f}+M_{p}\right)\left(1-\cos ^{n} \theta_{p}\right)
$$


These calculations and assumptions allow $\mathbf{M}_{1}, \mathbf{M}_{2}$, and $\mathbf{M}_{\mathbf{r}}$ to be treated as known quantities which reduces the number of unknowns to three. Since one of the equations was used in the preceding analysis, we now have a system of two equations in three unknowns $\left(V_{1}, V_{2}, V_{f}\right)$.

\subsection{Debris Cloud Axial Velocities}

Since the 'normal' debris cloud is assumed to contain only bumper plate material and the mass of that material is calculated assuming a normal impact, the method for calculating its velocity is based on a procedure currently utilized for calculating debris cloud velocities in normal impacts of thin plates. This procedure is summarized in the following paragraph.

The initial normal impact of a projectile on a thin plate produces a shock wave that undergoes reflection at the rear surface of the plate. An elementary shock wave propagation analysis indicates that the velocity of the rear surface at the moment of reflection is equal to twice the particle velocity of the plate material as the shock wave passes through the plate. For a normal impact of an aluminum projectile on an aluminum plate, particle velocity is equal to one-half of the impact velocity. Hence, a simple substitution shows that for the particular projectile and bumper plate materials under consideration, under normal impact, the velocity of the rear surface of the plate is equal to the initial normal impact velocity. Since the reflection of the shock wave from the rear surface causes the plate material to fragment and thereby creates the debris cloud, the presumption is made that the axial velocity of the debris cloud created by the normal impact is equal to the velocity of the rear surface of the plate.

Since the normal velocity assumed to create the 'normal' debris cloud is given by $V$ ', then the axial velocity of the 'normal' debris cloud is also given by $V$ ', that is,

$$
V_{1}=\eta V_{p} \cos \theta_{p}
$$

We are now left with a system of two equations in two unknowns, $V_{2}$ and $V_{r}$. This system 
is solved explicitly with the following results:

$$
\begin{aligned}
& V_{2}=\frac{M_{p} V_{p} \cos \left(\theta_{p}-\theta_{i}\right)-V_{1} \cos \left(\theta_{1}-\theta_{r}\right)}{M_{2} \cos \left(\theta_{2}-\theta_{r}\right)} \\
& V_{r}=\frac{M_{p} V_{p} \sin \theta_{p}-M_{1} V_{1} \sin \theta_{1}-M_{2} V_{2} \sin \theta_{2}}{M_{r} \cos \theta_{r}}
\end{aligned}
$$

Thus, all of the unknowns in equations (4.1-4.3) are now determined. The final unknown to be determined is $V_{o}$, which is found using the method presented in the next Section. It is necessary to determine this unknown in order to be able to validate this model.

\subsection{Debris Cloud Radial Expansion Velocities}

If we apply the principle of energy conservation before and after the initial impact of the projectile on the bumper plate, we have the following symbolic equation:

$$
K . E_{\text {.intiol }}=K . E_{\text {darie }}+K . E_{\text {tox }}
$$

where the initial kinetic energy is that of the incoming projectile, the kinetic energy of the debris clouds is that due to their axial motion and expansion, and the kinetic energy that is lost is due to the irreversible thermodynamic processes that result from the initial impact such as material heating, light flash, etc. If the energy that is lost is written as some fraction $\xi$ of the initial impact energy, then writing the kinetic energy of the projectile and the debris clouds in standard form yields the following:

$$
\frac{1}{2}(1-\xi) M_{p} V_{p}^{2}=\frac{1}{2}\left(M_{1}+M_{2}+M_{r}\right) V_{c}^{2}+\frac{1}{2}\left(M_{1} V_{1}^{2}+M_{2} V_{2}^{2}+M_{r} V_{z}^{2}\right)
$$

The term on the left hand side of equation (4.18) may be regarded as the energy available for debris cloud motion and expansion. Once the value of $\xi$ is known, the only unknown in equation (4.18) is $V_{o}$, which can be obtained explicitly as follows: 


$$
V_{e}=\sqrt{\frac{(1-\xi) M_{p} V_{p}^{2}-\left(M_{1} V_{1}^{2}+M_{2} V_{2}^{2}+M_{r} V_{r}^{2}\right)}{M_{1}+M_{2}+M_{r}}}
$$

The parameter $\xi$, which defines the fraction of the initial impact energy that is lost to shock heating, is calculated as follows:

$$
\xi=\frac{E_{\text {lood }}^{\text {poj }} M_{p}+E_{\text {lope }}^{\text {bopr }} M_{f}}{\frac{1}{2} M_{p} V_{p}^{2}}
$$

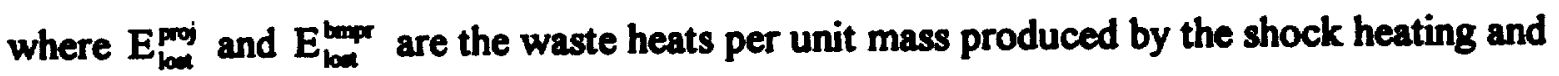
release of the projectile and bumper hole-out materials. We note that by neglecting energy losses such as those due to light flash, the results obtained herein should be conservative in nature. The procedure for calculating these waste heats is discussed in the following sub-section.

\subsubsection{Shock Loading and Release Due to High Speed Impact}

In calculating the shock loading and subsequent release of the projectile and outer bumper materials, the shock waves are considered to be initially planar. This simplification allows onedimensional relationships to be used for analyzing the creation and release of shock pressures. In this manner, the shock pressures, energies, etc., in the projectile and outer bumper materials are calculated using the three 1-D shock-jump conditions, a linear relationship between the shock wave velocity and particle velocity in each material, and continuity of pressure and velocity at the projectile/outer bumper interface. Specifically, if we consider the 1-D impact of a projectile with velocity $v_{0}$ on a stationary outer bumper, conservation of mass, momentum, and energy across the shock fronts in the projectile and in the outer bumper yields 


$$
\frac{u_{p}}{V_{\phi p}}=\frac{u_{p}-u_{p p}}{V_{p_{p}}}
$$

Projectile: $\quad P_{m}=P_{\phi}+\frac{u_{p} u_{p p}}{V_{\infty}}$

$$
E_{H \phi}=E_{\phi p}+\frac{1}{2}\left(P_{H \phi}+P_{\phi \phi}\right)\left(V_{s p}-V_{H \varphi}\right)
$$

$$
\frac{u_{u}}{V_{\alpha}}=\frac{u_{\alpha}-u_{p t}}{V_{p t}}
$$

$$
\text { Outer Bumpar: } \quad \begin{aligned}
P_{k} & =P_{\alpha}+\frac{u_{\alpha} u_{k}}{V_{\alpha}} \\
E_{H A} & =E_{\alpha}+\frac{1}{2}\left(P_{k t}+P_{\alpha}\right)\left(V_{\alpha}-V_{H k}\right)
\end{aligned}
$$

where $V=1 / \rho$ is specific volume, $u_{k}$ and $u_{p}$ are shock and particle velocity, respectively; $V_{H}, P_{H}, E_{H}$ and $V_{0,} P_{0} E_{0}$ are the density, pressure and energy states associated with the shocked and initial material states, respectively. In equations (4.21a-c) and (4.22a-c), the subscripts ' $p$ ', and ' $t$ ' refer to projectile and outer bumper quantities, respectively. In the development of equations (4.21a-c) and $(4.22 a-c)$, the shock velocity in the projectile is talen relative to a 'stationary' projectile.

The linear shock velocity-particle velocity relationships for the projectile and outer bumper materiais are taken to be in the form

$$
\mathbf{u}_{\mathbf{s}}=\mathbf{c}_{\mathbf{0}}+\mathbf{k} \mathbf{u}_{\mathbf{p}}
$$

where $c_{0}=\sqrt{ }\left(K V_{0}\right)$ is the material bulk speed of sound, $K=E / 3(1-2 v)$ is the adiabatic bulk modulus, $E$ and $v$ are Young's modulus and Poisson's ratio, respectively, and $k$ is an empirically-derived constant. Equations (4.21a-c, $4.22 \mathrm{a}-\mathrm{c})$ are applied to the initial impact on the outer bumper of a multi-wall system in the following manner. Upon inpact, pressure equilibrium at the projectile/outer bumper interface implies that

$$
\mathbf{P}_{\mathbf{H P}}=\mathbf{P}_{\mathbf{H z}}
$$


while material continuity at the interface implies that

$$
v_{0}=u_{p p}+u_{p t}
$$

Because the outer bumper in a multi-wall system is free from any initial mechanical stress (it is merely supported at its four corners a fixed distance away from the inner pressure wall), the initial conditions ahead of the projectile and outer bumper shock waves are taken to be zero (with the exception, of course, of the initial material densities). Solving equations (4.21-4.25) simultaneously yields expressions for projectile and outer bumper particle velocities which can then be used to calculate shock velocities, pressures, internal energies, and material densities after the passage of a shock wave. For example, using this procedure to solve initially for $u_{p}$ yields

$$
u_{p t}=\frac{b-\sqrt{\Delta}}{2 a}
$$

where

$$
\begin{aligned}
& a=k_{p}-k_{1}\left(\frac{\rho_{o t}}{\rho_{o p}}\right) \\
& b=2 k_{p} v_{o}+c_{o p}+c_{o t}\left(\frac{\rho_{o q}}{\rho_{o p}}\right) \\
& \Delta=b^{2}-4 a\left(c_{o p} v_{o}+k_{p} v_{o}^{2}\right)
\end{aligned}
$$

Then it follows that

$$
\begin{aligned}
& u_{p p}=v_{o}-u_{p t} \\
& u_{s t}=c_{o t}+k_{t} u_{p t} \\
& u_{p p}=c_{o p}+k_{p} u_{p p}
\end{aligned}
$$

The shocked densities of the projectile and outer bumper materials are found by substituting equations $(4.26,4.28 \mathrm{a}-\mathrm{c})$ into equations $(4.21 \mathrm{a})$ and $(4.22 \mathrm{a})$ to yield 


$$
\begin{aligned}
& \rho_{h p}=\frac{1}{V_{H p}}=\frac{u_{p} / V_{o p}}{u_{p}-u_{p p}} \\
& \rho_{H t}=\frac{1}{V_{H h}}=\frac{u_{t} / V_{\alpha Q}}{u_{*}-u_{p k}}
\end{aligned}
$$

Finally, equations $(4.21 b, c)$ and $(4.22 b, c)$ are then used to define the pressure and energy in the projectile and outer bumper materials, respectively, associated with the passage of the shock waves created by the initial impact. This completely defines the shocked atates of the projectile and outer materials due to the initial impact.

While the shock loading of a material is an irreversible process that results in an increase of the internal energy of the shocked material, the release of a shocked material occurs isentropically along an 'isentrope' or 'release adiabat'. The difference between the area under the isentrope and the energy of the shocked state is the amount of residual energy that remains in the material and can cause the material to melt or even vaporize. In order to calculate the release of the projectile and outer bumper materials from their respective shocked states (each characterized by $P_{H}, E_{H}$ and $V_{H}$, an appropriate equation-of-state is needed for each material. To keep the analysis relatively simple, the Mie-Gruneisen equation-of-state [6] was used in this study.

The Mie-Gruneisen equation-of-state (EOS) is an accurate thermodynamic description of most metals in the solid regime and is relatively easy to use. It has the form

$$
\mathbf{P}=\mathbf{P}_{\mathbf{H}}+\rho \Gamma\left(E-E_{\mathbf{H}}\right)
$$

where the time-dependent Gruneisen coefficient $\Gamma$ is given for most metals as

$$
\Gamma=\frac{\Gamma_{0} \rho_{0}}{\rho}
$$

In equation (4.31), 


$$
\Gamma_{0}=\frac{K \beta}{\rho_{0} C_{p}}
$$

is the ambient Gruneisen coefficient, where $K$ is the adiabatic bulk modulus, $\beta=3 \alpha$ is the volumetric coefficient of thermal expansion, and $C_{p}$ is specific heat at constant pressure. Invoking the Second Law of Thermodynamics

$$
d E=T d S-P d V
$$

along with the isentropic constraint $\mathrm{dS}=0$ for the release process allows us to construct the release isentrope in P-V space for a material referenced to the material Hugoniot in P-V space and a given initial shocked state defined by $P_{H}, V_{H}, E_{H}$. Using the procedure outlined in Reference [6], the pressure $P_{i}$ at a specific position ' $i$ ' along the isentrope can be shown to be given by

$$
P_{i}=\frac{P_{H i}+\left(\frac{\Gamma}{V}\right)_{i}\left(E_{i-1}-\frac{1}{2} P_{i-1}(\Delta V)-E_{H i}\right)}{1+\frac{1}{2}\left(\frac{\Gamma}{V}\right)_{i}(\Delta V)}
$$

where $\Delta \mathrm{V}$ is the incremental change in volume used to create the release isentrope, and $\mathrm{P}_{\mathrm{Hi}}$ and $E_{\mathrm{Hi}}$ are the pressure and energy along the Hugoniot corresponding to the $\mathrm{i}$-th position in the release process. The release process is continued using equation (4.34) until the release isentrope so determined crosses the $\mathrm{V}$-axis.

It should be noted that based on its formulation, the Mie-Gruneisen EOS cannot be expected to give accurate results in a highly expanded liquid regime or in a vapor regime. This is because as impact energy increases, the assumption that the Gruneisen coefficient is a function of density alone is no longer valid. At high impact energies, the Gruneisen coefficient is a function of internal energy as well as density. Experience has shown, however, that it does yield fairly accurate end-state results even when there is a small percentage of molten material present [7]. 
Once the release process calculations for the projectile and bumper materials have been completed, the areas under the respective isentropes are calculated and subtracted from the initial shocked energy state to determine the respective waste heats, that is,

$$
\begin{aligned}
& E_{\text {bod }}^{\text {poj }}=E_{H}-A \\
& E_{\text {lox }}=E_{H}-A^{m}
\end{aligned}
$$

\subsection{Oblique Impact Model Verifiention}

The validity of the proposed method of solution for the ten unknowns that characterize the debris clouds created as a result of an oblique hypervelocity impact of a thin plate (as well as all the attendant assumptions) is assessed by comparing model predictions of debris cloud spread angles with the predictions of empirically based equations for debris cloud spread angles. Model values for the spread angles of the 'normal' and 'in-line' debris clouds, $\phi_{1}$ and $\phi_{2}$, respectively, are given by:

$$
\phi_{i}=2 \tan ^{-1}\left(\frac{V_{i}}{V_{i}}\right) \quad i=1,2
$$

The empirical values of debris cloud spread angles are found using the following relationships [5]:

$$
\begin{aligned}
& \tan \phi_{1}=1.318\left(\frac{V_{p}}{C_{b}}\right)^{0.907}\left(\frac{t_{b}}{d_{p}}\right)^{0.195} \cos ^{0.394} \theta_{p} \\
& \tan \phi_{2}=1.556\left(\frac{V_{p}}{C_{b}}\right)^{1.906}\left(\frac{t_{b}}{d_{p}}\right)^{0.315} \cos ^{0.738} \theta_{p}
\end{aligned}
$$

Table 4.1 presents the a summary of the impact paramters used in the evduation of the model developed herein. Tables $4.2 \mathrm{a}-\mathrm{c}, 4.3 \mathrm{a}-\mathrm{c}$, and $4.4 \mathrm{a}-\mathrm{c}$ present the final values of the usercontrolled parameters $\alpha_{2}, \eta$ and $n$ corresponding to the impact conditions in Table 4.1. 
Table 4.1. Impact Conditions Considered in Model Validation

\begin{tabular}{|c|c|}
\hline Impact Parameter & Values Considered \\
\hline Impact Velocity, $V_{p}(\mathrm{~km} / \mathrm{s})$ & $4.0,5.5,7.0$ \\
\hline Trajectory Obliquity, $\theta_{p}(\mathrm{deg})$ & $30,45,60$ \\
\hline Projectile Diameter, $\mathrm{d}_{\mathrm{p}}(\mathrm{cm})$ & $0.635,0.795,0.953,1.13,1.27$ \\
\hline Bumper Thickness, $\mathrm{t}_{\mathrm{b}}(\mathrm{mm})$ & $1.3,1.6,2.0$ \\
\hline
\end{tabular}

Table 4.2a. Model Parameters $\alpha_{2}, \eta$ and $n$ for $\theta_{p}=30^{\circ}, t_{b}=1.3 \mathrm{~mm}$

\begin{tabular}{|c|c|c|c|c|}
\hline $\begin{array}{c}\mathbf{V} \\
(\mathrm{km} / \mathrm{s})\end{array}$ & $\begin{array}{c}\mathbf{d}_{\mathbf{p}} \\
(\mathrm{cm})\end{array}$ & $\eta$ & $\mathbf{N}$ & $\alpha_{2}$ \\
\hline 4.0 & 0.635 & 0.85 & 3.45 & 1.00 \\
\hline 4.0 & 0.795 & 1.00 & 2.40 & 1.00 \\
\hline 4.0 & 0.953 & 1.20 & 1.50 & 1.00 \\
\hline 4.0 & 1.13 & 1.35 & 0.35 & 1.00 \\
\hline 5.5 & 0.635 & 0.80 & 3.45 & 1.00 \\
\hline 5.5 & 0.795 & 0.85 & 2.45 & 1.00 \\
\hline 5.5 & 0.953 & 1.00 & 1.40 & 1.00 \\
\hline 5.5 & 1.13 & 1.20 & 0.60 & 1.00 \\
\hline 7.0 & 0.635 & 0.75 & 3.40 & 0.95 \\
\hline 7.0 & 0.795 & 0.80 & 2.50 & 0.93 \\
\hline 7.0 & 0.953 & 0.90 & 1.50 & 0.91 \\
\hline 7.0 & 1.13 & 1.10 & 0.90 & 0.89 \\
\hline
\end{tabular}

Table 4.2b. Model Parameters $\alpha_{2}, \eta$ and $n$ for $\theta_{p}=30^{\circ}, t_{b}=1.6 \mathrm{~mm}$

\begin{tabular}{|c|c|c|c|c|}
\hline $\begin{array}{c}\mathrm{V} \\
(\mathrm{km} / \mathrm{s})\end{array}$ & $\begin{array}{c}\mathbf{d}_{\mathbf{p}} \\
(\mathrm{cm})\end{array}$ & $\eta$ & $\mathrm{n}$ & $\boldsymbol{\alpha}_{2}$ \\
\hline 4.0 & 0.635 & 0.85 & 4.50 & 1.00 \\
\hline 4.0 & 0.795 & 0.95 & 3.40 & 1.00 \\
\hline 4.0 & 0.953 & 1.05 & 2.50 & 1.00 \\
\hline 4.0 & 1.13 & 1.15 & 1.60 & 1.00 \\
\hline 5.5 & 0.635 & 0.75 & 4.50 & 1.00 \\
\hline 5.5 & 0.795 & 0.85 & 3.45 & 1.00 \\
\hline 5.5 & 0.953 & 0.95 & 2.60 & 1.00 \\
\hline 5.5 & 1.13 & 1.05 & 1.80 & 1.00 \\
\hline 7.0 & 0.635 & 0.75 & 4.40 & 0.95 \\
\hline 7.0 & 0.795 & 0.80 & 3.50 & 0.93 \\
\hline 7.0 & 0.953 & 0.85 & 2.70 & 0.91 \\
\hline 7.0 & 1.13 & 0.90 & 1.90 & 0.89 \\
\hline
\end{tabular}


Table 4.2c. Model Parameters $\alpha_{2}, \eta$, and $n$ for $\theta_{p}=30^{\circ}, t=2.0 \mathrm{~mm}$

\begin{tabular}{|c|c|c|c|c|}
\hline $\begin{array}{c}V \\
(\mathrm{~m} / 0)\end{array}$ & $\begin{array}{c}\mathbf{d}_{\mathbf{p}} \\
(\mathrm{cm})\end{array}$ & $\eta$ & $\cdots$ & $\alpha_{2}$ \\
\hline 4.0 & 0.635 & 0.80 & 5.70 & 1.00 \\
\hline 4.0 & 0.795 & 0.90 & 4.50 & 1.00 \\
\hline 4.0 & 0.953 & 1.00 & 3.60 & 1.00 \\
\hline 4.0 & 1.13 & 1.10 & 2.80 & 1.00 \\
\hline 5.5 & 0.635 & 0.75 & 5.70 & 1.00 \\
\hline 5.5 & 0.795 & 0.80 & 4.45 & 1.00 \\
\hline 5.5 & 0.953 & 0.85 & 3.55 & 1.00 \\
\hline 5.5 & 1.13 & 0.90 & 2.75 & 1.00 \\
\hline 7.0 & 0.635 & 0.70 & 5.50 & 0.95 \\
\hline 7.0 & 0.795 & 0.75 & 4.30 & 0.93 \\
\hline 7.0 & 0.953 & 0.80 & 3.50 & 0.91 \\
\hline 7.0 & 1.13 & 0.85 & 2.70 & 0.89 \\
\hline
\end{tabular}

Table 4.3a. Model Parameters $\alpha_{2}, \eta$, and $n$ for $\theta_{p}=45^{\circ}, t_{6}=1.3 \mathrm{~mm}$

\begin{tabular}{|c|c|c|c|c|}
\hline $\begin{array}{c}\mathrm{V} \\
(\mathrm{km} / \mathrm{s})\end{array}$ & $\begin{array}{c}d_{p} \\
(\mathrm{~cm})\end{array}$ & $\eta$ & $n$ & $\alpha_{2}$ \\
\hline 4.0 & 0.635 & 1.00 & 1.85 & 1.00 \\
\hline 4.0 & 0.795 & 1.10 & 1.35 & 1.00 \\
\hline 4.0 & 0.953 & 1.35 & 0.85 & 1.00 \\
\hline 4.0 & 1.13 & 1.50 & 0.40 & 1.00 \\
\hline 5.5 & 0.635 & 0.95 & 1.95 & 1.00 \\
\hline 5.5 & 0.795 & 1.05 & 1.35 & 1.00 \\
\hline 5.5 & 0.953 & 1.10 & 0.85 & 1.00 \\
\hline 5.5 & 1.13 & 1.15 & 0.28 & 1.00 \\
\hline 7.0 & 0.635 & 0.85 & 1.85 & 0.95 \\
\hline 7.0 & 0.795 & 0.95 & 1.35 & 0.93 \\
\hline 7.0 & 0.953 & 1.05 & 0.90 & 0.91 \\
\hline 7.0 & 1.13 & 1.15 & 0.45 & 0.89 \\
\hline
\end{tabular}


Table 4.3b. Model Parameters $\alpha_{2}, \eta$, and $n$ for $\theta_{p}=45^{\circ}, t_{b}=1.6 \mathrm{~mm}$

\begin{tabular}{|c|c|c|c|c|}
\hline $\begin{array}{c}\mathrm{V} \\
(\mathrm{km} / \mathrm{s})\end{array}$ & $\begin{array}{c}\mathbf{d}_{\mathbf{p}} \\
(\mathrm{cm})\end{array}$ & $\eta$ & $\mathbf{n}$ & $\alpha_{2}$ \\
\hline 4.0 & 0.635 & 1.00 & 2.45 & 1.00 \\
\hline 4.0 & 0.795 & 1.10 & 1.90 & 1.00 \\
\hline 4.0 & 0.953 & 1.20 & 1.40 & 1.00 \\
\hline 4.0 & 1.13 & 1.35 & 1.00 & 1.00 \\
\hline 5.5 & 0.635 & 0.95 & 2.55 & 1.00 \\
\hline 5.5 & 0.795 & 1.05 & 1.95 & 1.00 \\
\hline 5.5 & 0.953 & 1.10 & 1.45 & 1.00 \\
\hline 5.5 & 1.13 & 1.15 & 1.05 & 1.00 \\
\hline 7.0 & 0.635 & 0.85 & 2.45 & 0.95 \\
\hline 7.0 & 0.795 & 0.95 & 1.90 & 0.93 \\
\hline 7.0 & 0.953 & 1.05 & 1.45 & 0.91 \\
\hline 7.0 & 1.13 & 1.15 & 1.05 & 0.89 \\
\hline
\end{tabular}

Table 4.3c. Model Parameters $\alpha_{2}, \eta$, and $n$ for $\theta_{p}=45^{\circ}, t_{b}=2.0 \mathrm{~mm}$

\begin{tabular}{|c|c|c|c|c|}
\hline $\begin{array}{c}\mathbf{V} \\
(\mathrm{km} / \mathrm{s})\end{array}$ & $\begin{array}{c}\mathbf{d}_{\mathbf{p}} \\
(\mathrm{cm})\end{array}$ & $\eta$ & $\mathbf{n}$ & $\boldsymbol{\alpha}_{2}$ \\
\hline 4.0 & 0.635 & 1.00 & 3.05 & 1.00 \\
\hline 4.0 & 0.795 & 1.10 & 2.50 & 1.00 \\
\hline 4.0 & 0.953 & 1.20 & 2.00 & 1.00 \\
\hline 4.0 & 1.13 & 1.35 & 1.60 & 1.00 \\
\hline 5.5 & 0.635 & 0.95 & 3.05 & 1.00 \\
\hline 5.5 & 0.795 & 1.05 & 2.45 & 1.00 \\
\hline 5.5 & 0.953 & 1.10 & 2.00 & 1.00 \\
\hline 5.5 & 1.13 & 1.15 & 1.65 & 1.00 \\
\hline 7.0 & 0.635 & 0.80 & 2.85 & 0.95 \\
\hline 7.0 & 0.795 & 0.90 & 2.40 & 0.93 \\
\hline 7.0 & 0.953 & 1.00 & 1.95 & 0.91 \\
\hline 7.0 & 1.13 & 1.10 & 1.65 & 0.89 \\
\hline
\end{tabular}


Table 4.4a. Model Parumeters $\alpha_{2}, \eta$, and $n$ for $\theta_{2}=60^{\circ}, t_{t}=1.3 \mathrm{~mm}$

\begin{tabular}{|c|c|c|c|c|}
\hline $\begin{array}{c}v \\
(\mathrm{~m} / \mathrm{b})\end{array}$ & $\begin{array}{c}\mathrm{d}_{\mathrm{p}} \\
(\mathrm{cm})\end{array}$ & $\eta$ & $\mathrm{n}$ & $\alpha_{2}$ \\
\hline 4.0 & 0.635 & 1.50 & 1.55 & 1.00 \\
\hline 4.0 & 0.795 & 1.60 & 1.20 & 1.00 \\
\hline 4.0 & 0.953 & 1.70 & 0.90 & 1.00 \\
\hline 4.0 & 1.13 & 1.80 & 0.65 & 1.00 \\
\hline 5.5 & 0.635 & 1.40 & 1.55 & 1.00 \\
\hline 5.5 & 0.795 & 1.50 & 1.25 & 1.00 \\
\hline 5.5 & 0.953 & 1.60 & 0.95 & 1.00 \\
\hline 5.5 & 1.13 & 1.70 & 0.70 & 1.00 \\
\hline 7.0 & 0.635 & 1.30 & 1.55 & 0.95 \\
\hline 7.0 & 0.795 & 1.40 & 1.25 & 0.93 \\
\hline 7.0 & 0.953 & 1.50 & 0.95 & 0.91 \\
\hline 7.0 & 1.13 & 1.60 & 0.70 & 0.89 \\
\hline
\end{tabular}

Table 4.4b. Model Parameters $\alpha_{2}, \eta$ and $n$ for $\theta_{p}=60^{\circ}, t_{b}=1.6 \mathrm{~mm}$

\begin{tabular}{|c|c|c|c|c|}
\hline $\begin{array}{c}\bar{V} \\
(\mathrm{~km} / \mathrm{s})\end{array}$ & $\begin{array}{c}\mathrm{d}_{\mathbf{p}} \\
(\mathrm{cm})\end{array}$ & $\eta$ & $\mathrm{a}$ & $\alpha_{2}$ \\
\hline 4.0 & 0.635 & 1.50 & 1.90 & 1.00 \\
\hline 4.0 & 0.795 & 1.50 & 1.50 & 1.00 \\
\hline 4.0 & 0.953 & 1.55 & 1.20 & 1.00 \\
\hline 4.0 & 1.13 & 1.75 & 1.00 & 1.00 \\
\hline 5.5 & 0.635 & 1.40 & 1.90 & 1.00 \\
\hline 5.5 & 0.795 & 1.50 & 1.60 & 1.00 \\
\hline 5.5 & 0.953 & 1.60 & 1.30 & 1.00 \\
\hline 5.5 & 1.13 & 1.70 & 1.05 & 1.00 \\
\hline 7.0 & 0.635 & 1.30 & 1.85 & 0.95 \\
\hline 7.0 & 0.795 & 1.40 & 1.55 & 0.93 \\
\hline 7.0 & 0.953 & 1.50 & 1.25 & 0.91 \\
\hline 7.0 & 1.13 & 1.60 & 1.00 & 0.89 \\
\hline
\end{tabular}


Table 4.4c. Model Parameters $\alpha_{2}, \eta$ and $n$ for $\theta_{p}=60^{\circ}, t_{b}=2.0 \mathrm{~mm}$

\begin{tabular}{|c|c|c|c|c|}
\hline $\begin{array}{c}\mathrm{V} \\
(\mathrm{km} / \mathrm{s})\end{array}$ & $\begin{array}{c}\mathbf{d}_{\mathbf{p}} \\
(\mathrm{cm})\end{array}$ & $\eta$ & $\mathbf{n}$ & $\boldsymbol{\alpha}_{2}$ \\
\hline 4.0 & 0.635 & 1.50 & 2.25 & 1.00 \\
\hline 4.0 & 0.795 & 1.50 & 1.90 & 1.00 \\
\hline 4.0 & 0.953 & 1.55 & 1.60 & 1.00 \\
\hline 4.0 & 1.13 & 1.75 & 1.35 & 1.00 \\
\hline 5.5 & 0.635 & 1.30 & 2.20 & 1.00 \\
\hline 5.5 & 0.795 & 1.40 & 1.90 & 1.00 \\
\hline 5.5 & 0.953 & 1.50 & 1.60 & 1.00 \\
\hline 5.5 & 1.13 & 1.60 & 1.40 & 1.00 \\
\hline 7.0 & 0.635 & 1.15 & 2.10 & 0.95 \\
\hline 7.0 & 0.795 & 1.25 & 1.80 & 0.93 \\
\hline 7.0 & 0.953 & 1.35 & 1.60 & 0.91 \\
\hline 7.0 & 1.13 & 1.45 & 1.40 & 0.89 \\
\hline
\end{tabular}

Finally, Table 4.5a-c present percent error summaries showing differences between prediction and experiment for the various bumper plate thicknesses, impact trajectories, projectile diameters, and obliquities considered. For each perforating debris cloud spread angle, the value shown is the precent difference between model prediction and empirical equation prediction. As can be seen from Table 4.5a-c, the values of the spread angles that result from the calculations described herein are very close to the experimental values. Naturally, the values of the parameters $\alpha_{2}, \eta$ and $n$ have been adjusted to ensure that model predictions and empirical results are closely matched. 
Table 4.5a. Percent Error Summaries for $t_{\mathrm{t}}=1.3 \mathrm{~mm}$

\begin{tabular}{|c|c|c|c|c|c|c|}
\hline \multicolumn{7}{|c|}{$\mathrm{V}_{\mathrm{n}}=4.0 \mathrm{~km}$} \\
\hline \multirow{2}{*}{${ }_{(\mathrm{cm})}^{d_{p}}$} & \multicolumn{2}{|c|}{30 de: } & \multicolumn{2}{|c|}{$45 \mathrm{det}$} & \multicolumn{2}{|c|}{$60 \mathrm{dez}$} \\
\hline & 1 & 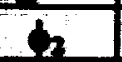 & $\phi$ & h & $\phi$ & $\phi_{2}$ \\
\hline 0.635 & 0.35 & 1.81 & 8.55 & 8.92 & -1.16 & 0.6 \\
\hline 0.795 & -11.76 & 11.01 & -8.00 & 1.2 & -9.23 & $\overline{3.4}$ \\
\hline 0.953 & -22.10 & 22.52 & -14.62 & 32.70 & -11.00 & 16.2 \\
\hline 1.13 & -3289 & 53,16 & -21.37 & 51.30 & -18.35 & $\overline{19.79}$ \\
\hline \multicolumn{7}{|c|}{$v_{1}=5.5 \mathrm{~mm} / \mathrm{h}$} \\
\hline d. & \multicolumn{2}{|c|}{$30 \mathrm{de}$} & \multicolumn{2}{|c|}{$45 \mathrm{des}$} & \multicolumn{2}{|c|}{ Codes } \\
\hline$(\mathrm{cm})$ & & & $\phi$ & 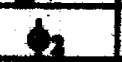 & 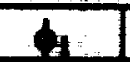 & $b$ \\
\hline 0.635 & 1.19 & 482 & 4.51 & 4.25 & 4.59 & 8.05 \\
\hline 0.795 & 24 & 2,32 & -0.52 & 10.62 & $\mathbf{- 5 . 7 7}$ & 3.41 \\
\hline 0.953 & -7.63 & 25.38 & -5.21 & 26.38 & -7.89 & 14.63 \\
\hline 1.13 & -22.26 & 37.46 & 5.30 & 65:27 & -13.44 & 20.5 \\
\hline \multicolumn{7}{|c|}{$V_{h}=7.0 \mathrm{TH}$} \\
\hline d. & \multicolumn{2}{|c|}{$30 d-1$} & \multicolumn{2}{|c|}{ Asde: } & \multicolumn{2}{|c|}{$60 \mathrm{deg}$} \\
\hline (cm) & h & h & $\Phi_{1}$ & h & $\phi_{1}$ & $\phi_{2}$ \\
\hline 0.635 & -0.30 & 3.63 & 8.57 & 6.22 & 2.09 & 3.79 \\
\hline 0.795 & -4.20 & -3.27 & 2.11 & 4.94 & -3.81 & -1.01 \\
\hline 0.953 & -6.95 & 10.12 & -2.69 & 11.45 & -5.62 & 8.05 \\
\hline 1.13 & -26.23 & 14.18 & -4.24 & 26.97 & -9.86 & 14.57 \\
\hline
\end{tabular}


Table 4.5b. Percent Error Summaries for $t_{b}=1.6 \mathrm{~mm}$

\begin{tabular}{|c|c|c|c|c|c|c|}
\hline \multicolumn{7}{|c|}{$V_{0}=4.0 \mathrm{~km} / \mathrm{s}$} \\
\hline \multirow{2}{*}{$\begin{array}{c}d_{p} \\
(\mathrm{~cm})\end{array}$} & \multicolumn{2}{|c|}{30 dex } & \multicolumn{2}{|c|}{$45 \mathrm{deg}$} & \multicolumn{2}{|c|}{$60 \mathrm{deg}$} \\
\hline & $\phi$ & $\phi$ & $\phi_{1}$ & $b_{2}$ & $\phi_{1}$ & $\phi_{2}$ \\
\hline 0.635 & -1.30 & 4.97 & 1.83 & 2.20 & -3.59 & -3.72 \\
\hline 0.795 & -9.38 & 7.50 & -7.50 & 1.26 & 4.43 & 9.00 \\
\hline 0.953 & -15.55 & 15.73 & -8.33 & 16.09 & 4.96 & 18.93 \\
\hline 1.13 & -17.19 & $\overline{35.45}$ & -16.88 & 27.99 & -15.71 & 11.89 \\
\hline \multicolumn{7}{|c|}{$V_{0}=5.5 \mathrm{~km} / \mathrm{s}$} \\
\hline \multirow{2}{*}{$\begin{array}{c}d_{p} \\
(\mathrm{~cm})\end{array}$} & \multicolumn{2}{|c|}{$30 \mathrm{deg}$} & \multicolumn{2}{|c|}{45 des } & \multicolumn{2}{|c|}{$60 \mathrm{deg}$} \\
\hline & $\phi_{1}$ & $\phi 2$ & $\phi_{1}$ & $d_{2}$ & $\phi_{1}$ & $\phi$ \\
\hline 0.635 & 1.23 & 3.83 & -3.15 & 0.62 & -2.16 & 1.74 \\
\hline 0.795 & -5.85 & 3.79 & -8.65 & 3.54 & -4.79 & 0.18 \\
\hline 0.953 & -13.02 & 7.67 & -6.42 & 13.20 & -5.48 & 9.39 \\
\hline 1.13 & \begin{tabular}{|c|}
-18.37 \\
\end{tabular} & 16.95 & -9.89 & 20.85 & -13.71 & 12.97 \\
\hline \multicolumn{7}{|c|}{$V_{0}=7.0 \mathrm{~km} / \mathrm{s}$} \\
\hline \multirow{2}{*}{$\begin{array}{c}d_{p} \\
(\mathrm{~cm})\end{array}$} & \multicolumn{2}{|c|}{$30 \mathrm{deg}$} & \multicolumn{2}{|c|}{$45 \mathrm{deg}$} & \multicolumn{2}{|c|}{60 deg } \\
\hline & $\phi_{1}$ & $\phi$ & $\bar{\phi}$ & $\phi 2$ & $\phi_{1}$ & $\phi_{2}$ \\
\hline 0.635 & -8.26 & 9.55 & -2.56 & 1.72 & -5.71 & 5.12 \\
\hline 0.795 & -9.06 & -1.28 & -4.63 & 2.66 & -5.92 & 1.94 \\
\hline 0.953 & -11.65 & -3.94 & -8.89 & 6.60 & -6.00 & 10.71 \\
\hline 1.13 & \begin{tabular}{|c|}
-12.07 \\
\end{tabular} & 1.43 & -13.33 & 13.38 & -8.95 & 17.75 \\
\hline
\end{tabular}


Table 4.5c. Percent Error Summaries for $t_{\mathrm{t}}=2.0 \mathrm{~mm}$

\begin{tabular}{|c|c|c|c|c|c|c|}
\hline \multicolumn{7}{|c|}{$v_{0}=40 \mathrm{ltah}$} \\
\hline \multirow{2}{*}{ (c) } & \multicolumn{2}{|c|}{$\overline{30 d y}$} & \multicolumn{2}{|c|}{456} & \multicolumn{2}{|c|}{$60 d e$} \\
\hline & 4 & 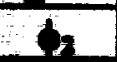 & $\overline{1}$ & $b$ & 4 & 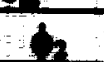 \\
\hline 0.635 & 0.90 & 5.74 & -7.35 & 5.92 & -5.54 & -0.85 \\
\hline 0.795 & -6.74 & 8.65 & -9.07 & 2.55 & -4.10 & 4.50 \\
\hline 0.953 & -15.04 & 11.36 & -11.24 & 11.53 & -4.19 & 0.96 \\
\hline 1.13 & $.16,07$ & 167 & -23.04 & 18.12 & -10.27 & 15.35 \\
\hline \multicolumn{7}{|c|}{$v_{1}=5 S$ wht } \\
\hline \multirow{2}{*}{ (b) } & \multicolumn{2}{|c|}{$30 \mathrm{det}$} & \multicolumn{2}{|c|}{$45 d$ ? } & \multicolumn{2}{|c|}{$60 \mathrm{de}$} \\
\hline & $A$ & 2 & $\boldsymbol{s}$ & $h$ & 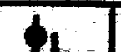 & 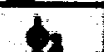 \\
\hline 0.635 & -8.76 & 9.13 & -8.79 & 8.85 & -4.58 & 3.79 \\
\hline 0.795 & 4.12 & 9,67 & -9.10 & 11.7 & -2.40 & 1.18 \\
\hline 0.953 & 4.46 & 9.55 & -10.13 & 13.93 & -0.93 & 9.91 \\
\hline 1.13 & 4.96 & 14.05 & -15.89 & 13.79 & -9.50 & 10.00 \\
\hline \multicolumn{7}{|c|}{$v_{0}=7.0 \mathrm{~L}^{\mathrm{t}}$} \\
\hline \multirow{2}{*}{ (cm) } & \multicolumn{2}{|c|}{30 de: } & \multicolumn{2}{|c|}{$4 \mathrm{der}$} & \multicolumn{2}{|c|}{$60 \mathrm{det}$} \\
\hline & & $=$ & h & . & st & 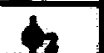 \\
\hline 0.635 & -14.14 & 14.05 & -7.02 & 13.81 & -6.88 & 7.85 \\
\hline 0.795 & -7.69 & 11.44 & -6.78 & 7.39 & -0.49 & 8.47 \\
\hline 0.953 & -7.80 & 6.33 & -9.77 & 10.24 & 4.13 & 0.19 \\
\hline 1.13 & -7.95 & 9.03 & -16.63 & 5.31 & -9.58 & -3.26 \\
\hline
\end{tabular}




\subsection{CHARACTERIZING RICOCHET DEBRIS CLOUD PARTICLES}

Damage potential estimates of ricochet debris particles created in an oblique hypervelocity impact will contribute significantly to the successful design of an effective protection systems for external spacecraft components and will assist in determining the overall survivability probability of a spacecraft following such an impact. A simple way of modelling the damage potential of a ricochet debris particle is through its size and speed.

In this Chapter, a technique is presented for developing empirical relationships that predict the velocity and mass of the largest ricochet debris cloud particle in terms of impact parameters and bumper plate thickness. This is accomplished by "backing out" the diameters, masses, and velocities of the ricochet debris cloud particles from measured craters penetration depths and surface diameters on the ricochet witness plates of 139 oblique impact tests performed at the NASA/Marshall Space Flight Center. Measured values of crater depth and diameter are used together with empirical relationships for these quantities to determine particle diameters and velocities. Results obtained using these relationships are compared with those obtained previously and presented in Reference [2]. Visual inspection of damaged ricochet witness plates reveal several interesting features that address the validity of this method.

1) The surface openings of ricochet witness plate craters formed by debris impacts were very nearly circular, which is indicative of near-normal impact trajectories. This observation is confirmed by the analysis performed in the preceding chapter; which concluded that most of the ricochet debris particles will be contained within a cone having an apex angle of 300 or less, regardless of the original impact angle. 
2) In the teats where the ricochet witness plates were sufficiently thick, the reverse sides of the plates remained smooth and undamaged even though the front sides exhibited significant crater damage. In these cases, the post-impact appearance of the ricochet witness plate was identical to that of a "thick plate" subjected to the same debris particle impact loading.

Based on these observations, the use of thick plate equations for penetration depth and crater diameter due to normal hypervelocity impact is justified provided that the reverse side of the ricochet witness plate in which the crater dopths are measured is smooth and undamaged (i.e., no spall or dimpling).

Examination of existing penetration depth equations revealed a strong coupling between particle size and velocity effects. That is, the same size crater can be produced by a small particle traveling at a high speed or by a larger particle traveling at a slower speed. Therefore, in order to have a unique solution for particle size and speed, a second set of equations describing another measurable crater quantity was needed. A search of existing literature on cratering phenomena in hypervelocity impact suggested crater volume to be such a quantity. Thus, a crater volume equation used in conjunction with an equation for penetration depth could be used to solve uniquely for particle size and speod. Since it is more facile to measure the surface diameter of an impact crater than it is to determine its exact volume, the crater volume equations were rewritten in terms of surface diameter. The analysis then proceeded as follows.

First, penetration depths and surface diameters of the three largest craters on ricochet witness plates with undamaged rear surfaces were measured (plates with through-holes or only splash damage were not considered). Second, crater volumes were calculated for each measured crater. The crater with the largest volume, deemed the most damage as a result, was identified and 
retained for future analysis. By considering only the most damaging crater, the diameters and velocities subsequently calculated would represent upper bounds on ricochet debris sizes and speeds. Measured crater depths and diameters, as well as calculated crater volumes, for each of the 139 ricochet witness plates considered herein are presented in Appendix C.

In the last phase of the analysis, equations for penetration depth and crater diameter were solved for particle diameter and velocity in terms of all other parameters, such as density, yield strength, wave speed, and so forth. Substitution of the appropriate parameter values in these equations yielded an estimate for the size and speed of the particle that produced a particular crater. This procedure was applied to the most damaging crater dimensions as identified previously. The penetration depth and crater mouth diameter equations are listed in Appendix D, some rewritten for consistency. The material property values used in these equations is presented in Table 5.1 below.

Table 5.1 Material Property Values

\begin{tabular}{|c|c|c|c|}
\hline Symbol & Property & Value & Units \\
\hline $\mathrm{C}_{\mathrm{b}}$ & Bumper Speed of Sound & 5.04 & $\mathrm{~km} / \mathrm{s}$ \\
\hline$\rho_{p}$ & Projectile Density & 2.718 & $\mathrm{gm} / \mathrm{cm}^{3}$ \\
\hline$\rho_{b}$ & Bumper Density & 2.718 & $\mathrm{gm} / \mathrm{cm}^{3}$ \\
\hline $\mathbf{H}_{b}$ & Brinell Hardness Number & 130 & $\mathrm{~kg} / \mathrm{mm}^{2}$ \\
\hline $\mathbf{S}_{\mathbf{b}}$ & Bumper Dynamic Hardness & $6.37 \mathrm{E}+10$ & dynes $/ \mathrm{cm}^{2}$ \\
\hline $\mathbf{S}$ & Bumper Shear Strength & 2.83E+09 & dynes/cm ${ }^{2}$ \\
\hline$S_{x b}$ & Bumper Dynamic Yield Strength' & $1.85 E+10$ & dynes/cm $\mathrm{cm}^{2}$ \\
\hline$Y_{b}$ & Bumper Dynamic Shear Strength & $2.78 E+09$ & dynes/cm ${ }^{2}$ \\
\hline $\mathbf{B}_{b}$ & Bumper Hardness & $1.27 \mathrm{E}+10$ & dynes $/ \mathrm{cm}^{2}$ \\
\hline $\mathbf{E}_{\mathrm{b}}$ & Bumper Elastic Modulus & 73.8 & GPa \\
\hline
\end{tabular}

Since there are 12 penetration depth equations and 6 crater diameter equations, this method should have resulted in 72 estimates for the diameter and 72 estimates for the velocity of each crater-producing projectile. However, equations (D.11) and (D.12) were not used in 
subsequent analyses because the upper limit of the velocity regime for which they are valid is much lower than that of the other penetration depth equations. Additionally, in the process of pairing the penetration depth and crater diameter equations, it became evident that not all equation pairs were compatible. Because of the exponential form of the equations, certain combinations of equations led to powers of zero for an unknown diameter or velocity. These particular equation pairs, therefore, could not be used to solve for the unknown quantities. This situation is analogous to finding the intersection of two parallel lines in Euclidean geometry. Specifically, penetration depth equations with a $\mathrm{V}^{2 / 3}$ term could not be paired with crater diameter equations having a $\mathrm{V}^{2}$ term. Thus, in order to obtain unique solutions for particle velocity and diameter, depth equations with a $\mathrm{V}^{2 / 3}$ term could only have been paired against diameter equations without a $V^{2}$ term, while depth equations without a $V^{2 / 3}$ term were paired against diameter equations with a $V^{2}$ term.

Furthermore, even though an equation pair did produce a solution, the resultant particle size occasionally exceeded that of the crater diameter, sometimes by a factor of three or four. However, it was previously shown that the heated material surrounding a high-speed impact crater relaxes as it cools after the impact event, which can cause a reduction in crater diameter and depth of approximately 20-25\%. Therefore, while it is possible that a crater could have been produced by a particle whose diameter exceeded the size of the crater opening, it is unlikely that the diameter of the particle could have exceeded the surface diameter of the crater it produced by more than $25 \%$. As a result, a particle diameter value greater than 1.25 times a corresponding measured crater surface diameter was rejected.

Figures 5.1 and 5.2 show plots of equations (D.1-D.10), the penetration depth equations, and (D.13-D.18), the crater mouth diameter equations, as a function of impact velocity for the 
material parameter values given in Table 5.1. Examination of these plots reveals several interesting characteristics of the crater depth and diameter equations.

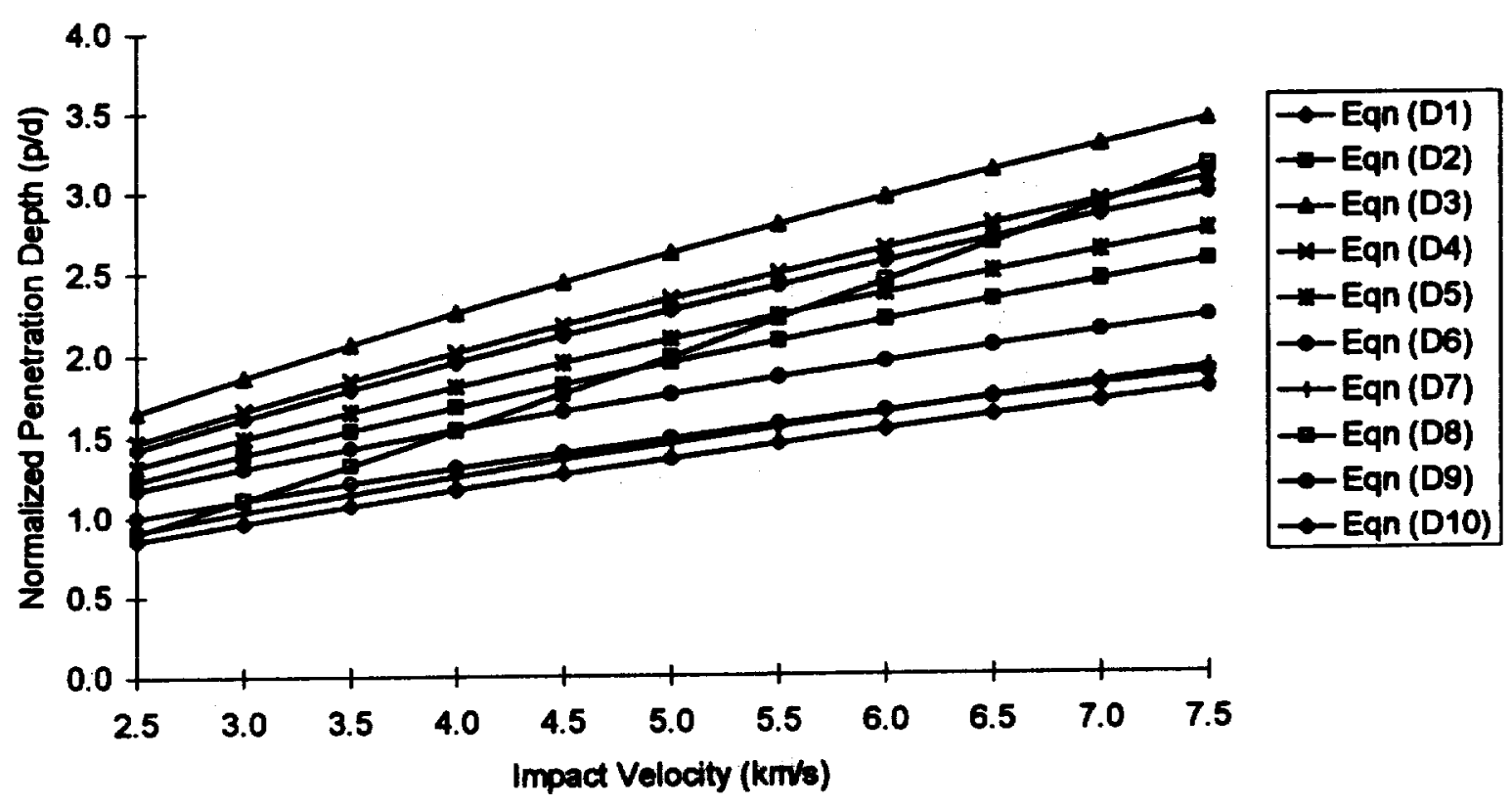

Figure 5.1 Penetration Depth Equations (D.1-D10)

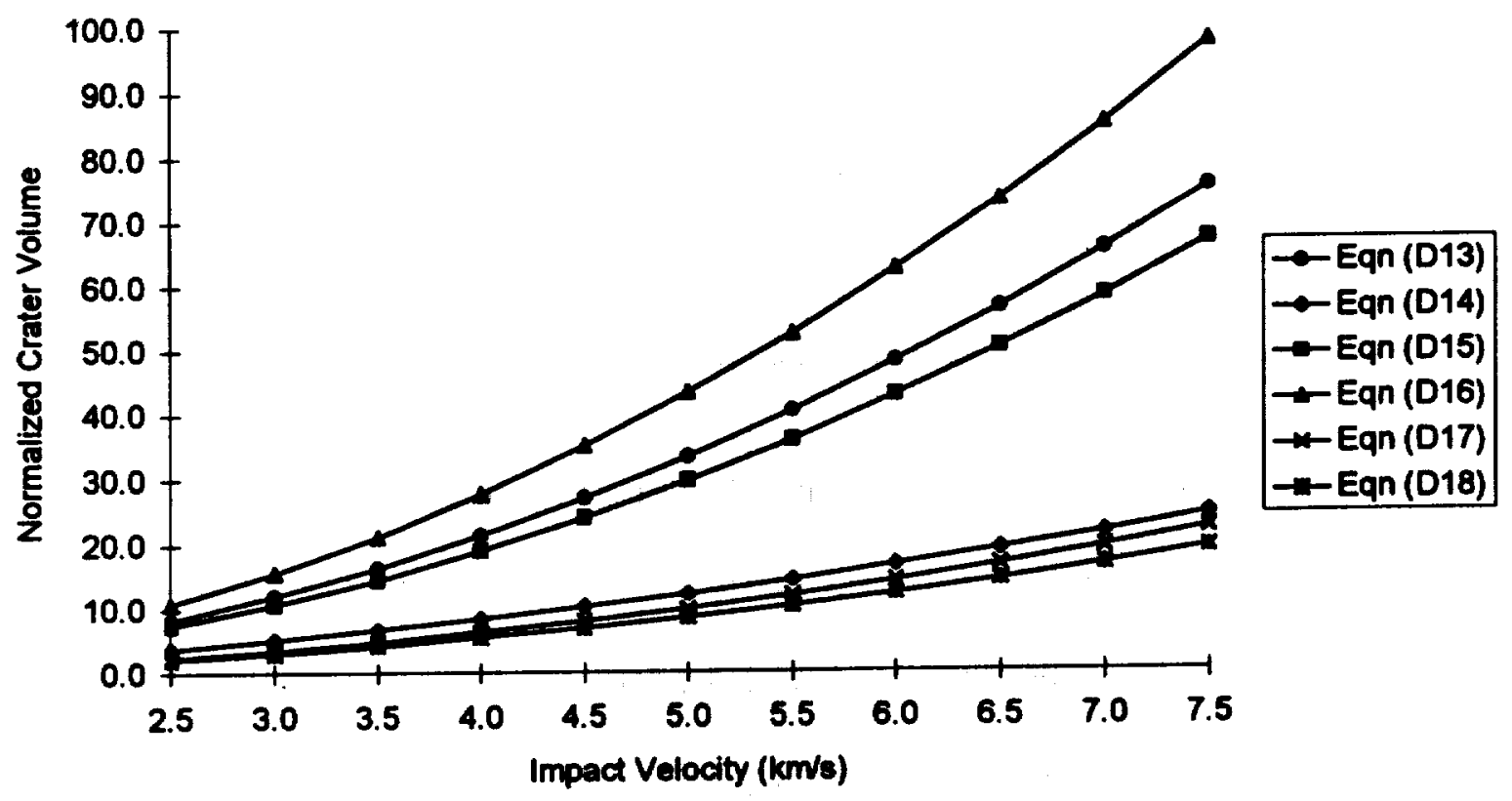

Figure 5.2 Crater Diameter Equations (D.13-D18) 
1) With the exception of equation (D.8), all the penetration depth equations are fairly consistent in their prediction trends. The actually values, however, can vary significantly. Because of a lack of corroborative information for the trends and values predicted by equation (D.8), it was not considered in any of the subsequent analyses.

2) The crater equations appear to fall into two fairly distinct groups with regard to both predictive trends as well as predicted values. Within each group, however, the predicted values are fairly consistent.

Based on these observations and the comments made previously regarding the pairing requirements of the depth and diameter equations, the following depth and diameter equation combinations were used to calculate candidate ricochet perticle velocity-diameter values:

Table 5.2 Penetration Depth-Crater Dimeter Equation Pairs

\begin{tabular}{|c|c|c|c|}
\hline $\begin{array}{l}\text { Penctration Depth } \\
\text { Equation No. }\end{array}$ & $\begin{array}{l}\text { Velocity } \\
\text { Term }\end{array}$ & $\begin{array}{l}\text { Crater Dilimoter } \\
\text { Equation No. }\end{array}$ & $\begin{array}{l}\text { Velocity } \\
\text { Term }\end{array}$ \\
\hline$\overline{D .1}$ & $V^{35}$ & D.14 & $\mathrm{V}^{1.65}$ \\
\hline D.2 & $V^{23}$ & D.14 & $V^{1.65}$ \\
\hline D.3 & $v^{235}$ & D.14 & $V^{1.69}$ \\
\hline D.4 & $V^{23}$ & D.14 & $V^{1,69}$ \\
\hline D.5 & $V^{23}$ & D.14 & $V^{1.69}$ \\
\hline D.7 & $v^{2 / 3}$ & D.14 & $\mathrm{V}^{1.69}$ \\
\hline D.10 & $V^{23}$ & D.14 & $\mathrm{V}^{1.69}$ \\
\hline D.6 & $V^{0.376}$ & D.13 & $V^{2 / 3}$ \\
\hline D.9 & $v^{0.3 \%}$ & D.13 & $V^{2 / 3}$ \\
\hline
\end{tabular}

These considerations reduced the number of calculated ricochet particle velocity and diameter value pairs for each most damaging crater from 72 to 9 or less. The resulting calculated particle diameters and velocities corresponding to the depths and diameters of the most damaging craters (taken from Appendix D) are given in Appondix E. In Appendix E, 'Vx-y' and 'dx-y' refer to the a particle velocity or diameter, respectively, calculated using a combination of crater depth 
equation (D.x) and crater mouth diameter (D.y) from Appendix D. Grayed-out areas are calculated particle velocity-diameter combinations that are not valid, most likely because the calculated ricochet particle diameter exceeded the crater mouth diameter (indicated by a value of ' $\mathrm{dx}-\mathrm{y} / \mathrm{d}$ ' that is greater than one.

For each test, valid particle velocity-diameter were reviewed to determine two max-min combinations for subsequent regression analyses: $V_{\max }$ and the corresponding $d_{\min }$, and $V_{\min }$ and the corresponding $d_{\max }$. In this manner, upper and lower bounds on velocity and size can be formed for the most damaging ricochet debris particle to be created in a given impact scenario. These max-min values are provided in Appendix F.

Four empirical predictor equations for were developed using the data in Appendix F.

These equations can be used to calculate $\mathrm{V}_{\max }, \mathrm{d}_{\min }, \mathrm{V}_{\min }$, and $\mathrm{d}_{\max }$ in terms of bumper thickness and impact parameters, and were all in the following form:

$$
\begin{aligned}
& \frac{V_{i}}{V_{p}}=A\left(\frac{V_{p}}{C_{b}}\right)^{B}\left(\frac{t_{b}}{d_{p}}\right)^{C} \cos ^{D} \theta_{p}+E, i=\max , \min \\
& \frac{d_{i}}{d_{p}}=A\left(\frac{V_{p}}{C_{b}}\right)^{B}\left(\frac{t_{b}}{d_{p}}\right)^{C} \cos ^{D} \theta_{p}+E \quad, i=\max , \min
\end{aligned}
$$

Table 5.3 below presents the values of the regression coefficients A-E and the correlation coefficients for equations $(5.1 \mathrm{a}, \mathrm{b})$ and $(5.2 \mathrm{a}, \mathrm{b})$.

Table 5.3 Parameter Values and Correlation Coefficients for Equations (5.1) and (5.2)

\begin{tabular}{|c|c|c|c|c|c|c|c|}
\hline Equation & Quantity & $\mathbf{A}$ & $\mathbf{B}$ & $\mathbf{C}$ & $\mathbf{D}$ & $\mathbf{E}$ & $\begin{array}{c}\text { Correlation } \\
\text { Coefficient }\left(\mathbf{R}^{2}\right)\end{array}$ \\
\hline $\mathbf{5 . 1 a}$ & $\mathrm{V}_{\max }$ & 0.4294 & -1.8335 & -0.2799 & -0.2562 & 0.3384 & 0.417 \\
\hline $\mathbf{5 . 1 b}$ & $\mathrm{d}_{\min }$ & -0.6799 & -0.08769 & 0.01119 & 1.0558 & 0.5998 & 0.712 \\
\hline $\mathbf{5 . 2 \mathrm { a }}$ & $\mathrm{V}_{\min }$ & 0.3339 & -1.2209 & -0.1002 & -0.1588 & 0.2206 & 0.254 \\
\hline $\mathbf{5 . 2 b}$ & $\mathrm{d}_{\max }$ & 0.5732 & -0.02872 & -0.04935 & -0.4569 & -0.4978 & 0.747 \\
\hline
\end{tabular}


As can be seen from Table S.1, the equations for $d_{\text {max }}$ and $d_{\text {min }}$ have reasonable $R^{2}$ values while those for $d_{\text {max }}$ and $d_{\text {min }}$ are somewhat low. This indicates that there is a fair degree of scatter in the calculated ricochet particle velocity values, while the level of consistency in the calculated diameter values is fairly high. It is not clear at this time why this has occurred, especially since both velocity and diameter quantities were calculated simultaneously using the same data and the same equations.

Equation $(5.1 \mathrm{a}, \mathrm{b})$ and $(5.2 \mathrm{a}, \mathrm{b}) \mathrm{can}$ be used to obtain a bound on the velocity and diameter of the moat damaing ricochet debris particle that would be created in a given oblique hypervelocity impact event. However, these equations must be paired appropriately: $V_{\text {max }}$ must be paired with dim while $V_{m}$ must be paired with dma. This will provide, for example, upper and lower limits of expected ricochet particle velocity and the particle diameters corresponding to those velocities.

Figures 5.3 through 5.6 below show plots of equations $(5.1 a, b)$ and $(5.2 a, b)$ for an initial projectile diameter of $0.795 \mathrm{~cm}, 0.127$ bumper thickness, for impact velocities ranging between 3 and $8 \mathrm{~km} / \mathrm{s}$, and for initial trajectory obliquities of $30^{\circ}, 45^{\circ}, 60^{\circ}$, and $75^{\circ}$. In these plots, the open tick marks represent values calculated using equations (51a,b) and $(52 a, b)$, while the solid tick marks represent simple numerical averages of corresponding calculated values.

Table 5.4 below presents a comparison between the average ricochet debris particle diameters and velocities presented in Reference [2] and the average particle velocities and diameters calculated using equations $(5.1 \mathrm{a}, \mathrm{b})$ and $(5.2 \mathrm{a}, \mathrm{b})$ under the same impact conditions. As can be seen from this table, the average diameter values predicted by the equations developed in this study compare favorably with those obtained previously. However, the average velocity values calculated using equations $(5.1 \mathrm{a}, \mathrm{b})$ and $(5.2 \mathrm{a}, \mathrm{b})$ are approximately twice the values 
reported previously. These differences and similarities serve to 1) reinforce the need to explore further the particle velocities obtained using the technique developed in this study, and 2) increase the confidence in the particle diameter values obtained using this technique.

Table 5.4 Comparison of Average Ricochet Particle Diameters and Velocities

\begin{tabular}{|c|c|c|c|c|}
\hline & \multicolumn{2}{|c|}{ d.m $(\mathrm{cm})$} & \multicolumn{2}{|c|}{$V_{w e}(\mathrm{~km} / \mathrm{s})$} \\
\hline$\overline{\theta_{1}(\operatorname{deg})}$ & Reference [2] & This Stady & Reference [2] & This Study \\
\hline 45 & 0.174 & 0.121 & 2.07 & 4.25 \\
\hline 60 & 0.221 & 0.204 & 2.01 & 4.42 \\
\hline 75 & 0.357 & 0.348 & 2.35 & 4.78 \\
\hline & \multicolumn{2}{|c|}{$d_{n v}(\mathrm{~cm})$} & \multicolumn{2}{|c|}{$V_{m e}(\mathrm{~km} / \mathrm{s})$} \\
\hline$d_{p}(\mathrm{~cm})$ & Reference [2] & This Study & Reference [2] & This Study \\
\hline 0.475 & 0.203 & 0.164 & 2.17 & 4.35 \\
\hline 0.635 & 0.258 & 0.224 & 2.15 & 4.49 \\
\hline 0.795 & 0.303 & 0.285 & 2.08 & 4.61 \\
\hline
\end{tabular}

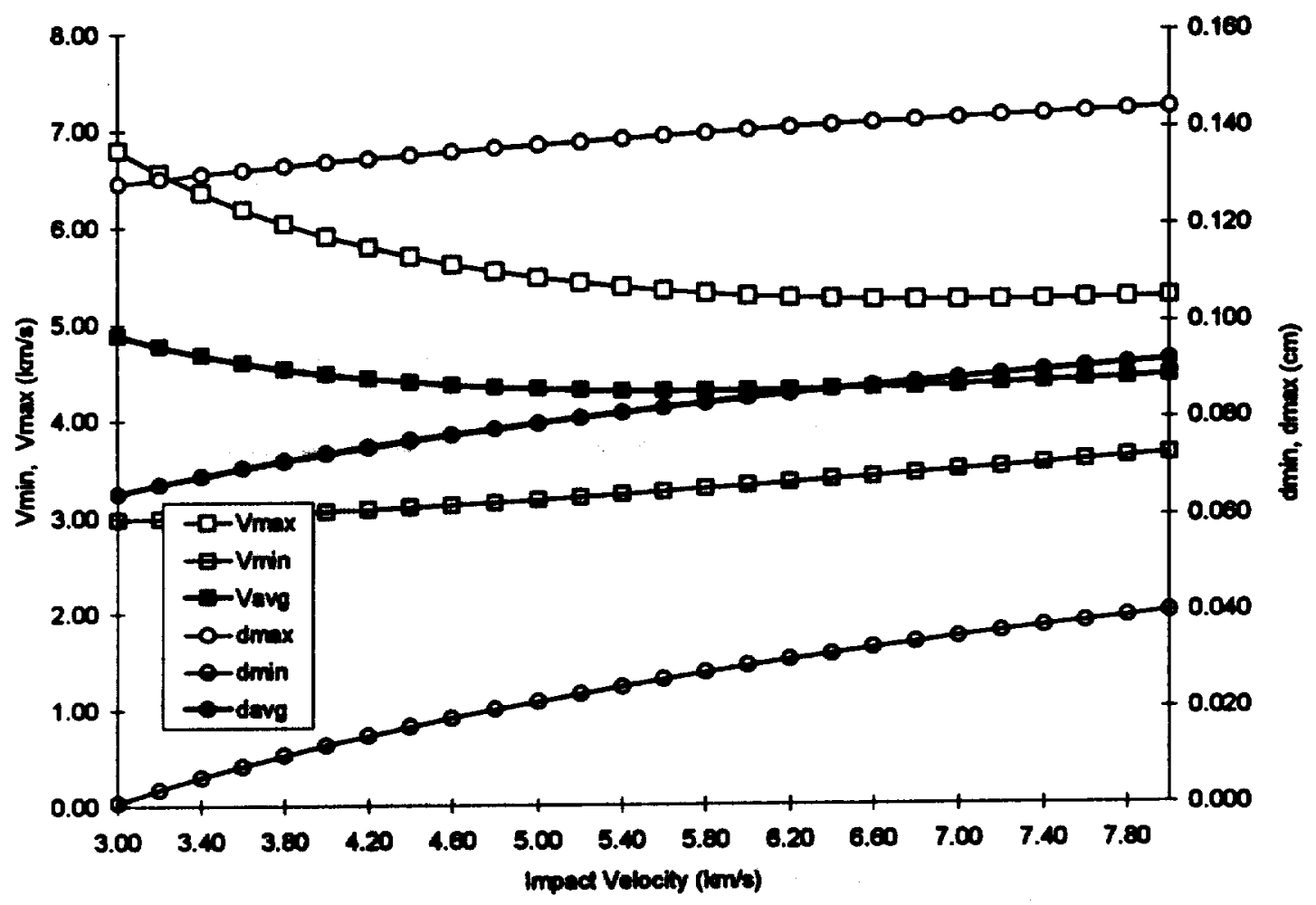

Figure $5.3 \mathrm{~V}_{\min }, \mathrm{V}_{\max }$ and $\mathrm{d}_{\min }, \mathrm{d}_{\max }$ for a $30^{\circ}$ Impact 


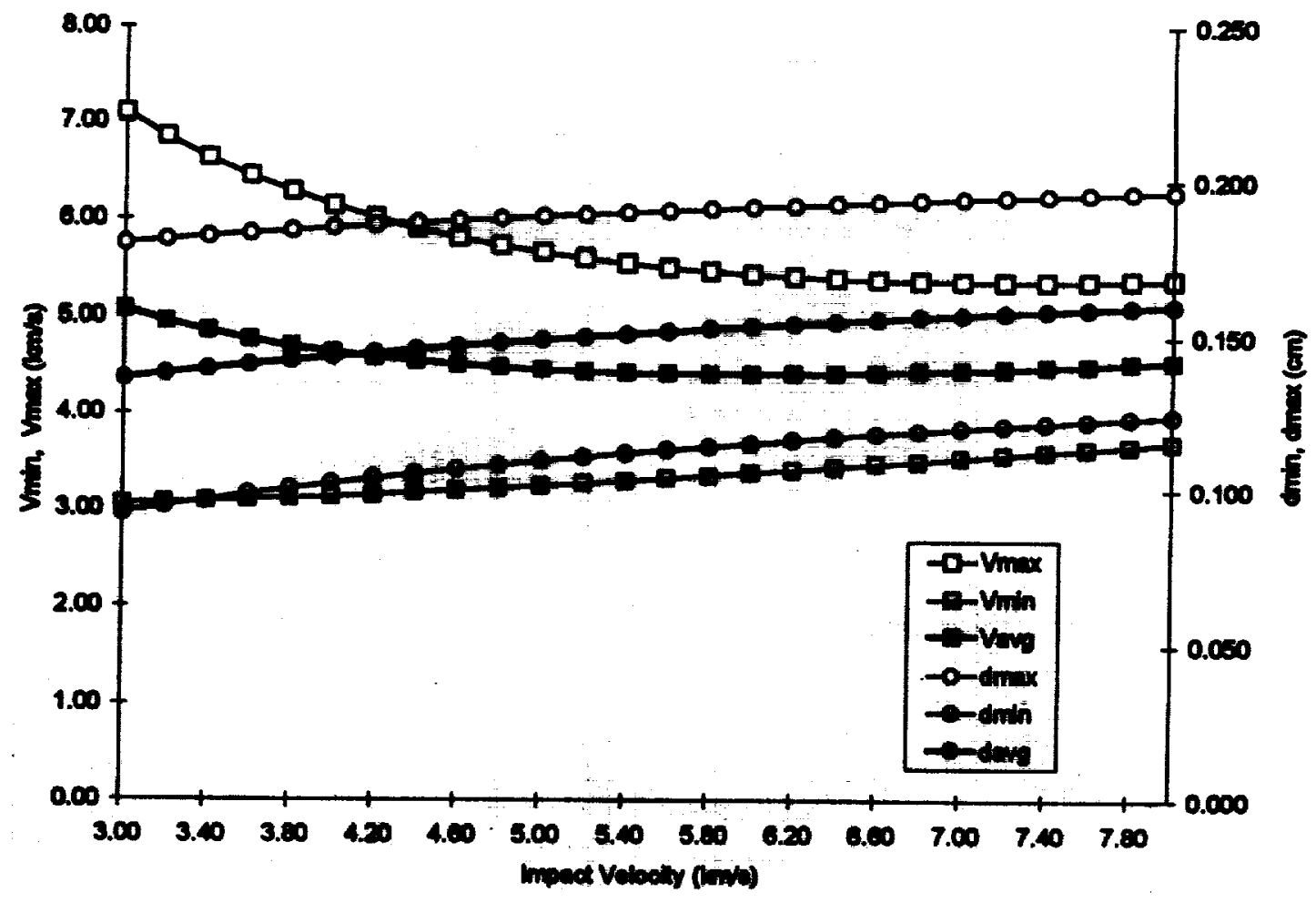

Figure 5.4 $V_{\text {man }} V_{\max }$ and $d_{\text {man }} d_{\max }$ for $245^{\circ}$ Impact

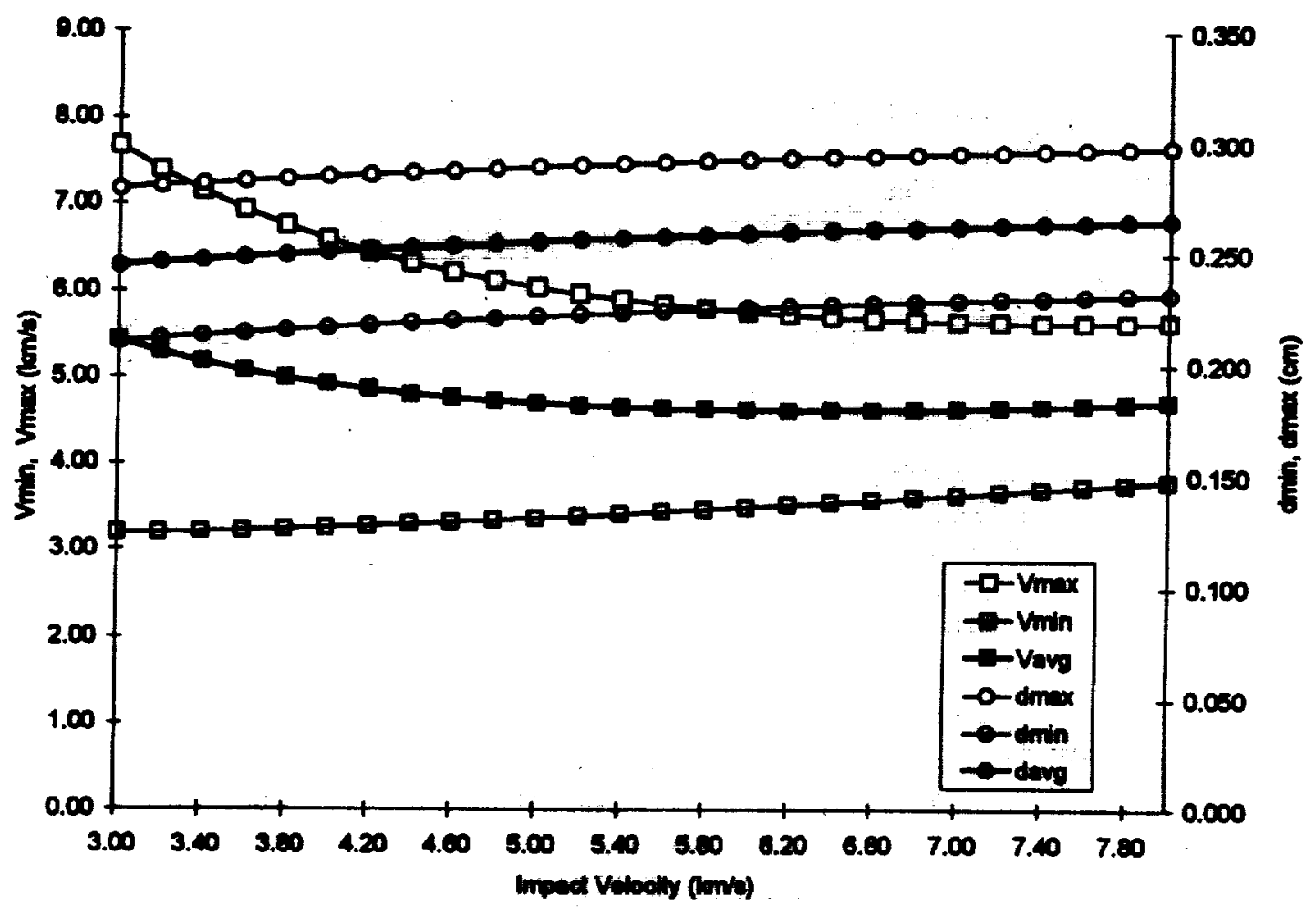

Figure $5.5 V_{\min } V_{\max }$ and $d_{\text {mim }} d_{\text {max }}$ for $260^{\circ}$ Impact 


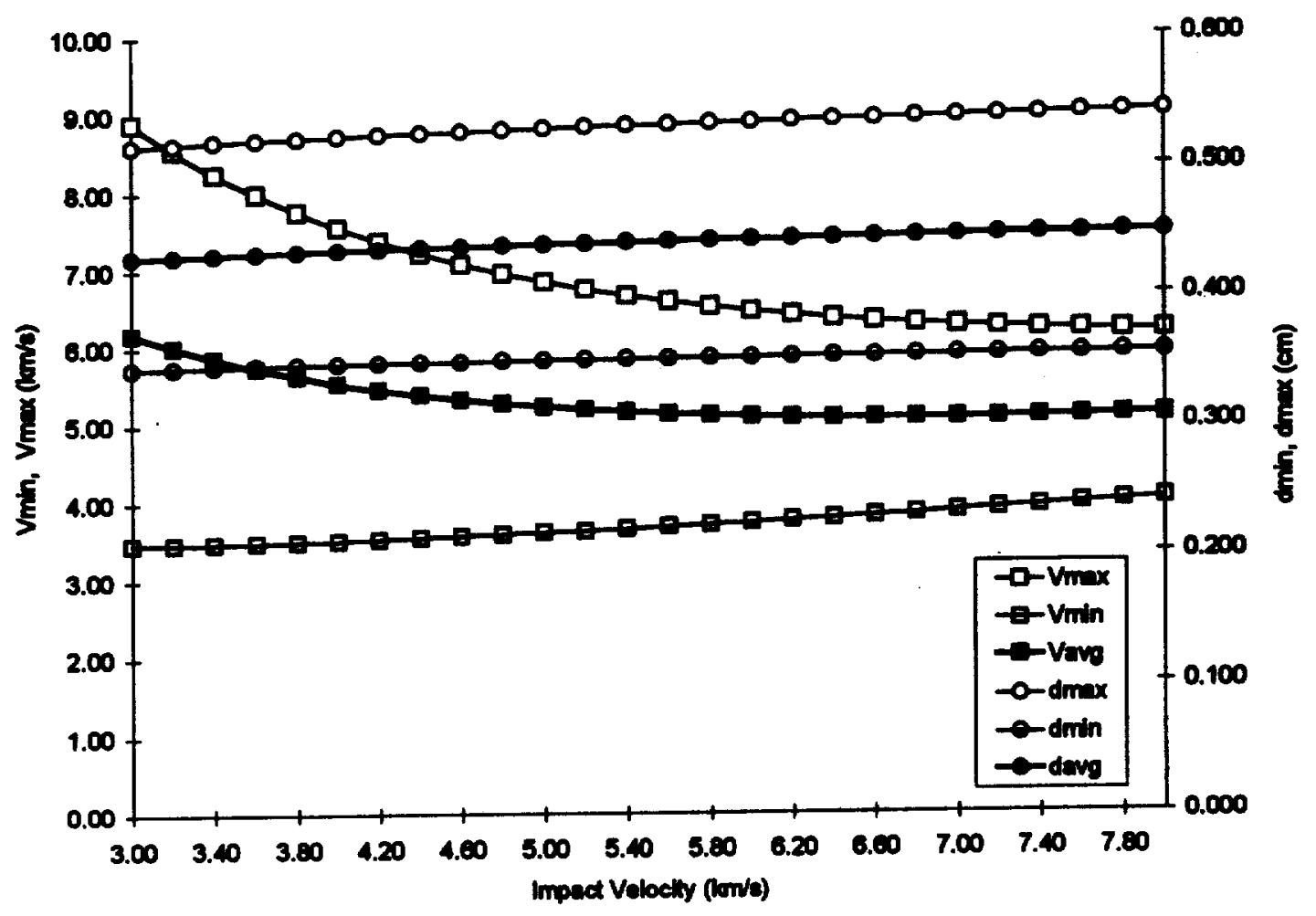

Figure $5.6 \mathrm{~V}_{\min }, V_{\max }$ and $d_{\min }, d_{\max }$ for $a 75^{\circ}$ Impact 


\subsection{SUMMARY AND RTCOMMENDATIONS}

\subsection{Summary}

An empirical model that that characterizes the secondary jecta created by a high speed impact on a typical aerospece structural surface has been succesefully developed. This model developed provides the following information as a function of impact parameters (speed, angle, projectile diameter) and target plate geometry (e.g. thickness, etc):

- angles dofining the spread of ricochet debris and the trajectory of the ricochet debris cloud center-of-mass;

- average velocity of the ricochet debris cloud material; and,

- velocity and mass of the largest particle(s) in the ricochet debris cloud.

The angles defining the spread of the ricochet debris cloud and the trajectory of the debris cloud center-of-mass were obtained using the spatial distributions of ricochet debris particle impacts on ricochet witness plates from over 200 high speed impact tests. The average velocity of the ricochet debris cloud is obtained using a model that characterizes the masses, trajectories, and velocities of the debris clouds created in an oblique high-speed impact. This model employs the three conservation principles, elementary shock physics theory, and fundamental thermodynamic principles to obtain a system of algebraic equations for the various debris cloud masses, trajectories, and velocities. Finally, relationships for crater diameter and depth are applied to the deepest craters in each ricochet witness plate to "back out" the diameters, masses, and velocities of the ricochet debris cloud particles that created these craters. This information is then used to develop empirical relationships that predict the velocity and mass of the largest ricochet debris cloud particle in terms of impact parameters and bumper plate thickness. 


\subsection{Recommendations}

Based on the work performed, the following recommendations are made for continued activities in this area.

\subsubsection{Ricochet Debris Cloud Spread Angle Modelling}

1) The discrepancy between empirical observations and SPH predictions of ricochet debris cloud spread should be explored and reconciled. It is suggested that an alternative means of defining ricochet debris cloud spread needs to be developed, one that will allow the successful use of empirical as well as numerical data.

2) Thus far, ricochet debris cloud spread angle modelling efforts have focussed on characterizing the spread of the debris cloud particles "in the plane of the impact trajectory". Future efforts should focus on the spread of the debris cloud out of this plane.

\subsubsection{Ricochet Debris Cloud Velocity Modelling}

Efforts should continue to reduce the dependence of the model on empirical or usercontrolled parameters. A preliminary effort involving oblique shock wave theory was successfully completed by the author [8]; however, the modelling effort was at a level of complexity that is inconsistent with that employed in the model presented in this report. Some aspects of oblique shock wave theory should, however, be explored and considered for implementation in the debris cloud model presented herein.

\subsubsection{Ricochet Debris Cloud Particle Diameter and Velocity Modelling}

The reasons for the differences between the values of the correlation coefficients for the empirical diameter and velocity equations should be explored and reconciled, including the consideration of an alternative equation form should be considered for the ricochet debris cloud particle velocity. 


\subsection{Ranhavess}

1. W.P. Schonberg and F. Yang, "Response of Spacecraft Structures to Orbital Debris Particle Impect," International Journal of Impact Engtmering, Vol. 14, 1993, pp. 647-658.

2. W.P. Schonberg and R.A.Taylor, "Exterior Spececrut Subgystem Protective Shielding Analysis and Devign," Jowimal of Spacecraft and Rockits, Vol. 27, 1990, pp. 267-274.

3. G. T. Burch, Multi-plate Damage Study, AFATL-TR-67-116, Eglin Air Force Base, Florida, 1967.

4. W.P. Schonberg and R.A Taylor, "Penetration and Ricochet Phenomena in Oblique Hypervelocity Impact," AIAA Journal, Vol. 27, No. 5, 1989, pp. 639-646.

5. W. P. Schonberg, A. J. Bean and K. Darzi, Hypervelocity Impact Physics, NASA CR-4343, Washington, D.C., 1991.

6. M.H. Rice, R.G. McQueen, and J.M. Walch "Compression of Solids by Strong Shock Waves," Solid Stnte Phycics, Volume V], (ed. F. Seitz and D. Turnbull), Academic Press, New York, 1958.

7. C.A. Anderson, T.G. Trucano, and S.A. Mullin, "Debris Cloud Dynamics," International Joumal of Impact Engineering, Vol. 9, No. 1, 1990, pp. 89-113.

8. Schonberg, W.P. and Ebrahim, A.R., Modelling Oblique Hypervelocity Impact Phenomena Using Elementary Shock Physics," International Jowrnal of Impact Engineering, to appear, 1999.

9. Sawle, D.R., "Hypervelocity Impact in Thin Sheets and Semi-Infinite Targets at $15 \mathrm{~km} / \mathrm{sec}$," AIAA Journal, Vol.8, No.7, 1970, pp. 1240-1244.

10. Bruce, E.P., "Review and Analysis of High Velocity Impact Data, "Proceedinos of the Fifth Hypervelocity Impact Symposium. 1962, pp. 439-474.

11. Schneider, E., "Velocity Dependence of Some Impuct Phenomena," Proceedings of the Comet Halley Micrometeoroid Hazard Workshop, ESA SP-1 53, ESA Scientific and Technical Publications Branch, The Netherlands, 1979, pp. 101 - 107.

12. Goodman, E.H., and Liles, C.D., "Particle-Solid Impact Phenomena," Proceedings of the Sixth Hypervelocity Impact Symposium, 1963, pp. 543-577

13. Dunn, W P., "On Material Strengths of the Hypervelocity Impact Problem," AJAA Journal, Vol.4, No.3, 1966, pp. 535-536. 
14. Sedgwick, R.T., Hageman, L.J., Herrmann, R.G., and Waddell, J.L., "Numerical Investigations in Penetration Mechanics," International Journal of Engineering Sciences, Vol.16, 1978, pp. 859-869.

15. Christman, D.R., "Target Strength and Hypervelocity Impact," AIAA Journal, Vol.4, No. 10, 1966, pp. 1872-1874.

16. Summers, J.L., and Charters, A.C., "High-Speed Impact of Metal Projectiles in Targets of Various Materials" Proceedings of the Third Hypervelocity Impact Symposium, 1959, pp. 101-113.

17. Sorenson, N.R., "Systematic Investigation of Crater Formation in Metals," Proceedings of the Seventh Hypervelocity Impact Symposium, 1962, Vol. 6, pp. 281-325.

18. Herrmann, W., and Jones, A.H., "Correlation of Hypervelocity Impact Data," Proceedings of the Fifth Hypervelocity Impact Symposium, 1962, pp. 389-438.

19. Cour-Palais, B.G., "Hypervelocity Impact Investigations and Meteoroid Shielding Experience Related to Apollo and Skylab," Orbital Debris, NASA CP-2360, 1982, pp. 247-275.

20. Summers, J.L., Investigation of High Speed Impact: Regions of impact and Impact at Oblique Angles, NASA TN D-94, 1959. 
APPENDIX A

\section{EMPIRICAL TEST PARAMETERS AND RESULTS}


Table A-1 Empirical Test Parameters and Results, Phase B NASAMMFC Test Series

\begin{tabular}{|c|c|c|c|r|r|r|}
\hline $\begin{array}{c}\text { Test } \\
\text { No. }\end{array}$ & $\begin{array}{c}\mathbf{t}_{\mathbf{b}} \\
(\mathbf{c m})\end{array}$ & $\begin{array}{c}\mathbf{d}_{\mathbf{p}} \\
(\mathbf{c m})\end{array}$ & $\begin{array}{c}\mathbf{V}_{\mathbf{p}} \\
(\mathbf{c m})\end{array}$ & $\begin{array}{c}\theta_{\mathbf{p}} \\
(\mathbf{c m})\end{array}$ & $\begin{array}{c}\theta_{\mathbf{r}} \\
(\mathbf{c m})\end{array}$ & $\begin{array}{c}\theta_{\mathbf{s}} \\
(\mathbf{c m})\end{array}$ \\
\hline $001 \mathrm{~A}$ & 0.203 & 0.795 & 6.62 & 45 & 11.3 & 26.3 \\
\hline $001 \mathrm{~B}$ & 0.203 & 0.795 & 6.53 & 45 & 12.6 & 26.9 \\
\hline $002 \mathrm{~A}$ & 0.160 & 0.795 & 6.50 & 45 & 9.5 & 23.0 \\
\hline $002 \mathrm{~B}$ & 0.160 & 0.795 & 6.45 & 45 & 12.1 & 26.0 \\
\hline $003 \mathrm{~A}$ & 0.102 & 0.795 & 6.54 & 45 & 6.0 & 20.9 \\
\hline $004 \mathrm{~A}$ & 0.203 & 0.795 & 6.28 & 65 & 7.6 & 25.3 \\
\hline $136 \mathrm{~A}$ & 0.160 & 0.635 & 6.25 & 55 & 8.6 & 25.1 \\
\hline $136 \mathrm{~B}$ & 0.160 & 0.635 & 7.24 & 55 & 10.8 & 29.2 \\
\hline $136 \mathrm{C}$ & 0.160 & 0.635 & 6.67 & 55 & 13.0 & 28.8 \\
\hline $137 \mathrm{D}$ & 0.081 & 0.635 & 7.03 & 45 & 9.6 & 24.7 \\
\hline $150 \mathrm{~A}$ & 0.160 & 0.635 & 7.00 & 45 & 11.4 & 24.2 \\
\hline $151 \mathrm{~A}$ & 0.203 & 0.635 & 6.88 & 45 & 13.5 & 21.5 \\
\hline $154 \mathrm{~A}$ & 0.102 & 0.475 & 6.83 & 45 & 11.1 & 19.2 \\
\hline $155 \mathrm{~A}$ & 0.160 & 0.475 & 7.02 & 45 & 12.6 & 18.1 \\
\hline $156 \mathrm{~A}$ & 0.160 & 0.475 & 7.10 & 65 & 6.8 & 16.9 \\
\hline $156 \mathrm{~B}$ & 0.160 & 0.475 & 5.95 & 65 & 7.7 & 19.2 \\
\hline $156 \mathrm{C}$ & 0.160 & 0.475 & 4.15 & 65 & 7.1 & 16.5 \\
\hline $157 \mathrm{~A}$ & 0.160 & 0.475 & 7.40 & 60 & 10.0 & 22.3 \\
\hline $162 \mathrm{~A}$ & 0.160 & 0.475 & 6.53 & 30 & 16.7 & 31.0 \\
\hline $168 \mathrm{~A}$ & 0.081 & 0.635 & 5.54 & 45 & 8.8 & 19.3 \\
\hline $168 \mathrm{~B}$ & 0.081 & 0.635 & 5.98 & 45 & 10.8 & 25.1 \\
\hline $168 \mathrm{C}$ & 0.081 & 0.635 & 6.67 & 45 & 19.4 & 29.9 \\
\hline $168 \mathrm{D}$ & 0.081 & 0.635 & 7.02 & 45 & 21.7 & 30.8 \\
\hline $169 \mathrm{~B}$ & 0.081 & 0.635 & 6.55 & 45 & 10.8 & 25.1 \\
\hline $201 \mathrm{~A}$ & 0.102 & 0.635 & 4.33 & 45 & 10.4 & 23.3 \\
\hline $201 \mathrm{~B}$ & 0.102 & 0.635 & 5.51 & 45 & 8.8 & 23.1 \\
\hline $201 \mathrm{D}$ & 0.102 & 0.635 & 7.59 & 45 & 14.3 & 22.8 \\
\hline $202 \mathrm{C}$ & 0.102 & 0.475 & 5.25 & 45 & 10.8 & 23.3 \\
\hline $202 \mathrm{D}$ & 0.102 & 0.475 & 6.44 & 45 & 6.2 & 14.6 \\
\hline $202 \mathrm{E}$ & 0.102 & 0.475 & 7.19 & 45 & 6.3 & 16.0 \\
\hline $203 \mathrm{~A}$ & 0.102 & 0.762 & 4.79 & 65 & 7.0 & 21.6 \\
\hline $203 \mathrm{~B}$ & 0.102 & 0.762 & 3.65 & 65 & 7.2 & 19.8 \\
\hline $203 \mathrm{C}$ & 0.102 & 0.762 & 2.72 & 65 & 6.8 & 21.0 \\
\hline $203 \mathrm{D}$ & 0.102 & 0.762 & 5.59 & 65 & 6.4 & 22.2 \\
\hline $203 \mathrm{E}$ & 0.102 & 0.762 & 6.72 & 65 & 8.1 & 23.5 \\
\hline $203 \mathrm{~F}$ & 0.102 & 0.889 & 3.05 & 65 & 8.5 & 26.0 \\
\hline $203 \mathrm{G}$ & 0.102 & 0.889 & 4.64 & 65 & 8.1 & 25.5 \\
\hline $204 \mathrm{~A}$ & 0.102 & 0.635 & 4.77 & 65 & 8.5 & 24.2 \\
\hline $204 \mathrm{~B}$ & 0.102 & 0.635 & 5.86 & 65 & 7.9 & 24.0 \\
\hline $204 \mathrm{C}$ & 0.102 & 0.635 & 4.25 & 65 & 9.0 & 28.2 \\
\hline & & & & & & \\
\hline
\end{tabular}




\begin{tabular}{|l|l|l|l|r|r|r|}
\hline 204D & 0.102 & 0.635 & 3.18 & 65 & 5.3 & 18.4 \\
\hline $205 \mathrm{~A}$ & 0.160 & 0.635 & 4.16 & 45 & 7.9 & 22.6 \\
\hline $205 \mathrm{~B}$ & 0.160 & 0.635 & 4.61 & 45 & 7.5 & 22.8 \\
\hline $205 \mathrm{C}$ & 0.160 & 0.635 & 5.30 & 45 & 11.6 & 22.6 \\
\hline $205 \mathrm{D}$ & 0.160 & 0.635 & 6.30 & 45 & 13.3 & 24.5 \\
\hline $205 \mathrm{E}$ & 0.160 & 0.635 & 3.15 & 45 & 9.9 & 22.2 \\
\hline $206 \mathrm{E}$ & 0.160 & 0.475 & 3.24 & 45 & 10.9 & 21.9 \\
\hline $206 \mathrm{~F}$ & 0.160 & 0.475 & 6.15 & 45 & 9.1 & 26.6 \\
\hline $207 \mathrm{~A}$ & 0.160 & 0.762 & 5.74 & 65 & 6.8 & 20.5 \\
\hline $207 \mathrm{~B}$ & 0.160 & 0.762 & 6.25 & 65 & 6.2 & 23.4 \\
\hline $207 \mathrm{C}$ & 0.160 & 0.762 & 7.03 & 65 & 6.7 & 20.9 \\
\hline $208 \mathrm{C}$ & 0.160 & 0.635 & 3.32 & 65 & 7.8 & 19.5 \\
\hline $208 \mathrm{D}$ & 0.160 & 0.635 & 5.63 & 65 & 5.8 & 13.1 \\
\hline $208 \mathrm{E}$ & 0.160 & 0.635 & 6.47 & 65 & 7.0 & 22.8 \\
\hline $209 \mathrm{~A}$ & 0.160 & 0.635 & 4.29 & 65 & 5.8 & 21.4 \\
\hline $209 \mathrm{~B}$ & 0.160 & 0.635 & 6.35 & 65 & 6.5 & 24.4 \\
\hline $209 \mathrm{D}$ & 0.160 & 0.635 & 7.34 & 65 & 12.0 & 32.0 \\
\hline $210 \mathrm{~B}$ & 0.160 & 0.889 & 5.69 & 65 & 7.9 & 23.5 \\
\hline $210 \mathrm{D}$ & 0.160 & 0.889 & 6.93 & 65 & 12.0 & 25.7 \\
\hline $211 \mathrm{~B}$ & 0.160 & 0.19 & 5.87 & 45 & 12.6 & 29.4 \\
\hline $211 \mathrm{D}$ & 0.160 & 0.839 & 6.97 & 45 & 13.9 & 28.7 \\
\hline $212 \mathrm{~B}$ & 0.160 & 0.762 & 6.27 & 45 & 15.4 & 28.7 \\
\hline $216 \mathrm{~A}$ & 0.203 & 0.889 & 5.99 & 45 & 13.2 & 25.2 \\
\hline $216 \mathrm{~B}$ & 0.203 & 0.889 & 6.54 & 45 & 12.9 & 25.2 \\
\hline $216 \mathrm{C}$ & 0.203 & 0.795 & 6.91 & 45 & 11.0 & 26.0 \\
\hline $217 \mathrm{~A}$ & 0.102 & 0.795 & 6.59 & 45 & 4.6 & 9.1 \\
\hline $217 \mathrm{~B}$ & 0.102 & 0.795 & 7.10 & 45 & 4.6 & 9.1 \\
\hline $217 \mathrm{C}$ & 0.102 & 0.635 & 6.05 & 45 & 5.5 & 13.5 \\
\hline $217 \mathrm{D}$ & 0.102 & 0.635 & 6.47 & 45 & 6.2 & 16.4 \\
\hline $217 \mathrm{E}$ & 0.102 & 0.635 & 7.14 & 45 & 8.4 & 16.3 \\
\hline $218 \mathrm{~A}$ & 0.102 & 0.889 & 5.82 & 45 & 10.2 & 29.2 \\
\hline $218 \mathrm{~B}$ & 0.102 & 0.899 & 6.30 & 45 & 10.6 & 23.3 \\
\hline $218 \mathrm{C}$ & 0.102 & 0.889 & 6.82 & 45 & 7.6 & 23.7 \\
\hline $221 \mathrm{~A}$ & 0.102 & 0.475 & 6.42 & 45 & 3.5 & 8.0 \\
\hline $221 \mathrm{~B}$ & 0.102 & 0.475 & 5.93 & 45 & 9.7 & 24.2 \\
\hline $221 \mathrm{C}$ & 0.102 & 0.475 & 4.60 & 45 & 11.4 & 28.7 \\
\hline $221 \mathrm{D}$ & 0.102 & 0.475 & 4.08 & 45 & 10.9 & 22.3 \\
\hline $222 \mathrm{~A}$ & 0.102 & 0.318 & 5.60 & 45 & 7.6 & 19.7 \\
\hline $222 \mathrm{~B}$ & 0.102 & 0.318 & 5.03 & 45 & 12.8 & 25.7 \\
\hline $222 \mathrm{C}$ & 0.102 & 0.318 & 3.33 & 45 & 11.0 & 23.5 \\
\hline $226 \mathrm{~A}$ & 0.081 & 0.635 & 4.45 & 45 & 6.6 & 16.4 \\
\hline $226 \mathrm{~B}$ & 0.081 & 0.635 & 5.49 & 45 & 10.0 & 23.5 \\
\hline $226 \mathrm{C}$ & 0.081 & 0.635 & 6.73 & 55 & 15.0 & 23.3 \\
\hline $227 \mathrm{~A}$ & 0.081 & 0.635 & 5.58 & 45 & 8.3 & 26.0 \\
\hline & & & & & & \\
\hline
\end{tabular}




\begin{tabular}{|c|c|c|r|r|r|r|}
\hline 227B & 0.081 & 0.635 & 7.19 & 45 & 13.8 & 25.6 \\
\hline 230A & 0.160 & 0.475 & 4.41 & 45 & 18.8 & 23.9 \\
\hline 230B & 0.160 & 0.475 & 3.23 & 45 & 10.8 & 21.8 \\
\hline 230C & 0.160 & 0.635 & 5.18 & 45 & 11.2 & 26.6 \\
\hline 230D & 0.160 & 0.635 & 5.55 & 45 & 10.4 & 27.0 \\
\hline 230E & 0.160 & 0.635 & 6.57 & 45 & 12.7 & 24.9 \\
\hline 231A & 0.160 & 0.475 & 3.34 & 65 & 5.4 & 19.4 \\
\hline 231B & 0.160 & 0.475 & 2.44 & 65 & 5.9 & 27.2 \\
\hline 231C & 0.160 & 0.795 & 6.59 & 65 & 8.1 & 20.9 \\
\hline 231D & 0.160 & 0.795 & 7.26 & 65 & 9.4 & 23.3 \\
\hline $301-$ & 0.160 & 0.635 & 2.94 & 45 & 9.0 & 19.3 \\
\hline $303-$ & 0.160 & 0.795 & 4.65 & 45 & 9.6 & 21.0 \\
\hline $303 \mathrm{~A}$ & 0.160 & 0.795 & 3.72 & 45 & 8.2 & 17.5 \\
\hline $303 \mathrm{~B}$ & 0.160 & 0.795 & 4.42 & 45 & 8.5 & 18.3 \\
\hline $306-$ & 0.160 & 0.953 & 6.35 & 45 & 10.1 & 18.4 \\
\hline $319-$ & 0.102 & 0.795 & 2.99 & 45 & 8.4 & 20.0 \\
\hline $320-$ & 0.160 & 0.795 & 3.08 & 45 & 9.8 & 22.6 \\
\hline $321-$ & 0.203 & 0.795 & 3.01 & 45 & 8.4 & 23.3 \\
\hline $324-$ & 0.102 & 0.795 & 4.12 & 45 & 9.3 & 24.0 \\
\hline $325-$ & 0.160 & 0.795 & 4.25 & 45 & 8.7 & 23.3 \\
\hline $326-$ & 0.203 & 0.795 & 4.25 & 45 & 11.0 & 25.2 \\
\hline $333-$ & 0.102 & 0.475 & 2.93 & 45 & 9.6 & 25.5 \\
\hline $334-$ & 0.102 & 0.475 & 3.66 & 45 & 10.6 & 24.0 \\
\hline $335-$ & 0.102 & 0.635 & 4.12 & 45 & 9.4 & 23.1 \\
\hline $336-$ & 0.102 & 0.635 & 4.54 & 45 & 9.9 & 20.9 \\
\hline $336 \mathrm{~A}$ & 0.102 & 0.635 & 5.76 & 45 & 12.5 & 24.2 \\
\hline $337-$ & 0.102 & 0.795 & 6.90 & 45 & 12.2 & 25.0 \\
\hline $338-$ & 0.102 & 0.795 & 7.02 & 45 & 12.4 & 25.2 \\
\hline $339-$ & 0.102 & 0.953 & 6.55 & 45 & 8.5 & 26.9 \\
\hline & & & & & & \\
\hline
\end{tabular}


Table A-2 Empirical Test Parameters and Results, Phase C/D NASA/MSFC Test Series

\begin{tabular}{|c|c|c|c|c|c|c|}
\hline $\begin{array}{l}\text { Test } \\
\text { No. }\end{array}$ & $(\mathrm{cm})$ & $\begin{array}{c}\mathbf{d}_{\mathbf{p}} \\
(\mathrm{em})\end{array}$ & $\begin{array}{c}V_{p} \\
(\mathrm{~cm})\end{array}$ & $\begin{array}{c}\theta_{p} \\
(\mathrm{~cm})\end{array}$ & $\begin{array}{c}\theta_{1} \\
\left(c_{i n}\right)\end{array}$ & $\begin{array}{c}\theta_{99} \\
(\mathrm{~cm})\end{array}$ \\
\hline $4001-A$ & 0.203 & 0.795 & 3.15 & 45 & 13.6 & 33.7 \\
\hline 4001-B & 0.203 & 0.795 & 4.29 & 45 & 12.3 & 28.4 \\
\hline $4001-C$ & 0.203 & 0.795 & 6.12 & 45 & 12.1 & 33.7 \\
\hline 4001-D & 0.203 & 0.795 & 6.71 & 45 & 16.5 & 33.0 \\
\hline $4002-A$ & 0.203 & 0.795 & 3.20 & 75 & 7.4 & 22.1 \\
\hline 4002-B & 0.203 & 0.795 & 3.97 & 75 & 7.9 & 26.6 \\
\hline $4002-C$ & 0.203 & 0.795 & 6.30 & 75 & 6.2 & 21.8 \\
\hline 4002-D & 0.160 & 0.795 & 7.14 & 75 & 7.0 & 20.9 \\
\hline 4002-E & 0.203 & 0.795 & 6.41 & 75 & 4.3 & 16.7 \\
\hline 4003-A & 0.160 & 0.795 & 3.43 & 45 & 11.2 & 32.3 \\
\hline 4003-B & 0.203 & 0.795 & 6.29 & 45 & 14.6 & 34.9 \\
\hline $4003-C$ & 0.203 & 0.795 & 3.18 & 45 & 13.3 & 29.5 \\
\hline 4003-D & 0203 & 0.795 & 6.22 & 45 & 12.1 & 31.5 \\
\hline $4004-A$ & 0.203 & 0.795 & 3.19 & 75 & 5.6 & 18.6 \\
\hline 4004-B & 0203 & 0.795 & 6.08 & T5 & 8.3 & 26.0 \\
\hline $4004 \mathrm{C}$ & 0.203 & 0.79 & 6.19 & 75 & 5.6 & 20.6 \\
\hline $4100-A$ & 0.127 & 0.475 & 3.00 & 45 & 11.1 & 25.3 \\
\hline $4100-B$ & 0.127 & 0.475 & 3.78 & 45 & 12.4 & 29.9 \\
\hline $4100-C$ & 0.127 & 0.475 & 5.66 & 45 & 7.6 & 23.3 \\
\hline 4100-D & 0.127 & 0.475 & 7.20 & 45 & 17.3 & 28.4 \\
\hline 4101-A & 0.127 & 0.635 & 3.14 & 45 & 9.5 & 27.0 \\
\hline 4101-B & 0.127 & 0.635 & 4.13 & 45 & 11.6 & 30.4 \\
\hline 4101-C & 0.127 & 0.635 & 6.14 & 45 & 9.0 & 28.4 \\
\hline 4101-D & 0.127 & 0.635 & 7.52 & 45 & 12.8 & 28.4 \\
\hline 4102-A & 0.127 & 0.795 & 2.95 & 45 & 8.3 & 18.6 \\
\hline $4102-B$ & 0.127 & 0.795 & 4.12 & 45 & 5.2 & 14.3 \\
\hline $4102-C$ & 0.127 & 0.795 & 6.24 & 45 & 6.7 & 19.2 \\
\hline $4102-\mathrm{Cl}$ & 0.127 & 0.795 & 6.05 & 45 & 11.3 & 29.5 \\
\hline $4102-C 2$ & 0.127 & 0.795 & 6.02 & 45 & 6.3 & 19.0 \\
\hline $4102-D$ & 0.127 & 0.795 & 7.18 & 45 & 6.4 & 19.3 \\
\hline 4103-A & 0.127 & 0.475 & 2.94 & 60 & 10.4 & 25.8 \\
\hline 4103-B & 0.127 & 0.475 & 3.98 & 60 & 7.9 & 25.1 \\
\hline 4103-C & 0.127 & 0.475 & 5.88 & 60 & 20.0 & 37.4 \\
\hline 4103-D & 0.127 & 0.475 & 7.37 & 60 & 5.5 & 13.7 \\
\hline 4104-A & 0.127 & 0.635 & 7.23 & 60 & 9.5 & 29.1 \\
\hline 4104-B & 0.127 & 0.635 & 4.19 & 60 & 8.1 & 27.6 \\
\hline 4104-C & 0.127 & 0.635 & 6.12 & 60 & 8.0 & 28.9 \\
\hline 4104-D & 0.127 & 0.635 & 7.52 & 60 & 15.9 & 29.5 \\
\hline $4105-A$ & 0.127 & 0.795 & 2.92 & 60 & 4.9 & 21.0 \\
\hline 4105-A1 & 0.127 & 0.795 & 2.98 & 60 & 7.6 & 23.5 \\
\hline
\end{tabular}




\begin{tabular}{|c|c|c|c|c|c|c|}
\hline $4105-B$ & 0.127 & 0.795 & 4.02 & 60 & 7.3 & 25.1 \\
\hline $4105-C$ & 0.127 & 0.795 & 6.15 & 60 & 7.6 & 24.8 \\
\hline $4105-D$ & 0.127 & 0.795 & 7.23 & 60 & 7.6 & 25.5 \\
\hline 4106-A & 0.127 & 0.475 & 3.05 & 60 & 9.4 & 26.8 \\
\hline 4106-A1 & 0.127 & 0.475 & 3.10 & 75 & 4.8 & 16.3 \\
\hline 4106-B & 0.127 & 0.475 & 4.12 & 60 & 12.7 & 28.7 \\
\hline 4106-B1 & 0.127 & 0.475 & 3.99 & 75 & 4.1 & 16.1 \\
\hline $4106-C$ & 0.127 & 0.475 & 5.95 & 75 & 4.3 & 19.0 \\
\hline 4106-D & 0.127 & 0.475 & 7.56 & 75 & 5.8 & 22.4 \\
\hline $4107-A$ & 0.127 & 0.635 & 3.05 & 75 & 6.5 & 22.8 \\
\hline 4107-B & 0.127 & 0.635 & 4.11 & 75 & 5.8 & 24.9 \\
\hline $4107-C$ & 0.127 & 0.635 & 6.20 & 75 & 6.0 & 20.6 \\
\hline $4107-D$ & 0.127 & 0.635 & 7.64 & 75 & 6.1 & 23.0 \\
\hline $4108-A$ & 0.127 & 0.795 & 3.12 & 75 & 7.0 & 22.6 \\
\hline 4108-A1 & 0.127 & 0.795 & 2.95 & 75 & 5.4 & 18.7 \\
\hline 4108-B & 0.127 & 0.795 & 3.97 & 75 & 6.7 & 22.8 \\
\hline $4108-C$ & 0.127 & 0.795 & 5.96 & 75 & 6.9 & 23.5 \\
\hline 4108-D & 0.127 & 0.795 & 7.07 & 75 & 6.5 & 22.6 \\
\hline $4109-A$ & 0.203 & 0.475 & 3.27 & 45 & 14.7 & 39.4 \\
\hline 4109-B & 0.203 & 0.475 & 4.14 & 45 & 15.3 & 31.8 \\
\hline $4109-C$ & 0.203 & 0.475 & 6.53 & 45 & 13.2 & 29.5 \\
\hline 4109-D & 0.203 & 0.475 & 7.46 & 45 & 25.6 & 34.8 \\
\hline $4110-A$ & 0.203 & 0.635 & 3.25 & 45 & 16.1 & 32.3 \\
\hline $4110-B$ & 0.203 & 0.635 & 4.00 & 45 & 22.3 & 32.3 \\
\hline $4110-C$ & 0.203 & 0.635 & 5.76 & 45 & 18.4 & 30.6 \\
\hline $4110-\mathrm{D}$ & 0.203 & 0.635 & 6.96 & 45 & 17.5 & 33.6 \\
\hline $4111-A$ & 0.203 & 0.795 & 2.85 & 45 & 19.3 & 33.0 \\
\hline $4111-B$ & 0.203 & 0.795 & 3.94 & 45 & 17.6 & 35.0 \\
\hline $4111-C$ & 0.203 & 0.795 & 5.97 & 45 & 20.9 & 35.5 \\
\hline 4111-D & 0.203 & 0.795 & 6.81 & 45 & 18.4 & 36.9 \\
\hline $4112-A$ & 0.203 & 0.475 & 3.33 & 60 & 10.2 & 29.1 \\
\hline 4112-B & 0.203 & 0.475 & 4.05 & 60 & 8.9 & 26.8 \\
\hline $4112-C$ & 0.203 & 0.475 & 5.87 & 60 & 12.8 & 31.0 \\
\hline $4112-D$ & 0.203 & 0.475 & 7.50 & 60 & 14.4 & 28.0 \\
\hline $4113-A$ & 0.203 & 0.635 & 2.97 & 60 & 7.1 & 29.8 \\
\hline 4113-B. & 0.203 & 0.635 & 3.77 & 60 & 12.1 & 41.0 \\
\hline $4113-C$ & 0.203 & 0.635 & 6.30 & 60 & 10.1 & 28.0 \\
\hline 4113-D & 0.203 & 0.635 & 7.12 & 60 & 10.2 & 31.0 \\
\hline $4114-\mathrm{A}$ & 0.203 & 0.795 & 3.13 & 60 & 9.5 & 27.8 \\
\hline 4114-B & 0.203 & 0.795 & 3.98 & 60 & 12.4 & 32.0 \\
\hline 4114-C & 0.203 & 0.795 & 5.92 & 60 & 13.3 & 28.9 \\
\hline 4114-D & 0.203 & 0.795 & 7.40 & 60 & 10.0 & 31.8 \\
\hline $4115-A$ & 0.203 & 0.475 & 3.13 & 75 & 7.0 & 19.5 \\
\hline $4115-B$ & 0.203 & 0.475 & 4.08 & 75 & 6.1 & 13.1 \\
\hline
\end{tabular}




\begin{tabular}{|c|c|c|c|c|c|c|}
\hline 4115-C & 0.203 & 0.475 & 6.06 & 75 & 9.3 & 30.0 \\
\hline $4115-\mathrm{D}$ & 0.203 & 0.475 & 7.30 & 75 & 6.0 & 24.7 \\
\hline $4116-\mathrm{A}$ & 0.203 & 0.635 & 2.92 & 75 & 4.4 & 17.5 \\
\hline $4116-\mathrm{B}$ & 0.203 & 0.635 & 4.48 & 75 & 8.7 & 27.4 \\
\hline $4116-\mathrm{C}$ & 0.203 & 0.635 & 6.24 & 75 & 5.8 & 20.3 \\
\hline $4116-\mathrm{D}$ & 0.203 & 0.635 & 7.36 & 75 & 7.3 & 22.8 \\
\hline $4117-\mathrm{A}$ & 0.203 & 0.795 & 3.11 & 75 & 5.3 & 18.0 \\
\hline $4117-\mathrm{B}$ & 0.203 & 0.795 & 4.05 & 75 & 7.7 & 22.6 \\
\hline 4117-C & 0.203 & 0.795 & 6.03 & 75 & 6.5 & 26.9 \\
\hline $4117-\mathrm{D}$ & 0.203 & 0.795 & 7.20 & 75 & 6.8 & 25.5 \\
\hline
\end{tabular}


Table A-3 Empirical Test Parameters and Results, NASA/MSFC EH Test Series

\begin{tabular}{|c|c|c|c|r|r|r|}
\hline $\begin{array}{c}\text { Teat } \\
\text { Ne. }\end{array}$ & $\begin{array}{c}\mathbf{t}_{\mathbf{b}} \\
(\mathbf{c m})\end{array}$ & $\begin{array}{c}\mathbf{d}_{\mathbf{p}} \\
(\mathbf{c m})\end{array}$ & $\begin{array}{c}\mathbf{v}_{\mathbf{p}} \\
(\mathbf{c m})\end{array}$ & $\begin{array}{c}\boldsymbol{\theta}_{\mathbf{p}} \\
(\mathbf{c m})\end{array}$ & $\begin{array}{c}\boldsymbol{\theta}_{\mathbf{r}} \\
(\mathbf{c m})\end{array}$ & $\begin{array}{c}\boldsymbol{\theta}_{\mathbf{m}} \\
(\mathbf{c m})\end{array}$ \\
\hline EH1AA & 0.160 & 0.795 & 6.93 & 75 & 9.5 & 31.1 \\
\hline EHIAB & 0.160 & 0.795 & 6.91 & 75 & 7.4 & 27.2 \\
\hline EH1AP & 0.160 & 0.795 & 6.82 & 75 & 9.3 & 29.8 \\
\hline EHIB & 0.160 & 0.795 & 7.01 & 45 & 15.5 & 29.3 \\
\hline EH1BP & 0.160 & 0.635 & 7.22 & 75 & 6.6 & 27.5 \\
\hline EHIC & 0.160 & 0.795 & 7.17 & 60 & 10.6 & 27.9 \\
\hline EH1CP & 0.160 & 0.475 & 7.52 & 75 & 8.2 & 25.1 \\
\hline EHID & 0.160 & 0.795 & 7.16 & 75 & 7.9 & 29.0 \\
\hline EHRP1 & 0.160 & 0.795 & 6.93 & 60 & 10.6 & 24.2 \\
\hline EHRP2 & 0.160 & 0.795 & 6.85 & 65 & 8.7 & 21.2 \\
\hline EHRP3 & 0.160 & 0.795 & 6.83 & 45 & 12.5 & 27.7 \\
\hline EHRP4 & 0.160 & 0.635 & 7.71 & 60 & 10.8 & 26.0 \\
\hline EHRP5 & 0.160 & 0.635 & 7.56 & 65 & 13.0 & 30.1 \\
\hline EHRP6 & 0.160 & 0.635 & 7.63 & 45 & 11.5 & 24.5 \\
\hline EHRP7 & 0.160 & 0.475 & 8.04 & 60 & 18.5 & 30.8 \\
\hline EHRP8 & 0.160 & 0.475 & 7.39 & 45 & 11.9 & 27.2 \\
\hline EHRP9 & 0.160 & 0.475 & 7.34 & 65 & 13.8 & 34.1 \\
\hline EHSS4C & 0.160 & 0.635 & 5.58 & 45 & 9.9 & 28.9 \\
\hline
\end{tabular}




\section{APPENDLX B}

SPH NUMERICAL SMULATION PARAMETERS AND RESULTS 
Table B-1 SPH Numerical Simulation Parameters and Results

\begin{tabular}{|c|r|r|r|r|r|r|}
\hline $\begin{array}{c}\text { Test } \\
\text { No. }\end{array}$ & $\begin{array}{c}\mathbf{t}_{\mathbf{b}} \\
(\mathbf{c m})\end{array}$ & $\begin{array}{c}\mathbf{d}_{\mathbf{p}} \\
(\mathbf{c m})\end{array}$ & $\begin{array}{c}\mathbf{V}_{\mathbf{p}} \\
(\mathbf{k m} / \mathbf{s})\end{array}$ & $\begin{array}{c}\boldsymbol{\theta}_{\mathbf{p}} \\
(\mathbf{d e g})\end{array}$ & $\begin{array}{c}\boldsymbol{\theta}_{\mathbf{r}} \\
\text { (deg) }\end{array}$ & $\begin{array}{c}\boldsymbol{\theta}_{\mathbf{g}} \\
(\mathbf{d e g})\end{array}$ \\
\hline SPH-01 & 0.160 & 0.635 & 7 & 45 & 24 & 40 \\
\hline SPH-02 & 0.160 & 0.635 & 7 & 60 & 13 & 28 \\
\hline SPH-03 & 0.160 & 0.635 & 7 & 75 & 4 & 11 \\
\hline SPH-04 & 0.160 & 0.635 & 11 & 45 & 21 & 39 \\
\hline SPH-05 & 0.160 & 0.635 & 11 & 60 & 12 & 29 \\
\hline SPH-06 & 0.160 & 0.635 & 11 & 75 & 5 & 10 \\
\hline SPH-07 & 0.160 & 0.635 & 15 & 45 & 17 & 33 \\
\hline SPH-08 & 0.160 & 0.635 & 15 & 60 & 12 & 23 \\
\hline SPH-09 & 0.160 & 0.635 & 15 & 75 & 4 & 11 \\
\hline SPH-10 & 0.160 & 0.953 & 7 & 45 & 16 & 40 \\
\hline SPH-11 & 0.160 & 0.953 & 7 & 60 & 12 & 26 \\
\hline SPH-12 & 0.160 & 0.953 & 7 & 75 & 5 & 12 \\
\hline SPH-13 & 0.160 & 0.953 & 11 & 45 & 28 & 40 \\
\hline SPH-14 & 0.160 & 0.953 & 11 & 60 & 12 & 21 \\
\hline SPH-15 & 0.160 & 0.953 & 11 & 75 & 4 & 11 \\
\hline SPH-16 & 0.160 & 0.953 & 15 & 45 & 20 & 40 \\
\hline SPH-17 & 0.160 & 0.953 & 15 & 60 & 10 & 22 \\
\hline SPH-18 & 0.160 & 0.953 & 15 & 75 & 5 & 13 \\
\hline SPH-19 & 0.160 & 1.270 & 7 & 45 & 25 & 41 \\
\hline SPH-20 & 0.160 & 1.270 & 7 & 60 & 14 & 25 \\
\hline SPH-21 & 0.160 & 1.270 & 7 & 75 & 6 & 14 \\
\hline SPH-22 & 0.160 & 1.270 & 11 & 45 & 23 & 40 \\
\hline SPH-23 & 0.160 & 1.270 & 11 & 60 & 10 & 24 \\
\hline SPH-24 & 0.160 & 1.270 & 11 & 75 & 5 & 14 \\
\hline SPH-25 & 0.160 & 1.270 & 15 & 45 & 19 & 39 \\
\hline SPH-26 & 0.160 & 1.270 & 15 & 60 & 11 & 20 \\
\hline SPH-27 & 0.160 & 1.270 & 15 & 75 & 4 & 10 \\
\hline SPH-28 & 0.127 & 0.795 & 9 & 45 & 18 & 40 \\
\hline SPH-29 & 0.127 & 0.795 & 9 & 60 & 11 & 20 \\
\hline SPH-30 & 0.127 & 0.795 & 9 & 75 & 5 & 12 \\
\hline SPH-31 & 0.127 & 0.795 & 13 & 45 & 24 & 41 \\
\hline SPH-32 & 0.127 & 0.795 & 13 & 60 & 13 & 23 \\
\hline SPH-33 & 0.127 & 0.795 & 13 & 75 & 8 & 14 \\
\hline SPH-34 & 0.127 & 1.113 & 9 & 45 & 20 & 41 \\
\hline SPH-35 & 0.127 & 1.113 & 9 & 60 & 13 & 23 \\
\hline SPH-36 & 0.127 & 1.113 & 9 & 75 & 5 & 14 \\
\hline SPH-37 & 0.127 & 1.113 & 13 & 45 & 24 & 41 \\
\hline SPH-38 & 0.127 & 1.113 & 13 & 60 & 13 & 25 \\
\hline SPH-39 & 0.127 & 1.113 & 13 & 75 & 6 & 14 \\
\hline
\end{tabular}


APPENDEX C

MTASURED CRATER DEPTHS AND DIAMETERS 
Table C-1 Measured Crater Depths and Diameters, Calculated Crater Volumes Phase B NASAMSFC Test Series

\begin{tabular}{|c|c|c|c|c|c|c|c|c|c|c|c|c|c|}
\hline $\begin{array}{l}\text { Test } \\
\text { No. }\end{array}$ & $\begin{array}{c}V_{p} \\
(\mathrm{~km} / \mathrm{s})\end{array}$ & $\begin{array}{c}\theta_{1} \\
\text { (deg) }\end{array}$ & $\begin{array}{c}d_{p} \\
(c m)\end{array}$ & $\left(\begin{array}{c}t_{b} \\
(\mathrm{~cm})\end{array}\right.$ & $\begin{array}{c}\mathbf{p}_{1} \\
(\mathrm{~cm})\end{array}$ & $\begin{array}{c}d_{1} \\
(\mathrm{~cm})\end{array}$ & $\begin{array}{c}\mathrm{Vol}_{1} \\
\left(\times 10^{-2} \mathrm{~cm}^{3}\right)\end{array}$ & $\begin{array}{c}\mathbf{p 2} \\
(\mathrm{cm})\end{array}$ & $\begin{array}{c}d_{2} \\
(c m)\end{array}$ & $\begin{array}{c}\mathrm{Voh_{2 }} \\
\left(\times 10^{-2} \mathrm{~cm}^{3}\right)\end{array}$ & $\begin{array}{c}p_{3} \\
(\mathrm{~cm})\end{array}$ & $\begin{array}{c}d_{3} \\
(\mathrm{~cm})\end{array}$ & $\begin{array}{c}\text { Vols } \\
\left(\times 10^{-2} \mathrm{~cm}^{3}\right)\end{array}$ \\
\hline 001B & 6.56 & 45 & 0.795 & 0.20 & 0.042 & 0.095 & 0.020 & 0.043 & 0.088 & 0.017 & 0.046 & 0.101 & 0.025 \\
\hline 002B & 6.51 & 45 & 0.795 & 0.16 & 0.033 & 0.113 & 0.022 & 0.040 & 0.095 & 0.019 & 0.041 & 0.088 & 0.017 \\
\hline $201 A$ & 4.33 & 45 & 0.635 & 0.10 & 0.026 & 0.055 & 0.004 & 0.028 & 0.071 & 0.007 & 0.026 & 0.056 & 0.004 \\
\hline $205 A$ & 4.20 & 45 & 0.635 & 0.16 & 0.037 & 0.084 & 0.014 & 0.018 & 0.099 & 0.009 & 0.048 & 0.088 & 0.015 \\
\hline $205 C$ & 5.30 & 45 & 0.635 & 0.16 & 0.018 & 0.071 & 0.005 & 0.033 & 0.071 & 0.009 & 0.024 & 0.082 & 0.008 \\
\hline 205D & 6.42 & 45 & 0.635 & 0.16 & 0.018 & 0.074 & 0.005 & 0.029 & 0.092 & 0.013 & 0.024 & 0.062 & 0.005 \\
\hline 205E & 3.15 & 45 & 0.635 & 0.16 & 0.023 & 0.089 & 0.010 & & & & & & \\
\hline $206 \mathrm{E}$ & 3.24 & 45 & 0.462 & 0.16 & 0.012 & 0.070 & 0.003 & 0.014 & 0.048 & 0.002 & & & \\
\hline $206 \mathrm{~F}$ & $\overline{6.42}$ & 45 & 0.475 & 0.16 & 0.037 & 0.061 & 0.005 & 0.006 & 0.052 & 0.001 & & & \\
\hline 211B & 5.88 & 45 & 0.889 & \begin{tabular}{|l|}
0.16 \\
\end{tabular} & 0.058 & 0.105 & 0.025 & 0.035 & 0.089 & 0.015 & 0.047 & 0.101 & 0.025 \\
\hline 211D & $\overline{6.84}$ & 45 & 0.889 & 0.16 & 0.052 & 0.105 & 0.030 & 0.024 & 0.111 & 0.015 & 0.035 & 0.091 & 0.015 \\
\hline 212B & 6.38 & 45 & 0.762 & 0.16 & 0.031 & 0.096 & 0.015 & 0.026 & 0.081 & 0.009 & 0.019 & 0.091 & 0.008 \\
\hline $216 A$ & 6.10 & 45 & 0.889 & 0.20 & 0.058 & 0.101 & 0.023 & 0.038 & 0.112 & 0.025 & 0.039 & 0.067 & 0.007 \\
\hline $216 \mathrm{C}$ & 6.96 & 45 & 0.795 & 0.20 & 0.045 & 0.119 & 0.033 & 0.058 & 0.131 & 0.052 & 0.045 & 0.103 & 0.025 \\
\hline $217 A$ & 6.65 & 45 & 0.795 & 0.10 & 0.036 & 0.098 & 0.018 & 0.028 & 0.099 & 0.014 & 0.029 & 0.099 & 0.015 \\
\hline 217B & 7.10 & 45 & 0.795 & 0.10 & 0.077 & 0.092 & 0.026 & 0.032 & 0.076 & 0.010 & 0.031 & 0.076 & 0.009 \\
\hline $217 \mathrm{C}$ & 6.05 & 45 & 0.635 & 0.10 & 0.036 & 0.076 & 0.011 & 0.029 & 0.068 & 0.007 & & & \\
\hline 217D & 6.47 & 45 & 0.635 & 0.10 & 0.029 & 0.088 & 0.012 & 0.026 & 0.072 & 0.007 & & & \\
\hline 217E & 7.14 & 45 & 0.635 & 0.10 & 0.018 & 0.071 & 0.005 & 0.031 & 0.058 & 0.004 & & & \\
\hline $218 A$ & 5.82 & 45 & 0.889 & \begin{tabular}{|l|}
0.10 \\
\end{tabular} & 0.040 & 0.115 & 0.028 & 0.036 & \begin{tabular}{|l|}
0.087 \\
\end{tabular} & 0.014 & 0.042 & 0.096 & 0.020 \\
\hline $218 \mathrm{C}$ & 6.88 & 45 & 0.889 & 0.10 & 0.063 & 0.121 & 0.036 & 0.032 & 0.098 & 0.016 & 0.031 & 0.072 & 0.008 \\
\hline $221 B$ & 5.97 & 45 & 0.475 & 0.10 & 0.020 & 0.076 & 0.006 & 0.029 & 0.058 & 0.004 & & & \\
\hline $221 \mathrm{C}$ & 4.62 & 45 & \begin{tabular}{|l|}
0.475 \\
\end{tabular} & 0.10 & 0.012 & 0.032 & 0.001 & & & & & & \\
\hline $226 A$ & 4.48 & 45 & 0.635 & 0.08 & 0.004 & 0.062 & 0.001 & & & & & & \\
\hline $226 B$ & 5.49 & 45 & 0.635 & 0.08 & 0.015 & 0.052 & 0.002 & 0.027 & \begin{tabular}{|l|}
0.098 \\
\end{tabular} & 0.014 & & & \\
\hline $227 A$ & 5.64 & 45 & \begin{tabular}{|l|}
0.635 \\
\end{tabular} & 0.08 & 0.102 & 0.085 & 0.029 & 0.030 & 0.085 & 0.011 & 0.020 & 0.085 & $\overline{0.008}$ \\
\hline $227 \mathrm{~B}$ & 7.25 & 45 & 0.635 & 0.08 & 0.027 & 0.082 & 0.010 & & & & & & \\
\hline $230 \mathrm{~B}$ & 3.23 & 45 & 0.475 & 0.16 & 0.036 & 0.085 & 0.014 & 0.038 & 0.086 & 0.015 & & & \\
\hline $230 \mathrm{C}$ & 5.16 & 45 & 0.635 & 0.16 & 0.024 & 0.081 & 0.008 & 0.030 & 0.090 & 0.013 & 0.021 & 0.088 & 0.009 \\
\hline $230 D$ & 5.51 & 45 & 0.635 & 0.16 & 0.023 & 0.086 & 0.009 & 0.045 & 0.088 & 0.014 & 0.028 & 0.063 & 0.006 \\
\hline $230 \mathrm{E}$ & 6.62 & 45 & 0.635 & 0.16 & 0.043 & 0.112 & 0.028 & 0.021 & 0.065 & 0.005 & & & \\
\hline 301- & 2.95 & 45 & 0.635 & 0.16 & 0.026 & 0.086 & 0.010 & 0.027 & 0.084 & 0.010 & 0.012 & 0.076 & 0.004 \\
\hline 303- & 4.59 & 45 & 0.795 & 0.16 & 0.062 & 0.082 & 0.016 & 0.046 & 0.081 & 0.012 & 0.078 & 0.101 & 0.031 \\
\hline $303 \mathrm{~A}$ & 3.65 & 45 & 0.795 & 0.16 & 0.016 & 0.131 & 0.014 & 0.031 & 0.088 & 0.013 & 0.022 & 0.081 & 0.008 \\
\hline 303B & 4.34 & 45 & 0.795 & 0.16 & 0.040 & 0.086 & 0.015 & 0.033 & 0.085 & 0.012 & 0.075 & 0.074 & 0.016 \\
\hline 319- & 2.93 & 45 & 0.795 & 0.10 & 0.042 & 0.061 & 0.006 & 0.029 & 0.084 & 0.011 & & & \\
\hline 321- & 2.97 & 45 & 0.795 & 0.20 & 0.071 & 0.091 & 0.023 & 0.043 & 0.098 & 0.022 & 0.026 & 0.069 & 0.006 \\
\hline $324-$ & 4.05 & 45 & 0.795 & 0.10 & 0.016 & 0.101 & 0.009 & 0.025 & 0.088 & 0.010 & 0.018 & 0.085 & 0.007 \\
\hline 325- & 4.14 & 45 & 0.795 & 0.16 & 0.026 & 0.088 & 0.011 & 0.029 & 0.084 & 0.011 & 0.036 & 0.073 & 0.010 \\
\hline $326-$ & 4.22 & 45 & 0.795 & 0.20 & 0.105 & 0.151 & 0.094 & 0.076 & 0.138 & 0.057 & 0.060 & 0.131 & 0.054 \\
\hline$\overline{333-}$ & 2.88 & 45 & 0.475 & 0.10 & 0.020 & 0.068 & 0.005 & & & & & & \\
\hline
\end{tabular}




\begin{tabular}{|c|c|c|c|c|c|c|c|c|c|c|c|c|c|}
\hline 334 & 3.61 & 45 & $\overline{0.473}$ & 0.10 & 0.012 & 0.031 & 001 & & & & & & \\
\hline 335 & 4.07 & 45 & 0.635 & 0.10 & 0.02 & 0.066 & 0.003 & 0.019 & 0.067 & 0.004 & & & \\
\hline 32 & 447 & TS & $\mathbf{0 . 6 3 5}$ & 0.10 & 0.033 & 0,1 & 09 & 0.023 & 0.039 & 060 & & & \\
\hline $3 \mathbf{3 A}$ & 5.70 & 75 & 0.635 & 0.10 & 0.027 & 0.01 & ODL & 0.022 & 0.076 & 0.007 & 0.023 & 0.059 & 0.004 \\
\hline 37 & 681 & 45 & 0.793 & 0.10 & 0.026 & 001 & 0.009 & 0.033 & 0.097 & 0.013 & 0.020 & 0.091 & 0.009 \\
\hline 35 & 6.98 & $\overline{45}$ & 0.795 & 0.10 & 0.034 & 0.078 & 0.011 & 0.026 & 0.106 & 0.015 & 0.016 & 0.069 & 0.004 \\
\hline
\end{tabular}


Table C-2 Measured Crater Depths and Diameters, Calculated Crater Volumes Phase C/D NASA/MSFC Test Series

\begin{tabular}{|c|c|c|c|c|c|c|c|c|c|c|c|c|c|}
\hline $\begin{array}{l}\text { Test } \\
\text { No. }\end{array}$ & $\begin{array}{c}V_{p} \\
(\mathrm{~km} / \mathrm{s})\end{array}$ & $\begin{array}{c}\theta_{p} \\
\text { (deg) }\end{array}$ & $\begin{array}{c}d_{p} \\
(c m)\end{array}$ & $\begin{array}{c}t_{b} \\
(\mathrm{~cm})\end{array}$ & $\begin{array}{c}p_{1} \\
(\mathrm{~cm})\end{array}$ & $\begin{array}{c}d_{1} \\
(c m)\end{array}$ & $\begin{array}{c}\text { Vol } \\
\left(\mathrm{x}^{-2} \mathrm{~cm}^{3}\right)\end{array}$ & $\begin{array}{c}\mathbf{p}_{2} \\
(\mathrm{~cm})\end{array}$ & $\begin{array}{c}d_{2} \\
(\mathrm{~cm})\end{array}$ & $\begin{array}{c}V o L_{2} \\
\left(\times 10^{-2} \mathrm{~cm}^{3}\right)\end{array}$ & $\underset{(\mathrm{cm})}{\mathrm{P3}}$ & $\begin{array}{c}d_{3} \\
(c m)\end{array}$ & $\begin{array}{c}\text { Vols } \\
\left(x 10^{-2} \mathrm{~cm}^{3}\right)\end{array}$ \\
\hline $4001 \mathrm{~A}$ & 3.15 & 45 & 0.795 & 0.20 & 0.021 & 0.085 & 0.008 & 0.018 & 0.086 & 0.007 & 0.039 & 0.109 & 0.024 \\
\hline $4001 B$ & 4.29 & 45 & 0.795 & 0.20 & 0.053 & 0.103 & 0.022 & 0.033 & 0.089 & 0.014 & 0.036 & 0.096 & 0.017 \\
\hline $4001 \mathrm{C}$ & 6.12 & 45 & 0.795 & 0.20 & 0.045 & 0.138 & 0.045 & 0.073 & 0.119 & 0.041 & 0.038 & 0.101 & 0.020 \\
\hline 4001D & 6.71 & 45 & 0.795 & 0.20 & 0.029 & 0.104 & 0.016 & 0.040 & 0.104 & 0.023 & 0.035 & 0.084 & 0.013 \\
\hline 4002B & 3.97 & 75 & 0.795 & 0.20 & 0.194 & 0.282 & 0.606 & 0.174 & 0.184 & 0.231 & 0.214 & 0.161 & 0.218 \\
\hline $4002 \mathrm{D}$ & 7.14 & 75 & 0.795 & 0.16 & 0.500 & 0.226 & 1.003 & 0.319 & 0.161 & 0.325 & 0.308 & 0.132 & 0.211 \\
\hline $4002 \mathrm{E}$ & 6.41 & 75 & 0.795 & 0.20 & 0.500 & 0.204 & 0.817 & 0.314 & 0.137 & 0.231 & 0.381 & 0.187 & 0.523 \\
\hline $4003 A$ & 3.43 & 45 & 0.795 & 0.16 & 0.041 & 0.086 & 0.016 & 0.040 & 0.082 & 0.014 & 0.024 & 0.081 & 0.008 \\
\hline $4003 B$ & 6.29 & 45 & 0.795 & 0.20 & 0.052 & 0.065 & 0.009 & 0.035 & 0.091 & 0.015 & 0.029 & 0.065 & 0.006 \\
\hline $4003 \mathrm{C}$ & 3.18 & 45 & 0.795 & 0.20 & 0.019 & 0.091 & 0.008 & 0.032 & 0.088 & 0.013 & 0.039 & 0.071 & 0.008 \\
\hline 4003D & 6.22 & 45 & 0.795 & 0.20 & 0.058 & 0.079 & 0.014 & 0.029 & 0.095 & 0.014 & 0.033 & 0.101 & 0.018 \\
\hline $4004 A$ & 3.19 & 75 & 0.795 & 0.20 & 0.211 & 0.202 & 0.338 & 0.124 & 0.251 & 0.409 & 0.155 & 0.232 & 0.328 \\
\hline $4004 \mathrm{~B}$ & 6.08 & 75 & 0.795 & 0.20 & 0.291 & 0.151 & 0.261 & 0.261 & 0.201 & 0.414 & 0.230 & 0.191 & 0.329 \\
\hline $4101 \mathrm{~A}$ & 3.14 & 45 & 0.635 & 0.13 & 0.029 & 0.065 & 0.006 & & & & & & \\
\hline 4101B & 4.13 & 45 & 0.635 & 0.13 & 0.029 & 0.085 & 0.011 & 0.035 & 0.076 & 0.011 & 0.135 & 0.074 & 0.029 \\
\hline $4101 C$ & 6.14 & 45 & 0.635 & 0.13 & 0.041 & 0.124 & 0.033 & 0.015 & 0.105 & 0.009 & & & \\
\hline $4102 A$ & 2.95 & 45 & 0.795 & 0.13 & 0.031 & 0.084 & 0.011 & 0.041 & 0.088 & 0.017 & 0.041 & 0.081 & 0.011 \\
\hline $4102 \mathrm{C}$ & 6.24 & 45 & 0.795 & 0.13 & 0.042 & 0.088 & 0.017 & 0.046 & 0.110 & 0.029 & 0.062 & 0.081 & $\overline{0.016}$ \\
\hline 4102C1 & 6.05 & 45 & 0.795 & 0.13 & 0.035 & 0.131 & 0.031 & 0.062 & 0.065 & 0.010 & 0.032 & 0.081 & 0.011 \\
\hline $4103 A$ & 2.94 & 60 & 0.475 & 0.13 & 0.006 & 0.042 & 0.001 & & & & & & \\
\hline $4103 B$ & 3.98 & 60 & 0.475 & 0.13 & 0.067 & 0.134 & 0.047 & 0.042 & 0.119 & 0.031 & 0.042 & 0.104 & 0.024 \\
\hline $4103 C$ & 5.88 & 60 & 0.475 & 0.13 & 0.041 & 0.086 & $\overline{0.016}$ & 0.026 & 0.109 & 0.016 & 0.043 & 0.078 & 0.010 \\
\hline 4103D & 7.37 & 60 & 0.475 & 0.13 & 0.053 & 0.118 & 0.039 & 0.040 & 0.135 & 0.038 & 0.038 & 0.088 & 0.015 \\
\hline $4104 \mathrm{~A}$ & 7.23 & 60 & 0.635 & 0.13 & 0.051 & 0.115 & 0.035 & 0.083 & 0.116 & 0.044 & 0.058 & 0.074 & 0.012 \\
\hline$\overline{4 B}$ & 4.19 & 60 & 0.635 & 0.13 & 0.049 & 0.136 & $\overline{0.047}$ & 0.068 & 0.084 & 0.019 & 0.037 & 0.081 & 0.013 \\
\hline $4104 \mathrm{C}$ & 6.12 & 60 & 0.635 & 0.13 & 0.079 & 0.114 & 0.040 & 0.067 & 0.152 & 0.081 & 0.051 & 0.136 & 0.049 \\
\hline 4104D & 7.52 & 60 & 0.635 & 0.13 & 0.051 & 0.124 & 0.041 & 0.037 & 0.101 & 0.020 & 0.054 & 0.095 & 0.019 \\
\hline $4105 A$ & 2.92 & 60 & 0.795 & \begin{tabular}{|l|}
0.13 \\
\end{tabular} & 0.071 & 0.111 & 0.034 & 0.065 & 0.165 & 0.093 & 0.115 & 0.204 & 0.188 \\
\hline $4105 \mathrm{A1}$ & 2.98 & 60 & 0.795 & 0.13 & 0.057 & 0.117 & 0.041 & 0.062 & 0.118 & 0.034 & 0.090 & 0.126 & 0.056 \\
\hline 4105B & 4.02 & 60 & 0.795 & 0.13 & 0.139 & 0.117 & 0.075 & 0.070 & 0.174 & 0.111 & 0.053 & 0.148 & 0.061 \\
\hline $4106 \mathrm{~A}$ & 3.05 & 60 & 0.475 & 0.13 & 0.052 & 0.102 & 0.021 & 0.039 & 0.101 & 0.021 & 0.039 & 0.116 & 0.027 \\
\hline $4106 \mathrm{A1}$ & 3.10 & 75 & 0.475 & 0.13 & 0.128 & 0.131 & 0.086 & 0.118 & 0.112 & 0.058 & 0.127 & 0.185 & 0.171 \\
\hline $4106 B$ & 4.12 & 60 & 0.475 & 0.13 & 0.044 & 0.105 & 0.025 & 0.025 & 0.118 & 0.018 & 0.058 & 0.091 & 0.019 \\
\hline 4106B1 & 3.99 & 75 & 0.475 & \begin{tabular}{|l|}
0.13 \\
\end{tabular} & 0.118 & 0.181 & 0.152 & 0.128 & 0.191 & 0.183 & 0.091 & 0.131 & 0.061 \\
\hline $4106 \mathrm{C}$ & 5.95 & 75 & 0.475 & 0.13 & 0.129 & 0.186 & 0.175 & 0.091 & 0.221 & 0.233 & 0.058 & 0.196 & 0.117 \\
\hline $4106 D$ & 7.56 & 75 & 0.475 & 0.13 & 0.160 & 0.241 & 0.365 & 0.241 & 0.149 & 0.210 & 0.066 & 0.159 & 0.087 \\
\hline $4107 A$ & 3.05 & 75 & 0.475 & 0.13 & 0.106 & 0.214 & 0.254 & 0.121 & 0.274 & 0.476 & 0.104 & 0.085 & 0.030 \\
\hline $4107 \mathrm{~B}$ & 4.11 & 75 & 0.635 & 0.13 & 0.161 & 0.263 & 0.437 & 0.132 & 0.221 & 0.253 & 0.124 & 0.194 & 0.183 \\
\hline $4107 \mathrm{C}$ & 6.20 & 75 & 0.635 & 0.13 & 0.238 & 0.174 & 0.283 & 0.185 & 0.221 & 0.355 & 0.191 & 0.115 & 0.099 \\
\hline \$107D & 7.64 & 75 & 0.635 & 0.13 & 0.254 & 0.164 & 0.268 & 0.301 & 0.175 & 0.362 & 0.218 & 0.139 & 0.165 \\
\hline $4108 A$ & 3.12 & 75 & 0.795 & 0.13 & 0.214 & 0.406 & 1.385 & 0.266 & 0.229 & 0.548 & 0.139 & 0.204 & 0.227 \\
\hline
\end{tabular}




\begin{tabular}{|c|c|c|c|c|c|c|c|c|c|c|c|c|c|}
\hline $4108 A 1$ & 2.95 & 75 & 0.838 & 0.13 & 0.321 & 0.212 & 0.367 & 0.171 & 0.14 & 0.139 & 0.151 & 0.186 & 0.205 \\
\hline 4160 & 3.97 & 75 & 0.795 & 013 & 0.251 & 0.269 & 0.713 & 0.151 & 0.225 & 0.300 & 0.135 & \begin{tabular}{|l|l|}
0.121 \\
\end{tabular} & 0.078 \\
\hline 410XX & 3,27 & 15 & 0.775 & 0.20 & 0.010 & 0.053 & 0.002 & & & & & & \\
\hline $410 \mathrm{~S}$ & 4.14 & 45 & $6{ }_{13}$ & 02 & 0.017 & 0.014 & 0.005 & 0.027 & 0.057 & 0.005 & & & \\
\hline A10sc & 6.33 & 45 & 0,475 & 020 & 0.021 & Dos & 003 & 0.011 & 0.069 & 0.003 & & & \\
\hline 41164 & 3.25 & 45 & 0.635 & 0.20 & 0.045 & 0.076 & 0010 & 0,050 & 0.064 & 0.008 & 27 & 0.075 & 0.008 \\
\hline 4110 & 4.00 & 45 & DSs & 029 & $\overline{0014}$ & 007 & 04 & 0032 & 0.07 & 0.005 & & & \\
\hline 4I10C & 5.76 & 73 & 063 & 8 & 00 & $16 \mathrm{Na}$ & 0,03 & goin & Wer & 0.007 & 0.018 & 0.092 & 0.008 \\
\hline $4110 b$ & 6.96 & 45 & 0.635 & 0.20 & 0.079 & 0EAT & 0.020 & 0.030 & 0.16 & 0.022 & 0.054 & 0.066 & 0.009 \\
\hline 4111 & 2.85 & 45 & 0.79 & 020 & 0.017 & 6014 & 0.15 & 0024 & 0.12 & 0.019 & & & \\
\hline 4111 & 3.94 & 45 & 6.798 & 05 & 0063 & 0.134 & 0.099 & 0.69 & 0679 & 0.012 & 0.039 & 0.081 & 0.013 \\
\hline A111C & 5.97 & 45 & 0.75 & 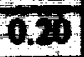 & $\mathrm{Org}^{2}$ & 1079 & 0.011 & 0.096 & 0.073 & 0.06 & 0.051 & 0.123 & 0.040 \\
\hline 4111 B & 6.81 & 45 & 0.793 & 0.20 & 0.052 & 0.101 & 0.021 & 0.060 & 0.073 & 0.013 & 0.024 & 0.091 & 0.010 \\
\hline aIm & 3.33 & $\mathrm{C}$ & 0,75 & 07 & Q0. & 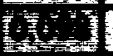 & 062 & 00. & DII & 0030 & 0.027 & 0.116 & 0.019 \\
\hline 4111 & 4.05 & 6 & 0.675 & 0.73 & 001 & (13) & 0032 & 0.051 & DES & 000 & 0.032 & 0.119 & 0.024 \\
\hline 4112C & 5.87 & 60 & 0.675 & 0.20 & 00050 & MUII & 010 & 0005 & 000 & 0.013 & 0059 & 0.086 & 0.017 \\
\hline 41120 & 7.50 & 60 & $6 \mathrm{RT}$ & 0.20 & 0.093 & 089 & 0.012 & 0.034 & 0.101 & 0.026 & 0.059 & 0.135 & 0.056 \\
\hline 41134 & 2.97 & 60 & 0.635 & 0.20 & 0.070 & 9157 & 0.05 & 0.053 & 0.069 & 0.010 & 0.065 & 0.069 & 0.012 \\
\hline 4113 & 3.77 & 60 & 0.635 & 0.20 & 0.077 & 0183 & 0105 & 0.010 & 0.102 & 0.029 & 0.032 & \begin{tabular}{|l|}
0.087 \\
\end{tabular} & 0.013 \\
\hline $4113 C$ & 6.30 & 60 & 0.635 & 0.20 & 0.161 & 0.175 & 0.194 & 0.072 & 0.141 & 0.056 & 0.099 & 0.112 & 0.049 \\
\hline 4113D & 7.12 & 60 & 0.635 & 0.20 & 0.051 & 0.161 & 0.069 & 0.125 & 0.095 & 0.044 & 0.102 & 0.079 & 0.025 \\
\hline$\$ 114 \mathrm{~A}$ & 3.13 & 60 & 0.795 & 0.20 & 0.114 & 0.113 & 0.059 & 0.094 & 0.134 & 0.066 & 0.093 & \begin{tabular}{|l|}
0.169 \\
\end{tabular} & 0.104 \\
\hline 1114 & 3.98 & 60 & 0.795 & 0.20 & 0.136 & 0001 & 0,09 & 0.101 & 0.093 & 0.034 & 0.085 & \begin{tabular}{|c|}
0.081 \\
\end{tabular} & 0.022 \\
\hline $1114 C$ & 5.92 & 60 & 0795 & 0.20 & 0.131 & 0.156 & 0.125 & 0.112 & 0.101 & 0.045 & 0.105 & \begin{tabular}{|l|l|}
0.115 \\
\end{tabular} & 0.055 \\
\hline 41140 & 7.40 & 60 & 0.79 & 020 & 0.095 & 0,13 & 0,129 & 0.091 & 0.116 & 0.111 & 0.101 & 0.078 & 0.024 \\
\hline $4115 A$ & 3.13 & 75 & 0.475 & 0.20 & 0.139 & 0.191 & 0.201 & 0.084 & 0.092 & 0.028 & 0.049 & 0.092 & 0.016 \\
\hline 4115B & 4.08 & 75 & 0.475 & 0.20 & 0.084 & 0.100 & 0.033 & 0.112 & 0.169 & 0.126 & 0.063 & 0.129 & 0.055 \\
\hline $4115 C$ & 6.06 & 75 & 0.475 & 0.20 & 0.195 & 0.145 & 0.161 & 0.139 & 0.091 & 0.045 & 0.139 & \begin{tabular}{|l|l|}
0.085 \\
\end{tabular} & 0.039 \\
\hline 4115D & 7.30 & 75 & 0.475 & 0.20 & 0.168 & 0.189 & 0.236 & 0.181 & 0.174 & 0.215 & 0.139 & 0.138 & 0.104 \\
\hline $4116 \mathrm{~A}$ & 2.92 & 75 & 0635 & 020 & 0.171 & 0.146 & 0.143 & 0.161 & 0.175 & 0.194 & 0.052 & 0.118 & 0.038 \\
\hline 4110 & 4.84 & 7 & 96 & 12 & 0.108 & 013 & $0, \overline{106}$ & 0.123 & 0.212 & 0.217 & 0.068 & \begin{tabular}{|l|}
0.181 \\
\end{tabular} & 0.117 \\
\hline $4116 C$ & 6.24 & 75 & 0.635 & 0.20 & G.TI & 0.292 & 0.506 & 0.174 & 0.19 & 0.249 & 0.166 & 0.192 & 0.240 \\
\hline 41160 & 7.36 & 75 & $\mathbf{0 . 6 3 5}$ & 0.20 & 0321 & (DEA & 0,79 & 0.271 & 0.222 & 0.524 & 0.139 & 0.101 & 0.056 \\
\hline $4117 A$ & 3.11 & 75 & 0.795 & 0.20 & 0.178 & 0.201 & $0 \%$ & a.tog & 0.134 & 0.119 & 0.139 & 0.125 & 0.085 \\
\hline 4117 & 4.05 & 75 & 0.795 & 0.20 & 0.500 & DS9 & 0.496 & 0.180 & 6.1.1 & 0.121 & 0.179 & 0.129 & 0.117 \\
\hline$\$ 117 \mathrm{C}$ & 6.03 & 75 & 0.795 & 0.20 & 0.489 & 0.181 & 0.629 & 0.534 & 0.182 & 0.695 & 0.327 & \begin{tabular}{|l|}
0.177 \\
\end{tabular} & 0.402 \\
\hline 4117D & 7.20 & 75 & 0.795 & 0.20 & 0.477 & 0.176 & 0.580 & 0.384 & 0.139 & 0.291 & 0.231 & 0.141 & 0.180 \\
\hline
\end{tabular}


Table C-3 Measured Crater Depths and Diameters, Calculated Crater Volumes NASAMSFC EH Test Series

\begin{tabular}{|c|c|c|c|c|c|c|c|c|c|c|c|c|c|}
\hline $\begin{array}{l}\text { Teat } \\
\text { Na. }\end{array}$ & $\begin{array}{c}V_{p} \\
(\mathrm{~km} / \mathrm{s})\end{array}$ & $\begin{array}{c}\theta_{p} \\
\left(d_{e g}\right)\end{array}$ & $\begin{array}{c}d_{p} \\
(\mathrm{~cm})\end{array}$ & $(c+m)$ & $\begin{array}{c}\mathbf{P}_{1} \\
(\mathrm{~cm})\end{array}$ & $\begin{array}{c}d_{1} \\
(c m)\end{array}$ & $\begin{array}{c}\mathrm{Vol}_{1} \\
\left(\times 10^{-2} \mathrm{~cm}^{3}\right)\end{array}$ & $\begin{array}{c}\mathbf{p} \\
(\mathrm{cm})\end{array}$ & $\begin{array}{c}d_{2} \\
(c m)\end{array}$ & $\begin{array}{c}\mathrm{Vol} \mathrm{l}_{2} \\
\left(\mathrm{x} 10^{-2} \mathrm{~cm}^{3}\right)\end{array}$ & $\begin{array}{c}\mathbf{P}_{3} \\
(\mathrm{~cm})\end{array}$ & $\begin{array}{c}d_{3} \\
(\mathrm{~cm})\end{array}$ & $\begin{array}{c}\text { Vols } \\
\left(10^{-2} \mathrm{~cm}^{3}\right)\end{array}$ \\
\hline ERAB & 6.91 & 75 & 0.795 & 0.16 & 0.615 & 0.734 & 13.011 & 0.368 & 0.686 & 6.801 & 0.483 & 0.566 & 6.076 \\
\hline LEPB & 7.22 & 75 & 0.635 & 0.16 & 0.495 & 0.650 & 8.213 & 0.361 & 0.602 & 5.138 & 0.310 & 0.445 & 2.411 \\
\hline EEPC & 7.58 & $\overline{75}$ & 0.475 & 0.16 & 0.386 & 0.599 & 5.439 & 0.318 & 0.447 & 2.495 & 0.345 & 0.422 & 2.413 \\
\hline PARP1 & 6.87 & 60 & 0.795 & 0.16 & 0.140 & 0.254 & 0.355 & 0.094 & 0.241 & 0.286 & 0.117 & 0.244 & 0.365 \\
\hline EARP2 & 6.80 & 65 & 0.795 & 0.16 & 371 & 0.632 & 5,819 & 0.229 & 0.445 & 1.781 & 211 & 0.445 & 2.188 \\
\hline LARP3 & 6.78 & 45 & 0.795 & 0.16 & 0.165 & 0.368 & 1.170 & 0.150 & 0.320 & 0.804 & 0.135 & 0.343 & 0.832 \\
\hline DERP4 & 7.65 & 60 & 0.635 & 0.16 & 0.152 & 0.279 & 0.465 & 0.216 & 0.371 & 1.168 & 0.157 & 0.328 & 0.884 \\
\hline ERRPS & 7.51 & 65 & 0.635 & 0.16 & 0.305 & 0.528 & 3.339 & 0.330 & 0.546 & 3.863 & 0.203 & 0.411 & 1.795 \\
\hline EARP6 & 7.57 & 45 & 0.635 & 0.16 & 0.097 & 0.201 & 0.205 & 0.114 & 0.267 & 0.426 & 0.084 & 0.211 & 0.196 \\
\hline EHRP7 & 7.98 & 60 & 0.475 & 0.16 & 0.323 & 0.488 & 3.021 & 0.254 & 0.396 & 1.564 & 0.203 & 0.465 & 2.298 \\
\hline EHRP8 & 7.34 & 45 & 0.475 & 0.16 & 0.155 & 0.262 & 0.418 & 0.137 & 0.279 & 0.558 & 0.168 & 0.295 & 0.574 \\
\hline EHRP9 & 7.29 & 65 & 0.475 & 0.16 & 0.108 & 0.221 & 0.276 & 0.096 & 0.266 & 0.356 & 0.089 & 0.197 & 0.181 \\
\hline BASS4C & 5.53 & 45 & 0.635 & 0.16 & 0.078 & 0.126 & 0.049 & 0.074 & 0.139 & 0.056 & 0.045 & 0.088 & 0.014 \\
\hline
\end{tabular}




\section{APRDNDX D}

\section{IMPRICAL DETTH AND DIAMITHRS EQUATIONS}


Penetration Depth Equations

$$
\begin{aligned}
& \mathrm{p} / \mathrm{d}=2.28\left(\rho_{\mathrm{p}} / \rho_{\mathrm{b}}\right)^{2 / 3}\left(\mathrm{~V}_{\mathrm{p}} / \mathrm{C}_{\mathrm{b}}\right)^{2 / 3} \\
& \mathrm{p} / \mathrm{d}=1.96\left(\rho_{\mathrm{p}} / \rho_{\mathrm{b}}\right)^{1 / 2}\left(\mathrm{~V}_{\mathrm{p}} / \mathrm{C}_{\mathrm{b}}\right)^{2 / 3} \\
& \mathrm{p} / \mathrm{d}_{\mathrm{p}}=1.50\left(\rho_{\mathrm{p}} / \rho_{\mathrm{b}}\right)^{1 / 3}\left(\rho_{\mathrm{p}} \mathrm{V}_{\mathrm{p}}^{2} / 2 \mathrm{~S}_{\mathrm{b}}\right)^{1 / 3} \\
& p / d_{p}=2.35\left(\rho_{p} / \rho_{b}\right)^{0.70}\left(V_{p} / C_{b}\right)^{2 / 3} \\
& p / d_{p}=0.63\left(\rho_{p} V_{p}^{2} / S_{y}\right)^{1 / 3} \\
& p / d_{p}=0.428\left(\rho_{p} / \rho_{b}\right)^{0.537}\left(V_{p} / C_{b}\right)^{0.576}\left(Y_{b} / \rho_{b} C_{b}^{2}\right)^{-0.235} \\
& \mathrm{p} / \mathrm{d}_{\mathrm{p}}=8.355 \times 10^{-4} \mathrm{pp} 2 / 3 \mathrm{\rho b}-1 / 3\left(\mathrm{~V}_{\mathrm{p}}^{2} / \mathrm{H}_{\mathrm{b}}\right)^{1 / 3} \\
& \mathrm{p} / \mathrm{d}_{\mathrm{p}}=2.00\left(\rho_{\mathrm{p}} / \rho_{\mathrm{b}}\right)^{4.52}\left(\mathrm{~V}_{\mathrm{p}} / \mathrm{C}_{\mathrm{b}}\right)^{1 / 136} \\
& p / d_{p}=0.311\left(\rho_{p} / \rho_{b}\right)^{0.17}\left(\rho_{p} V_{p}{ }^{2} / S_{b}\right)^{1 / 3} \\
& p / d_{p}=0.36\left(\rho_{p} / \rho_{b}\right)^{2 / 3}\left(\rho_{p} V_{p}^{2} / B_{b}\right)^{1 / 3} \\
& p=2.973 \times 10^{-7} \mathrm{~d}_{\mathrm{p}}^{1.1} \mathrm{H}_{b}^{-0.25} \rho_{\mathrm{p}}^{0.5} \rho_{b}^{-0.167} \mathrm{~V}_{\mathrm{p}}^{43} \\
& p=1.129 \times 10^{-6} d_{p}^{1.056} \mathrm{H}_{b}^{-0.25} P_{p}{ }^{0.5} \rho_{b}^{-0.167} E_{l}^{-0.33} V_{p}{ }^{4 / 3}
\end{aligned}
$$

\section{Crater Mouth Diameter Equations}

$$
\begin{aligned}
& \alpha d^{2} p / d_{p}^{3}=34\left(\rho_{p} / \rho_{b}\right)^{3 / 2}\left(V_{p} / C_{b}\right)^{2} \\
& \alpha d^{2} p / d_{p}^{3}=0.120\left(\rho_{p} / \rho_{b}\right)^{1 / 2}\left(\rho_{p} V_{p}^{2} / S_{b}\right)^{0.245} \\
& \alpha d^{2} p / d_{p}^{3}=30.25\left(\rho_{p} / \rho_{b}\right)^{3 / 2}\left(V_{p} / C_{b}\right)^{2} \\
& \alpha d^{2} p / d_{p}^{3}=44.10\left(\rho_{p} / \rho_{b}\right)^{3 / 2}\left(V_{p} / C_{b}\right)^{2} \\
& \alpha d^{2} p^{3} / d_{p}^{3}=2.65 \times 10^{-9} \rho_{p}{ }^{7 / 6} \rho_{b}^{-1 / 2} V_{p}^{4 / 3} / H_{b} \\
& \alpha d^{2} p / d_{p}^{3}=0.16\left(\rho_{p} / \rho_{b}\right)^{2 / 3} \rho_{p} V_{p}^{2} / B_{b}
\end{aligned}
$$

where $\alpha=0.75$ if $p>d / 2$ and $\alpha=1.00$ if $p<d / 2$. 


\section{APPTNDIX E}

\section{CALCULATED RICOCEITT PARTICLE VELOCTIES AND DIAMETERS}




\begin{tabular}{|c|c|c|c|c|c|c|c|c|c|c|c|}
\hline Test No. & p & d & V7-14 & D7-14 & $D 7-14 / d$ & $\overline{V 10-14}$ & D10-14 & $10-14 / d$ & $12-14$ & D2-14 & 14/d \\
\hline No. & (cm) & $(\mathrm{cm})$ & & & & & & & & & \\
\hline EHAB & 0.615 & 0.734 & & & & & & & & & \\
\hline EHPB & 0.495 & 0.650 & & & & & & & & & \\
\hline EHPC & 0.386 & 0.599 & & & & & & & 3.828 & 0.237 & 0.395 \\
\hline EHAP1 & 0.117 & 0.244 & 3.9 & 0.094 & 0.387 & 7.520 & 0.066 & 0.269 & & & \\
\hline EHAP2 & 0.371 & 0.632 & & & & & & & 2.097 & 0.340 & 0.537 \\
\hline EHAP3 & 0.165 & 0.368 & 2.5 & 0.178 & 0.483 & $4.87 t$ & 0.124 & 0.336 & & & \\
\hline EHAP4 & 0.216 & 0.371 & & & & & & & 1.989 & 0.205 & 0.552 \\
\hline EHAP5 & 0.330 & 0.546 & & & & & & & 2.531 & 0.266 & 0.488 \\
\hline EHAP6 & 0.114 & 0.267 & 1.8 & 0.152 & 0.568 & 3.556 & 0.105 & 0.39 & & & \\
\hline EHRP7 & 0.323 & 0.488 & & & & & & & 349 & 0.176 & 362 \\
\hline EHRP8 & 0.137 & 0.278 & 4.61 & 0.100 & 35 & 8.766 & 0.069 & 0.249 & & & \\
\hline EHAP9 & 0.244 & 0.676 & & & & 1.202 & 0.465 & 0.688 & & & \\
\hline EHSS4C & 0.188 & 0.353 & & & & & & & 116 & 0.262 & .742 \\
\hline 001B & 0.117 & 0.257 & 2.8 & 118 & 0.459 & 5.394 & 0.082 & 0.319 & & & \\
\hline $002 B$ & 0.084 & 0.287 & & & & & & & & & \\
\hline $201 \mathrm{~A}$ & 0.071 & 0.180 & it & 0.133 & 0.738 & 30 & & & & & \\
\hline 205A & 0.122 & 0.224 & & & & & & & 1.306 & 0.153 & 0.685 \\
\hline $205 C$ & 0.084 & 0.180 & 3.22 & 0.077 & 0.429 & 6.149 & 0.054 & 0.298 & & & \\
\hline 205D & 0.074 & 0.234 & & & & & & & & & \\
\hline 205E & 0.058 & 0.226 & & & & & & & & & \\
\hline $206 E$ & 0.030 & 0.178 & & & & & & & & & \\
\hline $206 \mathrm{~F}$ & 0.094 & 0.155 & & & & & & & 2.590 & 0.075 & 0.482 \\
\hline $211 B$ & 0.147 & 0.267 & & & & & & & 1.416 & 0.175 & 0.657 \\
\hline 211D & 0.132 & 0.267 & 4.86 & 093 & 348 & 9.261 & & 242 & & & \\
\hline 212B & 0.079 & 0.244 & & & & & & & & & \\
\hline $216 A$ & 0.097 & 0.284 & & & & 0.807 & 0.240 & 0.844 & & & \\
\hline $216 C$ & 0.147 & 0.333 & 2.36 & 0.168 & 0.504 & 4.495 & 0.117 & 0.350 & & & \\
\hline $217 \mathrm{~A}$ & 0.091 & 0.249 & 0.70 & 0.232 & 0.933 & 1.348 & 0.162 & 0.649 & & & \\
\hline $217 \mathrm{~B}$ & 0.196 & 0.234 & & & & & & & & & \\
\hline $217 \mathrm{C}$ & 0.091 & 0.193 & 3. & 0.078 & 403 & 6.850 & 0.054 & 0.280 & & & \\
\hline 2170 & 0.074 & 0.224 & & & & & & & & & \\
\hline 217E & 0.046 & 0.180 & & & & & & & & & \\
\hline 218A & 0.102 & 0.292 & & & & & 0.227 & $m$ & & & \\
\hline $218 \mathrm{C}$ & 0.160 & 0.307 & & & & & & & 0.967 & 0.245 & 0.799 \\
\hline 221B & 0.051 & 0.193 & & & & & & & & & \\
\hline $221 C$ & 0.030 & 0.081 & & & 87 & 3 & 0.049 & 0.609 & & & \\
\hline $226 A$ & 0.010 & 0.157 & & & & & & & & & \\
\hline $226 \mathrm{~B}$ & 0.069 & 0.249 & & & & & & & & & \\
\hline $227 \mathrm{~A}$ & 0.259 & 0.216 & & & & & & & & & \\
\hline 227B & 0.069 & 0.208 & & & & 0.665 & 0.194 & 0.031 & & & \\
\hline $230 B$ & 0.097 & 0.218 & 2.3 & 0.111 & 0.507 & 4.437 & 0.077 & 0.353 & & & \\
\hline $230 C$ & 0.076 & 0.229 & & & & 0.720 & 0.204 & 0.894 & & & \\
\hline 2300 & 0.114 & 0.224 & & & & & & & 86 & 0.189 & 0.847 \\
\hline $230 E$ & 0.109 & 0.284 & 0.9 & 0.229 & 0.806 & 1.702 & 160 & 0.561 & & 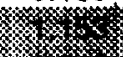 & \\
\hline $301-$ & 0.066 & 0.218 & & & & & & & & & \\
\hline 303. & 0.198 & 0.257 & & & & & & & & & \\
\hline $303 \mathrm{~A}$ & 0.041 & 0.333 & & & & & & & & & \\
\hline 303B & 0.191 & 0.188 & & & & & & & & & \\
\hline $319-$ & 0.074 & 0.213 & & & & 0.003 & 0.170 & 0.797 & & & \\
\hline 321- & 0.180 & 0.231 & & & & & & & & & \\
\hline$\frac{324-}{325-}$ & \begin{tabular}{|l|}
0.064 \\
0.066 \\
\end{tabular} & $\frac{0.224}{0.224}$ & & & & & & & & & \\
\hline $326-$ & 0.267 & 0.384 & & & & & & & 6.255 & 0.118 & 0.307 \\
\hline 333- & 0.051 & 0.173 & & & & & & & & & \\
\hline 334- & 0.030 & 0.079 & & & & 1.889 & 0.043 & 0.546 & 8 & & 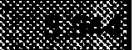 \\
\hline 335- & 0.048 & 0.170 & & & & m & $x$ & m.n.m. & $4 x$ & 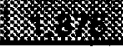 & \% \\
\hline
\end{tabular}




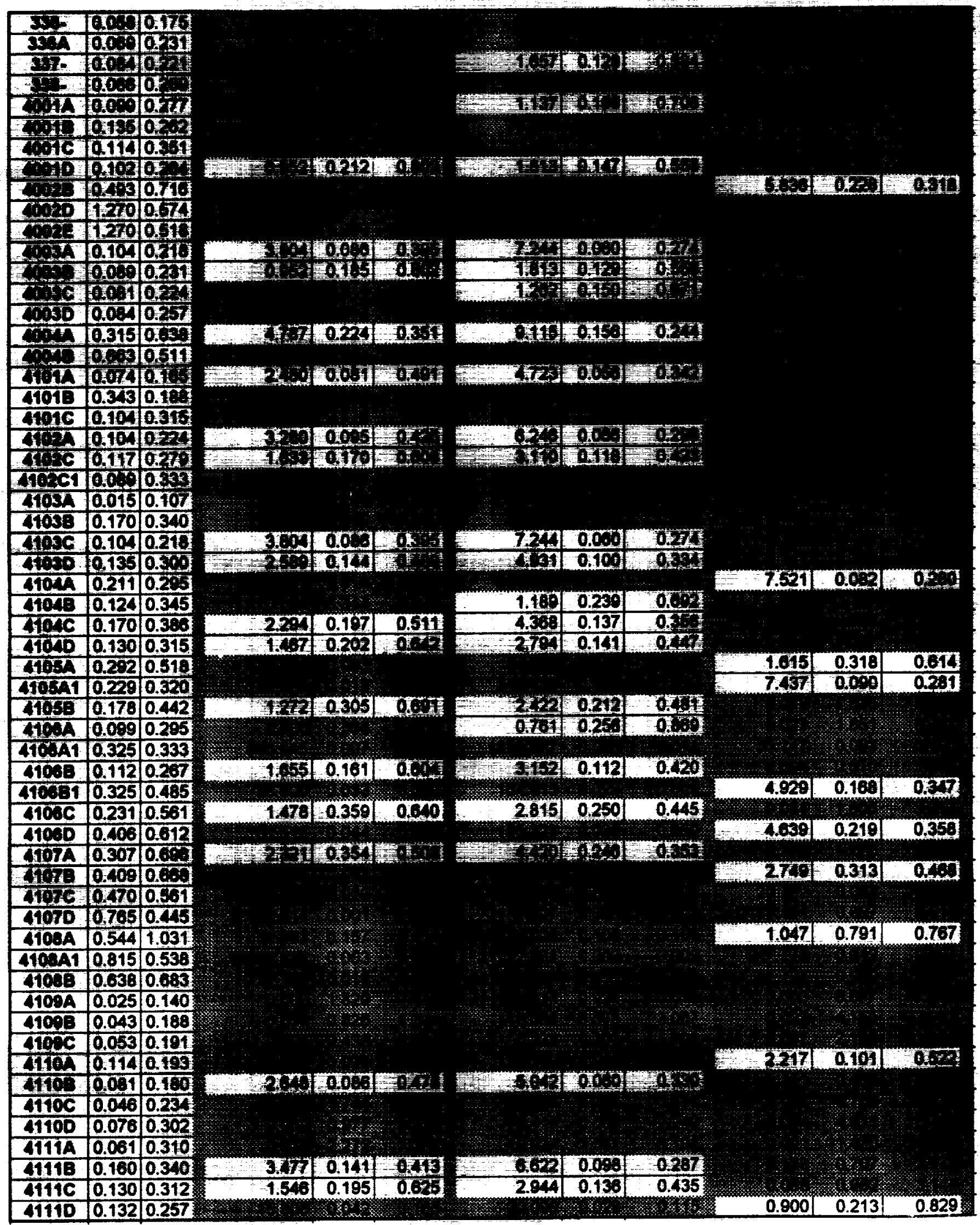




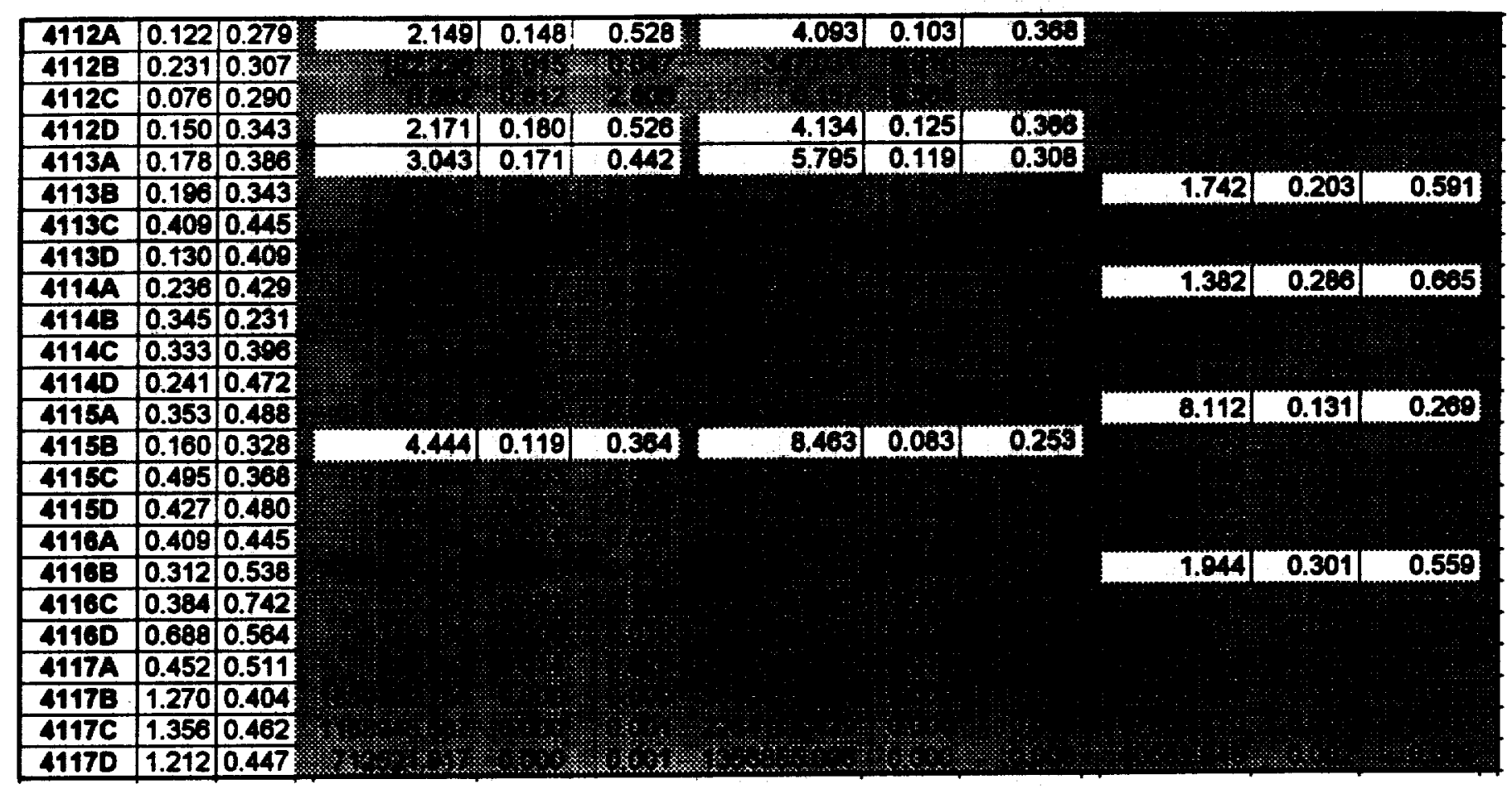




\begin{tabular}{|c|c|c|c|c|c|c|c|c|c|c|}
\hline Tals & P & $d$ & $\sqrt{814}$ & Bat & Ds-14d: & VEI & DI-14; D1-14d & V4-14 & D4-14 & D4-14d \\
\hline 15 & Eat & $(6,)^{2}$ & & & & & & & & \\
\hline Ditr & ODIs & 672 & & & & पा! & 0.37 & & 0.328 & 0.447 \\
\hline$\overline{T I S}$ & $0 \times$ & $6 \mathrm{CO}$ & 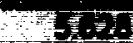 & 2810 & $0.3 \mathrm{~s}$ & 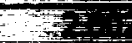 & GDO & & No: & Q11 \\
\hline & 10.3 & $\mathrm{at}$ & ET & 15 & 0.32 & & & & & \\
\hline Atit & $\frac{0.74}{0.619}$ & $\frac{689}{1+56}$ & 6 & $=0 \cos$ & $7 x^{7}$ & & & & & \\
\hline$\frac{1}{3}+\frac{2 x}{2}$ & $\frac{1}{A+13}$ & astas & & & & & & & & \\
\hline Hid & 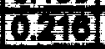 & tas & & 0 Bou & OAtin & & & & & \\
\hline$F_{i 21}$ & Dob & 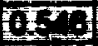 & & 65 & 072 & & & & & \\
\hline$\frac{T}{1}$ & $\frac{6 \pi}{6,3 x}$ & 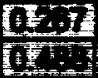 & & & Bis? & & $x_{n}$ & W. & 0.475 & 0.072 \\
\hline H. & 0111 & 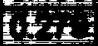 & & & & & & & & \\
\hline $\operatorname{Ein}$ & 0,21 & totian & & & & & & & & \\
\hline$\frac{1}{1}+\frac{10}{1}$ & 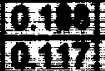 & $0+\frac{1}{10}$ & & & & & & & & \\
\hline & 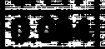 & 10 & & & & & & & & \\
\hline $8 \mathrm{II}$ & Q07 & d. & & & & & & & & \\
\hline 7.3 & $\frac{645}{15}$ & EI & & & & & & & & \\
\hline 3 & 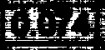 & to & & & & & & & & \\
\hline 31 & $\mathrm{CxO}$ & $u=$ & & & & & & & & \\
\hline $2+5$ & 6อd & Q1: & & & & & & & & \\
\hline 217 & atid & TE: & 18 & twi? & A & & & & & \\
\hline काT & 0.147 & 0.2 .7 & & & & & & & & \\
\hline 2110 & 0.132 & 0.207 & & & & & & & & \\
\hline 213 & 0.079 & 0.24 & & & & & & & & \\
\hline $216 \mathrm{~A}$ & 0.007 & 0.28 & & & & & & & & \\
\hline $216 C$ & 0.147 & 0.333 & & & & & 85 & & & \\
\hline $217 \mathrm{~A}$ & 0.091 & 0.249 & & & & & & & & \\
\hline 2178 & 0.186 & 0.234 & & & & AT: & 0.300 & 3.5 & 0.105 & 0.49 \\
\hline $217 \mathrm{C}$ & 0.091 & 0.193 & & & & & & & & \\
\hline 2170 & 0.074 & 0.21 & & & & & & & & \\
\hline 217E & 0.046 & 0.180 & & & & & & & & \\
\hline $21 \mathrm{AA}$ & 0.102 & 0.292 & & & & & & & & \\
\hline $218 C$ & 0.160 & 0.307 & & & & & & & & \\
\hline $221 \mathrm{~B}$ & 0.051 & 0.193 & & & & & & & & \\
\hline $221 \mathrm{C}$ & 0.030 & 0.001 & & & & & & & & \\
\hline $220 a$ & 0.010 & 0.157 & & & & & & & & \\
\hline 223 & 0.069 & 0.240 & & & & & & & & \\
\hline $227 \mathrm{~A}$ & 0.259 & 0.216 & & & & & & & & \\
\hline $29 B$ & 0.030 & 0.200 & & & & & & & & \\
\hline 2308 & 0.097 & 0.218 & & & & & & & & \\
\hline $2 \overline{0 C}$ & 0.076 & 0.229 & & & & & & & & \\
\hline 2300 & 0.114 & 0.224 & & & & & & & & \\
\hline $230 E$ & 0.109 & 0.284 & & & & & & & & \\
\hline 301 & 0.066 & 0.218 & & & & & & & & \\
\hline 303 & 0.198 & 0.257 & 6.160 & 0.082 & 0.321 & 2.84 & 0.496 & 212 & 0.150 & 0.584 \\
\hline $303 A$ & 0.041 & 0.333 & & & & & & & & \\
\hline 3038 & 0.191 & 0.180 & & & & & & & & \\
\hline $310-$ & 0.074 & 0.213 & & & & & & & & \\
\hline 321. & 0.180 & 0.231 & $6 \mathrm{~S}_{3}$ & 0.072 & 0.310 & 31 & 0.479 & 2.27 & 0.131 & 0.505 \\
\hline 324 & 0.064 & 0.224 & & & & & & & & \\
\hline 326 & 0.066 & 0.224 & & & & & & & & \\
\hline 326 & 0.207 & 0.39 & 3.150 & 0.174 & 0.7 & $F$ & 0.701 & 10 & 0.317 & 0.020 \\
\hline 333 & 0.051 & 0.173 & & & & & & & & \\
\hline 35 & 0.030 & 0.079 & & & & & & & & \\
\hline 338 & 0.048 & 0.170 & & & & & $x=$ & & & \\
\hline
\end{tabular}




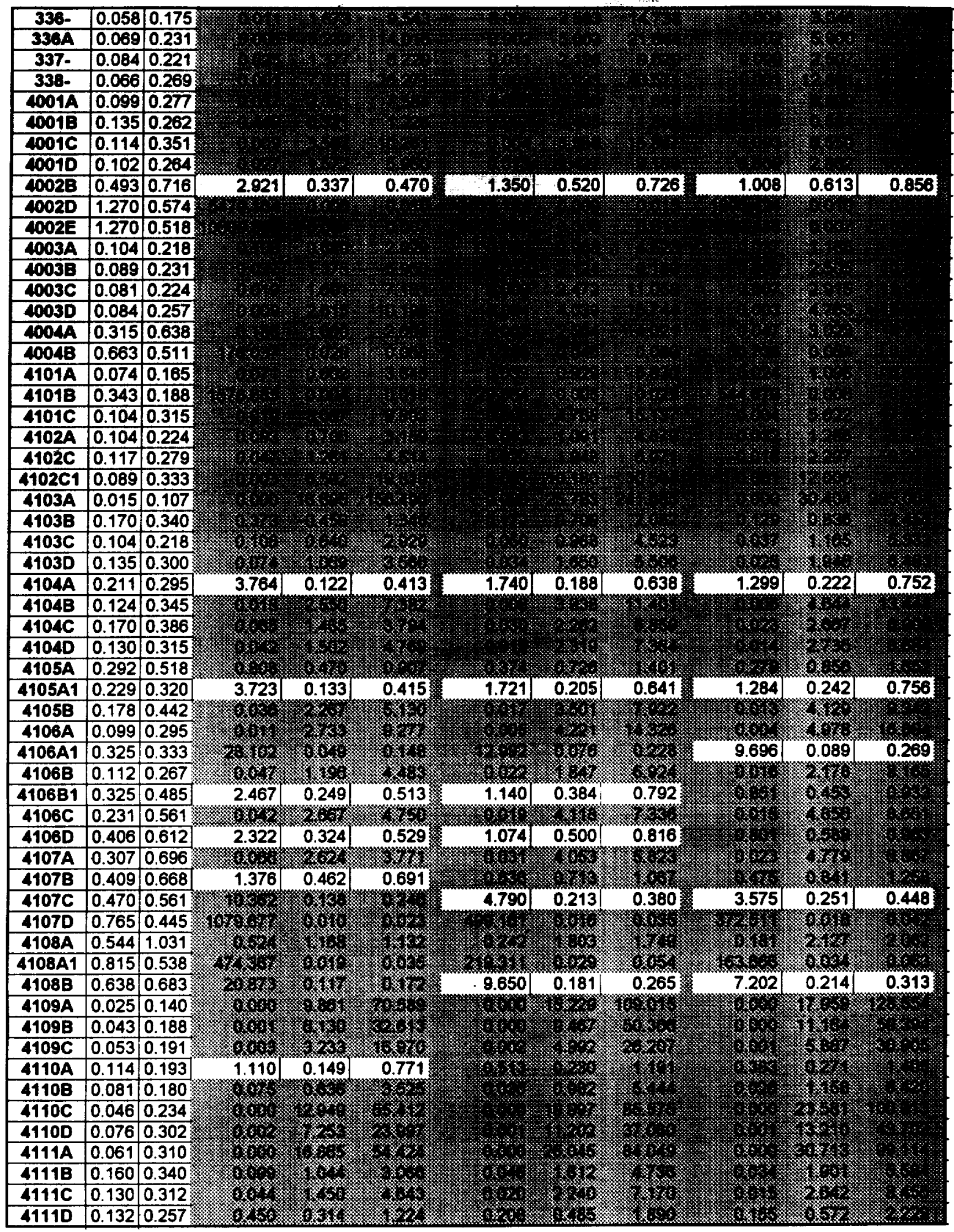




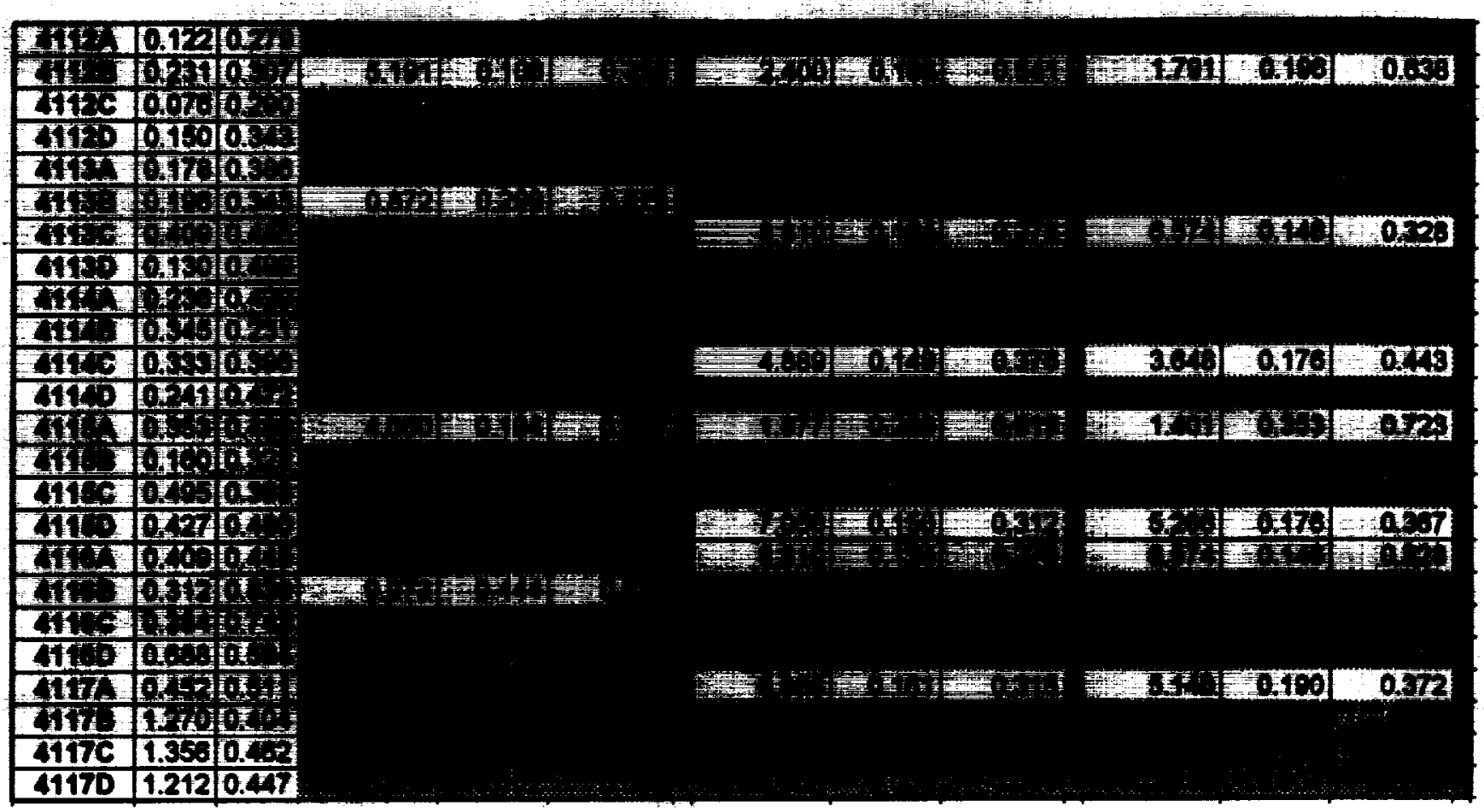




\begin{tabular}{|c|c|c|c|c|c|c|c|c|c|c|}
\hline Test No. & $\mathbf{p}$ & d & V3-14 & D3-14 & $D 3-14 / d$ & V9-13 & $D 9 \cdot 13$ & D9-13/d & V6-13 & D6-13 \\
\hline No. & $(\mathrm{cm})$ & $(\mathrm{cm})$ & & & & & & & & \\
\hline EHAB & 0.615 & 0.734 & & & & & & & & \\
\hline EHPB & 0.495 & 0.650 & & & & & & & (3) & 4 \\
\hline EHPC & 0.386 & 0.599 & & & & & & & & \\
\hline EHAP1 & 0.117 & 0.244 & 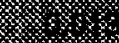 & & & & & & 1.352 & 0.142 \\
\hline EHRP2 & 0.371 & 0.632 & & & & & & & 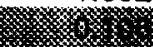 & \\
\hline EHRP3 & 0.165 & 0.368 & 25 & & & 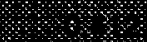 & & & 2.216 & 0.150 \\
\hline EHRP4 & 0.216 & 0.371 & 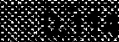 & & & & & & & \\
\hline EHRP5 & 0.330 & 0.546 & & & & & & & & \\
\hline EHRP6 & 0.114 & 0.267 & & & & & & & 3.175 & 0.084 \\
\hline EHRP7 & 0.323 & 0.488 & & & & & & & to & \\
\hline EHRP8 & 0.137 & 0.279 & & & & & & & 1.136 & 0.184 \\
\hline EHRP9 & 0.244 & 0.676 & & & & 1.841 & & 0.430 & & \\
\hline EHSS4C & 0.188 & 0.353 & & & & & & & & \\
\hline 001B & 0.117 & 0.257 & & & & & & & 1.975 & 0.114 \\
\hline $002 B$ & 0.084 & 0.287 & $4 \%$ & & & 7.931 & 0.043 & 0.151 & & \% \\
\hline $201 \mathrm{~A}$ & 0.071 & 0.180 & & & & 0.999 & 0.120 & 0.666 & 5.693 & 0.038 \\
\hline $205 A$ & 0.122 & 0.224 & 玟 & & & & & & (x) & \\
\hline $205 C$ & 0.084 & 0.180 & \% & & & & & & 1.701 & 0.089 \\
\hline 205D & 0.074 & 0.234 & 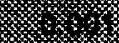 & & & 4.683 & 0.052 & 0.221 & & \% \\
\hline 205E & 0.058 & 0.226 & & & & 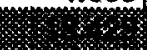 & & & & 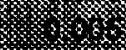 \\
\hline $206 E$ & 0.030 & 0.178 & & & & & & & & \\
\hline $206 \mathrm{~F}$ & 0.094 & 0.155 & 0.148 & 0.375 & 7 & & & & & $8 \%$ \\
\hline $211 B$ & 0.147 & 0.267 & & & & & & & & 3. \\
\hline 211D & 0.132 & 0.267 & x & & & & & & 1.067 & 0.183 \\
\hline 212B & 0.079 & 0.244 & & & & 3.965 & 0.061 & 0.249 & & \\
\hline $216 A$ & 0.097 & 0.284 & & & & 2.819 & 0.090 & 0.317 & & $x$ \\
\hline $216 C$ & 0.147 & 0.333 & & & & & & & 2.431 & 0.127 \\
\hline $217 A$ & 0.091 & 0.249 & 4 & $m$ & & 1.630 & 0.117 & 0.469 & 9.593 & 0.036 \\
\hline $217 \mathrm{~B}$ & 0.196 & 0.234 & 1.181 & 0.195 & 0.394 & & & & x & 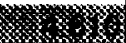 \\
\hline $217 C$ & 0.091 & 0.193 & & & & & & & 1.479 & 0.105 \\
\hline 2170 & 0.074 & 0.224 & & & & 3.446 & 0.061 & 0.275 & $2 \times$ & 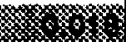 \\
\hline 217E & 0.046 & 0.180 & & & & - & & & t) & \\
\hline 218A & 0.102 & 0.292 & & & & 2.375 & 0.105 & 0.358 & (4) & \\
\hline $218 C$ & 0.160 & 0.307 & & & & & & & & \\
\hline 221B & 0.051 & 0.193 & & & & & & & & \\
\hline $221 C$ & 0.030 & 0.081 & & & & 1.414 & 0.042 & 0.519 & 8.243 & 0.013 \\
\hline $226 A$ & 0.010 & 0.157 & & & & & & & & \\
\hline $226 B$ & 0.069 & 0.249 & & & & & & & & \\
\hline $227 A$ & 0.259 & 16 & & & & & & & & 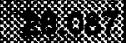 \\
\hline 2278 & 0.069 & 0.208 & & & & 3.467 & 0.057 & 0.274 & 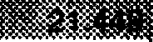 & $\%$ \\
\hline 2308 & 0.097 & 0.218 & & & & & & x & 2.467 & 0.083 \\
\hline $230 \mathrm{C}$ & 0.076 & 0.229 & & & & 3.185 & 0.066 & 0.291 & 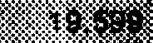 & 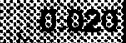 \\
\hline 2300 & 0.114 & 0.224 & & 48 & & & $\%$ & 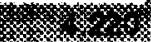 & 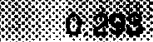 & 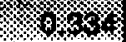 \\
\hline $230 E$ & 0.109 & 0.284 & 6. & 玟 & & 1.202 & 0.166 & 0.583 & 6.934 & 0.052 \\
\hline 301- & 0.066 & 0.218 & & & & $6.246 \mathrm{~J}$ & 0.039 & 0.180 & $46.10 \%$ & 0011 \\
\hline 303- & 0.198 & 0.257 & 0.703 & 0.280 & 0.564 & & & (4) & 801018 & 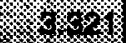 \\
\hline 303A & 0.041 & 0.333 & & & & & & & r. & 8088 \\
\hline $303 \mathrm{~B}$ & 0.191 & 0.188 & 4.059 & 0.084 & & & & & & 8.80 \\
\hline 319- & 0.074 & 0.213 & & & & 2.501 & 0.074 & 0.346 & & 6 \\
\hline $321-$ & 0.180 & 0.231 & 0.751 & 0.244 & 0.491 & 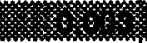 & & & & 8 \\
\hline 324- & 0.064 & 0.224 & & $\%$ & & 9.592 & 0.030 & 0.132 & & 8 \\
\hline 325- & 0.066 & 0.224 & & & & 7.319 & 0.036 & 0.160 & & X \\
\hline 326- & 0.267 & 0.384 & 0.357 & 0.591 & 1.192 & & 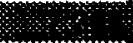 & & & \\
\hline 333- & 0.051 & 0.173 & & & & 7.551 & 0.027 & 0.157 & & 1. \\
\hline 334- & 0.030 & 0.079 & & & & 1.136 & 0.048 & 0.608 & 6.527 & 0.015 \\
\hline 335- & 0.048 & 0.170 & & & & 9.711 & 0.022 & 0.131 & 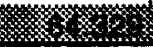 & 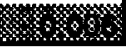 \\
\hline
\end{tabular}




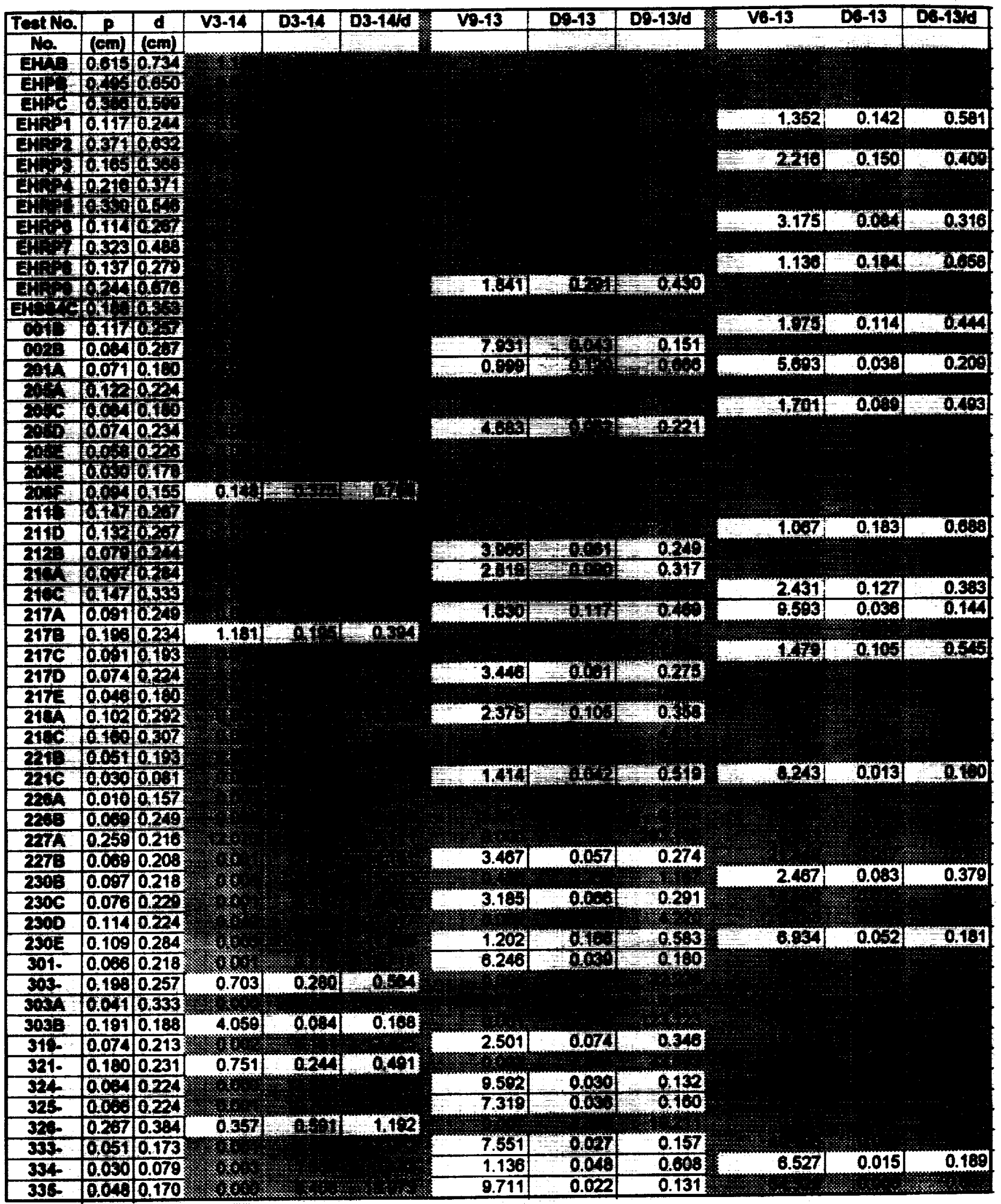




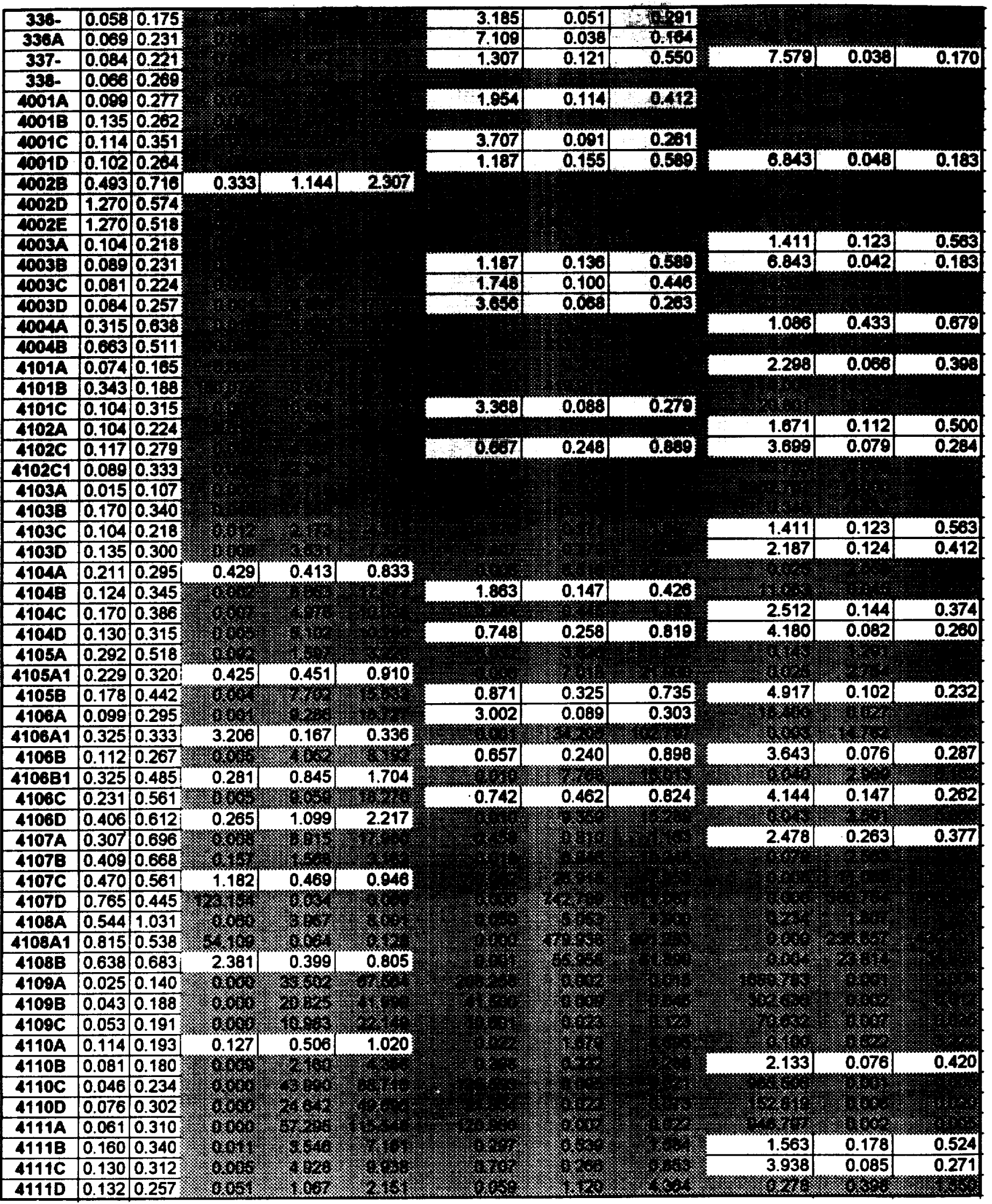




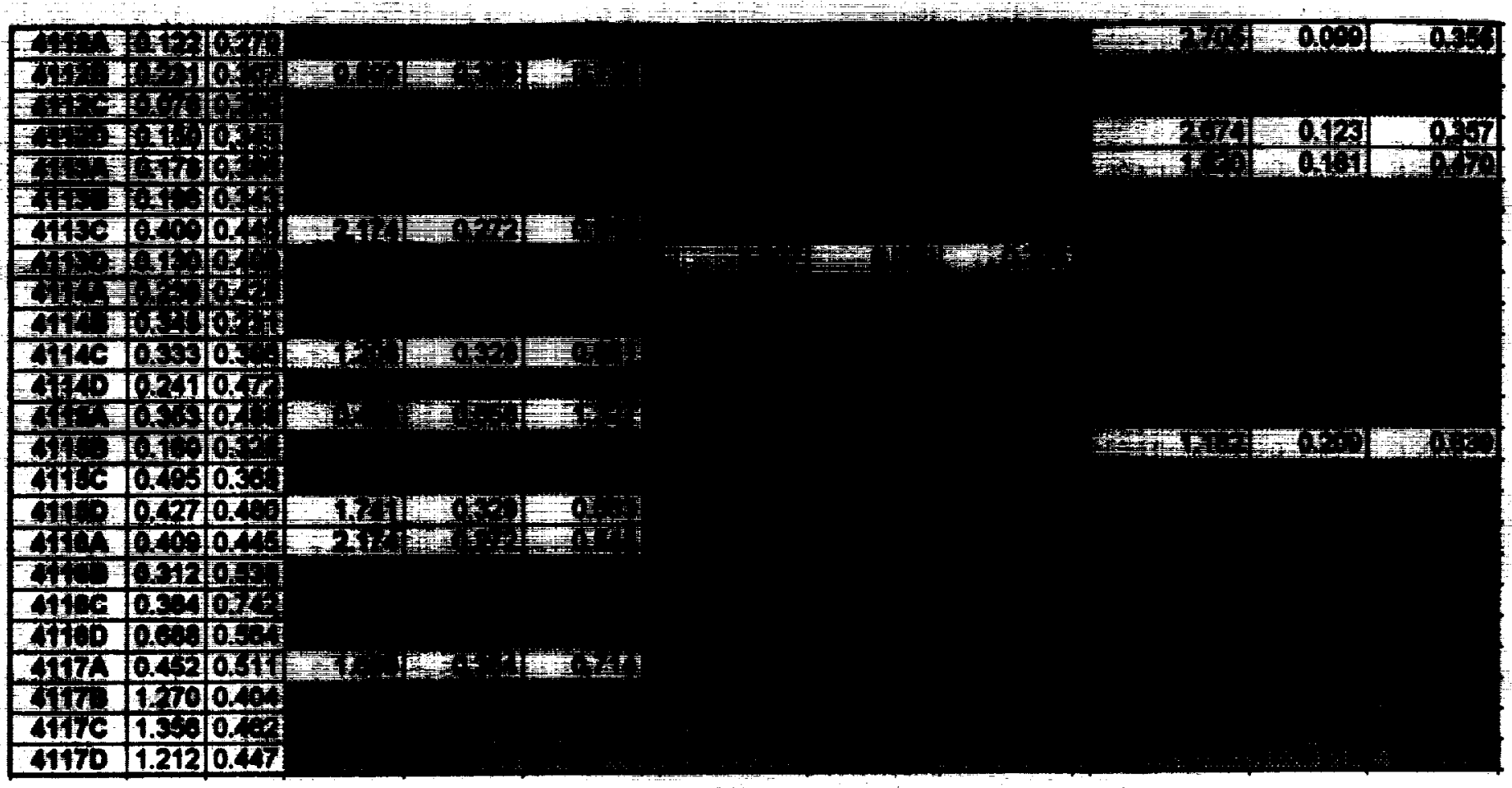




\section{APPENDIX F}

CALCULATTD RICOCHET PARTICLE MAX-MIN COMBINATIONS 
Table F-1 Calculated Ricochet Particle Max-Min Combinations Phase B NASAMMSFC Test Series

\begin{tabular}{|c|c|c|c|c|c|c|c|c|}
\hline $\begin{array}{l}\text { Test } \\
\text { No. }\end{array}$ & $\begin{array}{c}V_{p} \\
(\mathrm{~km} / \mathrm{s})\end{array}$ & $\begin{array}{c}\theta_{p} \\
\text { (dep) }\end{array}$ & $\begin{array}{c}d_{p} \\
(\mathrm{~cm})\end{array}$ & (cm) & $\begin{array}{l}V_{\max } \\
(\mathbf{k m} / \mathrm{s}\end{array}$ & $\begin{array}{l}d_{m} \\
(\mathrm{~cm})\end{array}$ & $\begin{array}{c}V_{\min } \\
(\mathbf{k m} / \mathbf{s})\end{array}$ & $\begin{array}{l}\mathbf{d}_{\max } \\
(\mathrm{cm})\end{array}$ \\
\hline $001 B$ & 6.56 & 45 & 0.795 & 0.203 & 5.394 & 0.082 & 2.833 & 0.118 \\
\hline 0023 & 6.51 & 45 & 0.795 & 0.160 & 7.931 & 0,043 & 7.931 & 0.043 \\
\hline $201 \mathrm{~A}$ & 4.33 & 45 & 0.635 & 0.102 & 2.130 & 0.093 & 0.999 & 0.120 \\
\hline $205 \mathrm{~A}$ & 4.20 & 45 & 0.635 & 0.160 & 1.306 & 0.153 & 1.306 & 0.153 \\
\hline $205 C$ & 5.30 & 45 & 0.635 & 0.160 & 6.149 & 0.054 & 3.229 & 0.077 \\
\hline 205D & 6.42 & 45 & 0.635 & 0.160 & 4.683 & 0.052 & 4.683 & 0.052 \\
\hline $206 \mathrm{~F}$ & 6.42 & 45 & 0.475 & 0.160 & 2.590 & 0.075 & 1.296 & 0.110 \\
\hline $211 B$ & 5.88 & 45 & 0.889 & 0.160 & 1.416 & 0.175 & 1.416 & 0.175 \\
\hline 211D & 6.84 & 45 & 0.889 & 0.160 & 9.261 & 0.065 & 4.86 .3 & 0.043 \\
\hline $212 B$ & 6.38 & 45 & 0.762 & 0.160 & 3.965 & 0.061 & 3.965 & 0.061 \\
\hline $216 A$ & 6.10 & 45 & 0.889 & 0.203 & 2.819 & 0.090 & 0.807 & 0.2411 \\
\hline $216 C$ & 6.96 & 45 & 0.795 & 0.203 & 4.495 & 0.117 & 2.360 & 0.168 \\
\hline $217 A$ & 6.65 & 45 & 0.795 & 0.102 & 1.630 & 0.117 & 1.348 & 0.162 \\
\hline $217 \mathrm{~B}$ & 7.10 & 45 & 0.795 & 0.102 & 4.785 & 0.089 & 1.181 & 0.195 \\
\hline $217 \mathrm{C}$ & 6.05 & 45 & 0.635 & 0.102 & 6.950 & 0.054 & 3.649 & 0.078 \\
\hline $217 \mathrm{D}$ & 6.47 & 45 & 0.635 & 0.102 & 3.446 & 0.061 & 3.446 & 0.061 \\
\hline $218 \mathrm{~A}$ & 5.82 & 45 & 0.889 & 0.102 & 2.375 & 0.105 & 0.947 & 0.227 \\
\hline $218 \mathrm{C}$ & 6.88 & 45 & 0.889 & 0.102 & 0.967 & 0.245 & 0.967 & 0.245 \\
\hline $221 \mathrm{C}$ & 4.62 & 45 & 0.475 & 0.102 & 1.539 & 0.049 & 0.808 & 0.071 \\
\hline $227 B$ & 7.25 & 45 & 0.635 & 0.081 & 3.467 & 0.057 & 0.665 & 0.194 \\
\hline $230 \mathrm{~B}$ & 3.23 & 45 & 0.475 & 0.160 & 4.437 & 0.077 & 2.330 & 0.111 \\
\hline $230 \mathrm{C}$ & 5.16 & 45 & 0.635 & 0.160 & 3.185 & 0.066 & 0.720 & 0.204 \\
\hline 2300 & 5.51 & 45 & 0.635 & 0.160 & 0.861 & 0.189 & 0.861 & 0.189 \\
\hline $230 \mathrm{E}$ & 6.62 & 45 & 0.635 & 0.160 & 1.792 & 0.160 & 1.202 & 0.166 \\
\hline 301- & 2.95 & 45 & 0.635 & 0.160 & 6.246 & 0.039 & 6.246 & 0.039 \\
\hline 303 & 4.59 & 45 & 0.795 & 0.160 & 6.160 & 0.082 & 2.125 & 0.150 \\
\hline 3038 & 4.34 & 45 & 0.795 & 0.160 & 4.059 & 0.084 & 4.059 & 0.084 \\
\hline 319. & 2.93 & 45 & 0.795 & 0.102 & 2.501 & 0.074 & 0.903 & 0.170 \\
\hline 321- & 2.97 & 45 & 0.795 & 0.203 & 6.580 & 0.072 & 2.270 & 0.131 \\
\hline 324 & 4.05 & 45 & 0.795 & 0.102 & 9.592 & 0.030 & 9.592 & 0.030 \\
\hline 325- & 4.14 & 45 & 0.795 & 0.160 & 7.319 & 0.036 & 7.319 & 0.036 \\
\hline 326 & 4.22 & 45 & 0.795 & 0.203 & 6.255 & 0.118 & 1.080 & 0.317 \\
\hline 333 & 2.88 & 45 & 0.475 & 0.102 & 7.551 & 0.027 & 7.551 & 0.027 \\
\hline 334 & 3.61 & 45 & 0.475 & 0.102 & 1.889 & 0.043 & 1.136 & 0.048 \\
\hline 335. & 4.07 & 45 & 0.635 & 0.102 & 9.711 & 0.022 & 9.711 & 0.022 \\
\hline $336-$ & 4.47 & 45 & 0.635 & 0.102 & 3.185 & 0.051 & 3.185 & 0.051 \\
\hline $336 A$ & 5.70 & 45 & $\overline{0.635}$ & 0.102 & 7.109 & 0.038 & 7.109 & 0.038 \\
\hline 337. & 6.81 & 45 & 0.795 & 0.102 & 1.657 & 0.129 & 1.307 & 0.121 \\
\hline
\end{tabular}


Table F-2 Calculated Ricochet Particle Max-Min Combinations Phase C/D NASAMMFC Test Series

\begin{tabular}{|c|c|c|c|c|c|c|c|c|}
\hline $\begin{array}{l}\text { Test } \\
\text { No. }\end{array}$ & $\begin{array}{c}V_{p} \\
(\mathrm{~km} / \mathrm{s})\end{array}$ & $\begin{array}{c}\theta_{\mathrm{p}} \\
(\mathrm{deg})\end{array}$ & $\begin{array}{c}\mathbf{d}_{\mathbf{p}} \\
(\mathrm{cm})\end{array}$ & $\begin{array}{c}\mathbf{t}_{\mathrm{b}} \\
(\mathrm{cm})\end{array}$ & $\begin{array}{l}V_{\max } \\
(\mathrm{km} / \mathrm{s}\end{array}$ & $\begin{array}{l}\mathbf{d}_{\mathrm{mm}} \\
(\mathrm{cm})\end{array}$ & $\begin{array}{c}V_{\min } \\
(\mathrm{km} / \mathrm{s})\end{array}$ & $\begin{array}{l}\mathbf{d}_{\max } \\
(\mathrm{cm})\end{array}$ \\
\hline $4001 \mathrm{~A}$ & 3.15 & 45 & 0.795 & 0.203 & 1.954 & 0.114 & 1.137 & 0.196 \\
\hline $4001 \mathrm{C}$ & 6.12 & 45 & 0.795 & 0.203 & 3.707 & 0.091 & 3.707 & 0.091 \\
\hline $4001 D$ & 6.71 & 45 & 0.795 & 0.203 & 1.813 & 0.147 & 1.187 & 0.155 \\
\hline 4002B & 3.97 & 75 & 0.795 & 0.203 & 5.836 & 0.228 & 2.921 & 0.337 \\
\hline $4003 A$ & 3.43 & 45 & 0.795 & 0.160 & 7.244 & 0.060 & 3.804 & 0.086 \\
\hline $4003 B$ & 6.29 & 45 & 0.795 & 0.203 & 1.813 & 0.129 & 0.952 & 0.185 \\
\hline $4003 C$ & 3.18 & 45 & 0.795 & 0.203 & 1.748 & 0.100 & 1.262 & 0.150 \\
\hline $4003 D$ & 6.22 & 45 & 0.795 & 0.203 & 3.656 & 0.068 & 3.656 & 0.068 \\
\hline $4004 A$ & 3.19 & 75 & 0.795 & 0.203 & 9.115 & 0.156 & 4.787 & 0.224 \\
\hline 4101A & 3.14 & 45 & 0.635 & 0.127 & 4.723 & 0.056 & 2.298 & 0.066 \\
\hline $4101 C$ & 6.14 & 45 & 0.635 & 0.127 & 3.368 & 0.088 & 3.368 & 0.088 \\
\hline $4102 \mathrm{~A}$ & 2.95 & 45 & 0.795 & 0.127 & 6.246 & 0.066 & 3.280 & 0.095 \\
\hline $4102 C$ & 6.24 & 45 & 0.795 & 0.127 & 3.699 & 0.079 & 1.633 & 0.170 \\
\hline $4103 C$ & 5.88 & 60 & 0.475 & 0.127 & 7.244 & 0.060 & 3.804 & 0.086 \\
\hline 4103D & 7.37 & 60 & 0.475 & 0.127 & 4.931 & 0.100 & 2.187 & 0.124 \\
\hline $4104 A$ & 7.23 & 60 & 0.635 & 0.127 & 7.521 & 0.082 & 3.764 & 0.122 \\
\hline 4104B & 4.19 & 60 & 0.635 & 0.127 & 1.863 & 0.147 & 1.189 & 0.239 \\
\hline $4104 C$ & 6.12 & 60 & 0.635 & 0.127 & 4.368 & 0.137 & 2.294 & 0.197 \\
\hline 4104D & 7.52 & 60 & 0.635 & 0.127 & 4.180 & 0.082 & 1.467 & 0.202 \\
\hline $4105 A$ & 2.92 & 60 & 0.795 & 0.127 & 1.615 & 0.318 & 1.615 & 0.318 \\
\hline $4105 \mathrm{~A} 1$ & 2.98 & 60 & 0.795 & 0.127 & 7.437 & 0.090 & 3.723 & 0.133 \\
\hline 4105B & 4.02 & 60 & 0.795 & 0.127 & 4.917 & 0.102 & 1.272 & 0.305 \\
\hline 4106A & 3.05 & 60 & 0.475 & 0.127 & 3.002 & 0.089 & 0.761 & 0.256 \\
\hline $4106 \mathrm{A1}$ & 3.10 & 75 & 0.475 & 0.127 & 9.696 & 0.089 & 3.206 & 0.167 \\
\hline $4106 B$ & 4.12 & 60 & 0.475 & 0.127 & 3.643 & 0.076 & 1.655 & 0.161 \\
\hline $4106 \mathrm{B1}$ & 3.99 & 75 & 0.475 & 0.127 & 4.929 & 0.168 & 2.467 & 0.249 \\
\hline $4106 C$ & 5.95 & 75 & 0.475 & 0.127 & 2.815 & 0.250 & 1.478 & 0.359 \\
\hline 4106D & 7.56 & 75 & 0.475 & 0.127 & 4.639 & 0.219 & 2.322 & 0.324 \\
\hline 4107A & 3.05 & 75 & 0.475 & 0.127 & 4.420 & 0.246 & 2.321 & 0.354 \\
\hline 4107B & 4.11 & 75 & 0.635 & 0.127 & 2.749 & 0.313 & 1.376 & 0.462 \\
\hline $4107 C$ & 6.20 & 75 & 0.635 & 0.127 & 4.790 & 0.213 & 1.182 & 0.469 \\
\hline $4108 A$ & 3.12 & 75 & 0.795 & 0.127 & 1.047 & 0.791 & 1.047 & 0.791 \\
\hline 4108B & 3.97 & 75 & 0.795 & 0.127 & 9.650 & 0.181 & 7.202 & 0.214 \\
\hline $4110 A$ & 3.25 & 45 & 0.635 & 0.203 & 2.217 & 0.101 & 1.110 & 0.149 \\
\hline 4110B & 4.00 & 45 & 0.635 & 0.203 & 5.042 & 0.060 & 2.648 & 0.086 \\
\hline 4111B & 3.94 & 45 & 0.795 & 0.203 & 6.622 & 0.098 & 3.477 & 0.141 \\
\hline $4111 C$ & 5.97 & 45 & 0.795 & 0.203 & 2.944 & 0.136 & 1.546 & 0.195 \\
\hline 4111D & 6.81 & 45 & 0.795 & 0.203 & 0.900 & 0.213 & 0.900 & 0.213 \\
\hline 4112A & 3.33 & 60 & 0.475 & 0.203 & 4.093 & 0.103 & 2.149 & 0.148 \\
\hline
\end{tabular}




\begin{tabular}{|c|c|c|c|c|c|c|c|c|}
\hline $4112 B$ & 4.05 & 60 & $\overline{0.75}$ & 0.203 & 5.191 & 0.108 & 2.400 & 0.166 \\
\hline 41123 & 7.50 & 60 & 0.47 & 0.203 & 4.134 & 0.125 & 2.171 & 0.180 \\
\hline 41134 & 297 & 60 & 0.63 & 0.203 & 5953 & 0119 & 3.043 & 0.171 \\
\hline 4113 & $3 n$ & 60 & 0.63 & 0.203 & 1.72 & 0303 & 0.872 & 0.299 \\
\hline $4115 C$ & 6.30 & 60 & 063 & 0.203 & 8,10 & 0.124 & 6.374 & 0.146 \\
\hline 41130 & 7.12 & 60 & 0.63 & 0233 & 457 & $0.0 \% 2$ & 4.527 & 0.022 \\
\hline $4114 \mathrm{~A}$ & $\overline{3.13}$ & 60 & 0.79 & 0.203 & 101 & 0.286 & 1.382 & 0.286 \\
\hline $4114 C$ & 5.92 & 60 & 0.795 & 0.203 & 59 & 0.149 & 3.648 & 0.176 \\
\hline 411s & $3: 13$ & 75 & 0.03 & 0203 & 8112 & 0.131 & 4.060 & 0.194 \\
\hline 41158 & 408 & 75 & 0.475 & 0.203 & 863 & 0.083 & 4.444 & 0.119 \\
\hline 4115D & 7.30 & 75 & 0.475 & B & 7.056 & 0.150 & 5.266 & 0.176 \\
\hline & $2 x$ & 75 & 0.05 & 0.203 & 8.810 & 0.124 & 6.574 & 0.146 \\
\hline & $7 \sqrt{4}$ & 75 & 0.635 & 0.203 & TSy & 0.301 & 0.973 & 0.444 \\
\hline 4114 & 3.11 & 75 & 0.793 & 0.203 & 6.0 .8 & 0.161 & 5.140 & 0.190 \\
\hline
\end{tabular}


Table F-3 Calculated Ricochet Particle Max-Min Combinations NASAMSFC EH Test Series

\begin{tabular}{|c|c|c|c|c|c|c|c|c|}
\hline $\begin{array}{c}\text { Test } \\
\text { No. }\end{array}$ & $\begin{array}{c}\mathbf{V}_{\mathbf{p}} \\
(\mathbf{k m} / \mathbf{s})\end{array}$ & $\begin{array}{c}\boldsymbol{\theta}_{\mathbf{p}} \\
\left(\mathbf{d e g}_{\mathbf{g}}\right)\end{array}$ & $\begin{array}{c}\mathbf{d}_{\mathbf{p}} \\
(\mathbf{c m})\end{array}$ & $\begin{array}{c}\mathbf{t}_{\mathbf{b}} \\
(\mathbf{c m})\end{array}$ & $\begin{array}{c}\mathbf{V}_{\max } \\
(\mathbf{k m} / \mathbf{s}\end{array}$ & $\begin{array}{c}\mathbf{d}_{\operatorname{m}} \\
(\mathbf{c m})\end{array}$ & $\begin{array}{c}V_{\mathbf{m}} \\
(\mathbf{k m} / \mathbf{s})\end{array}$ & $\begin{array}{c}\mathbf{d}_{\max } \\
(\mathbf{c m})\end{array}$ \\
\hline EHAB & 6.91 & 75 & 0.795 & 0.160 & 4.819 & 0.278 & 3.596 & 0.328 \\
\hline EHPB & 7.22 & 75 & 0.635 & 0.160 & 5.628 & 0.218 & 1.942 & 0.398 \\
\hline EHPC & 7.58 & 75 & 0.475 & 0.160 & 3.828 & 0.237 & 1.916 & 0.349 \\
\hline EHRP1 & 6.87 & 60 & 0.795 & 0.160 & 7.520 & 0.066 & 3.949 & 0.094 \\
\hline EHRP2 & 6.80 & 65 & 0.795 & 0.160 & 2.097 & 0.340 & 1.050 & 0.502 \\
\hline EHRP3 & 6.78 & 45 & 0.795 & 0.160 & 4.876 & 0.124 & 2.216 & 0.150 \\
\hline EHRP4 & 7.65 & 60 & 0.635 & 0.160 & 1.989 & 0.205 & 0.995 & 0.303 \\
\hline EHRP5 & 7.51 & 65 & 0.635 & 0.160 & 2.531 & 0.266 & 1.267 & 0.394 \\
\hline EHRP6 & 7.57 & 45 & 0.635 & 0.160 & 3.556 & 0.105 & 1.868 & 0.152 \\
\hline EHRP7 & 7.98 & 60 & 0.475 & 0.160 & 4.549 & 0.176 & 1.053 & 0.402 \\
\hline EHRP8 & 7.34 & 45 & 0.475 & 0.160 & 8.766 & 0.069 & 4.603 & 0.100 \\
\hline EHRP9 & 7.29 & 65 & 0.475 & 0.160 & 1.841 & 0.291 & 1.202 & 0.465 \\
\hline EHSS4C & 5.53 & 45 & 0.635 & 0.160 & 1.116 & 0.262 & 1.116 & 0.262 \\
\hline
\end{tabular}




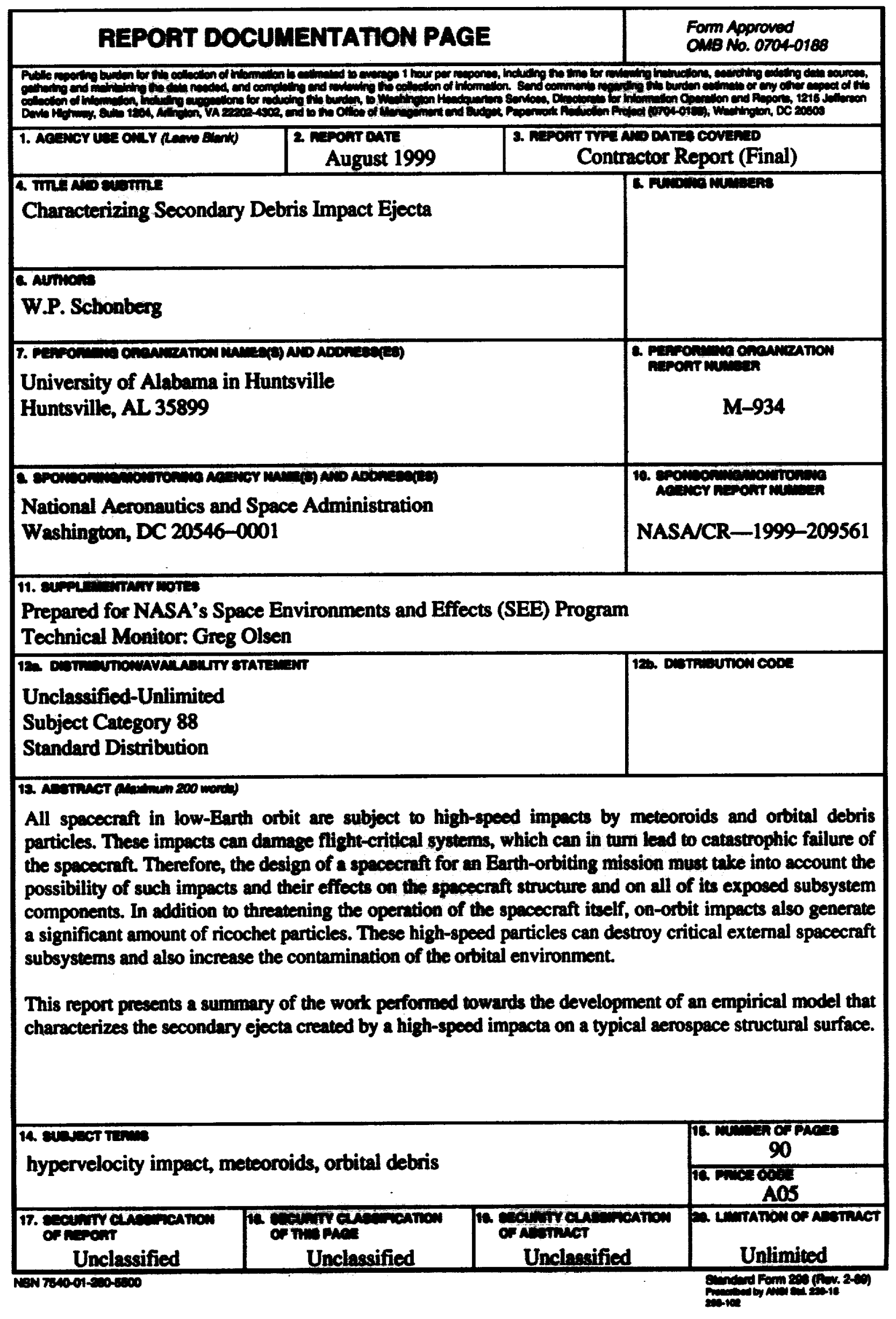

